\title{
Modeling And Development Of The Dynamic Environmental Simulation Chamber (Desc) For Calibration Of Air Quality Monitoring Sensors
}

Filiz Kazan

GRA, fk0007@mix.wvu.edu

Follow this and additional works at: https://researchrepository.wvu.edu/etd

Part of the Mechanical Engineering Commons

\section{Recommended Citation}

Kazan, Filiz, "Modeling And Development Of The Dynamic Environmental Simulation Chamber (Desc) For Calibration Of Air Quality Monitoring Sensors" (2019). Graduate Theses, Dissertations, and Problem Reports. 4089.

https://researchrepository.wvu.edu/etd/4089

This Thesis is protected by copyright and/or related rights. It has been brought to you by the The Research Repository @ WVU with permission from the rights-holder(s). You are free to use this Thesis in any way that is permitted by the copyright and related rights legislation that applies to your use. For other uses you must obtain permission from the rights-holder(s) directly, unless additional rights are indicated by a Creative Commons license in the record and/ or on the work itself. This Thesis has been accepted for inclusion in WVU Graduate Theses, Dissertations, and Problem Reports collection by an authorized administrator of The Research Repository @ WVU. For more information, please contact researchrepository@mail.wvu.edu. 


\title{
MODELING AND DEVELOPMENT OF THE DYNAMIC ENVIRONMENTAL SIMULATION CHAMBER (DESC) FOR CALIBRATION OF AIR QUALITY MONITORING SENSORS
}

\author{
Filiz KAZAN
}

Thesis submitted to the

Benjamin M. Statler College of Engineering and Mineral Resources

at West Virginia University

\begin{abstract}
in partial fulfillment of the requirements
for the degree of
\end{abstract}

Master of Science

in

Mechanical Engineering

\author{
Marc C. Besch, Ph.D., Chair \\ Arvind Thiruvengadam, Ph.D. \\ V'yacheslav Akkerman, Ph.D. \\ Pragalath Thiruvengadam, Ph.D. \\ Department of Mechanical and Aerospace Engineering \\ West Virginia University \\ Morgantown, West Virginia \\ 2019
}

Keywords: Ambient air quality, Sensors, DESC

Copyright 2019 Filiz KAZAN 


\section{Abstract \\ MODELING AND DEVELOPMENT OF THE DYNAMIC ENVIRONMENTAL SIMULATION CHAMBER (DESC) FOR CALIBRATION OF AIR QUALITY MONITORING SENSORS}

\section{Filiz KAZAN}

Ambient air quality has a significant impact on human health and the environment we live in with evidence showing that pollution increases the number of cardiovascular diseases, lung diseases, cancer, asthma cases and proven influences on the mortality rates. The United States Environmental Protection Agency (U.S. EPA) established the National Ambient Air Quality Standard (NAAQS) to limit exposure of the public to critical pollutants and monitors ambient air near highways and selected locations with elaborate monitoring stations. Instruments and analyzers utilized in current monitoring stations comprise laboratory-grade technology of high accuracy, which on the flipside, however, are characterized by high cost, complexity, and need for specialized operators. This effectively limits the number of monitoring stations and thus, the density of the monitoring network. Therefore, the development of low-cost sensors and gaining a better understanding of their responses and limits will benefit denser monitoring coverage of large areas with a growing number of monitoring stations. With recent sensor technology developments, increased numbers of miniaturized and low-cost sensors are commercialized and become available on the market. These sensors can be defined as low-cost $(<\$ 500)$ and are easy to operate due to the simplicity of the sensors. However, the response, accuracy, and possible interference of low-cost sensors must be characterized in detail. Numerous studies have been completed, focusing on the evaluation of low-cost sensor technologies and compare the sensor responses between laboratory testing versus field monitoring. Sensor readings were found to be affected by environmental conditions such as meteorology and from multi-constituent combinations in field experiments resulting in sensor cross-sensitivities.

The primary objective of this study is to evaluate the ambient air gas sensor responses due to the activity and meteorological events such as temperature, wind speed, humidity, as well as possible cross-interfering constituents. The secondary objective of this work is to tune the calibration function and understand possible interfering factors of the commercialized gas sensors for indoor/outdoor air quality monitoring. For the purpose of evaluating and calibrating the low-cost sensors, a custom-designed Dynamic Environmental Simulation Chamber (DESC) was developed and commissioned. In a first step, analysis of the simulation chamber was performed as a function of different geometries, wind speeds, and air properties using a Computational Fluid Dynamics (CFD) analyzing software (Fluent, ANSYS, USA) for the determination of flow profiles, gas mixing homogeneity, and sensor location positioning in the loop where wind velocity is vital for sensor responses. Based on the modeling results, the DESC was built and connected to a computer-controlled system that allows changing the composition of pollutant 
concentrations via injection of synthetic gases, temperature $\left(25-110{ }^{\circ} \mathrm{C}\right)$, relative humidity $(0-95 \%)$, and wind speed $(0-5 \mathrm{~m} / \mathrm{s})$ instantly by a custom-made control software. In the second step, $\mathrm{CO}_{2}$ gas sensors were evaluated in the DESC, including, i) a high and low-speed Senseair K30 (range 10000ppm), ii) a FIGARO FG-030 (range 5000ppm), and iii) a COZIR (range 2000ppm). The evaluated $\mathrm{CO}_{2}$ sensors were all based on nondispersive infrared detection (NDIR) technology which has interference with CO, humidity, and temperature. The experiments were performed with variable gas compositions and meteorological conditions using a design of experiment approach. The gas mixture components were $\mathrm{CO}, \mathrm{CO}_{2}$ and zero air. Fourier-Transform infrared spectroscopy (FTIR, MKS 2030-HS) was used in order to measure the gas concentrations and to cross-reference with the sensor readings. The calibration functions were generated as a function of pressure, temperature, humidity (i.e. water content), and $\mathrm{CO}$ as interference gas.

The calibration models improved the sensor responses when compared to raw measurements. For the K30 sensors, the overall relative error was decreased from $\pm 10 \%$ to $\pm 3 \%$. For the Figaro, the overall relative error was decreased from $\pm 15 \%$ to $\pm 4 \%$. Moreover, for the COZIR, the overall relative error was decreased from $\pm 22 \%$ to $\pm 14 \%$. The COZIR correction model was found to not significantly decrease the relative error, and thus, will need further investigation. 


\section{Acknowledgment}

I appreciate all the people who helped me and understood me while I am working on this study.

First, I would like to express gratitude to my mom and brother and my family members who supported me to start that journey. My journey started as a babysitter in this country. I am so thankful to lovely Moulton Family (Meredith, James, Trevor, Morgan) who opened their heart and house and Michelle Mason who is the best grandmother in the world. I spend a wonderful year with them. Then, I had to move to Chicago, but I wasn't alone, I would like to thank to my former roommate Taner Begenmis and Engin Katirci who became lifelong friends to me. They supported my education and helped me to contact to Cemal Yazici and Ismail Celik and Perihan Celik who became my family in US. Celik family treated me like their daughter. I will always try to make them proud of me and be successful in my life. I have never felt alone here because of their support and always felt 'I am at home' with them. I will be thankful to them all my life. Additionally, I would like to thank to Mehmet Aygun who became friend of me and helped me all the time whenever I need. And many thanks to my best friend Busra Yel and Emir Bozkurt who always supported me and they were always with me even though they live in Turkey. In advance I would like to thank to my undergrad advisor Dr. Burak Ozhan, who always pushes me to further goals and open my mind.

I would like to express my deepest appreciation to my committee members, Dr. V'yacheslav Akkerman and Dr. Pragalath Thiruvengadam who were always nice to me and they always answered my questions kindly. I am extremely grateful to my future advisor Dr. Arvind Thiruvengadam who always supported me and accepted me as a $\mathrm{PhD}$ student. I would like to express my gratitude to my advisor Dr.Marc C. Besch who accepted me as his student and gave me opportunity to be part of CAFEE group. The always guided in my education and career path. He always shared his experiences and wisdom.

I would express special thanks to Berk Demirgok who supported me to become a CAFEE member and always shared his experiences and friendship.

My office friends, Cem, Bethi,Vishnu, Saroj and many other, I would like to thank to all your kindness and support and I had good time in our office and work place. And Special thanks to my weekend work friend Rasik, thank you so much for working with even at the weekends.

In addition, I would specially thank to CAFEE director Dan Carter, VETL and ERC workers who helped me on my project and were kind to me answered my questions all the time even they were busy. There are many more whom I could name, I am very grateful to all those who have given me their friendship and help.

\footnotetext{
"The biggest battle is the war against ignorance."

Mustafa Kemal Ataturk
} 


\section{Table of contents}

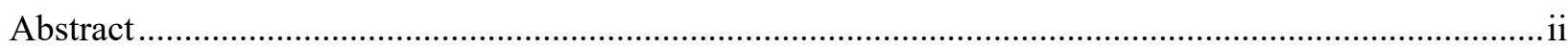

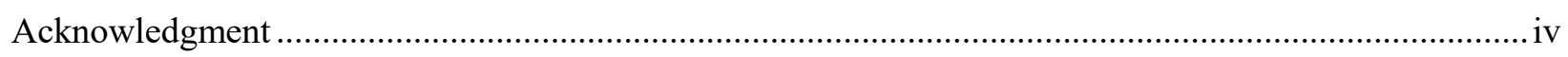

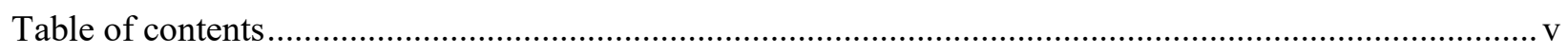

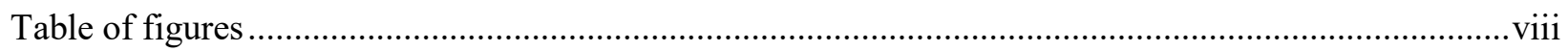

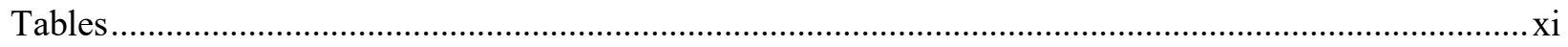

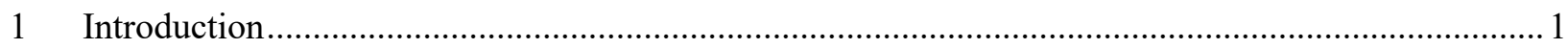

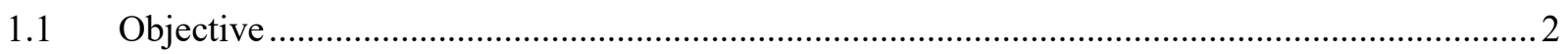

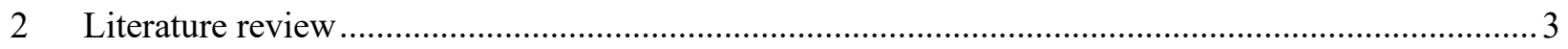

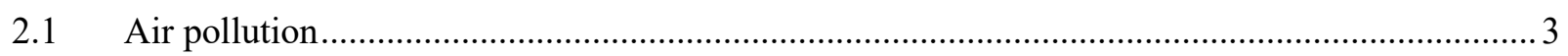

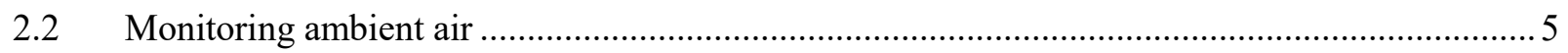

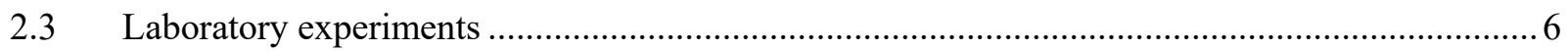

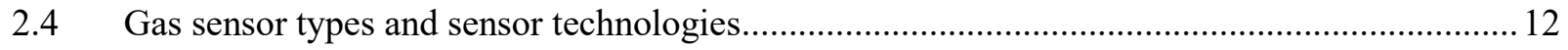

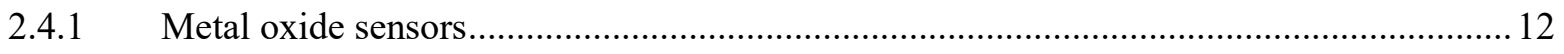

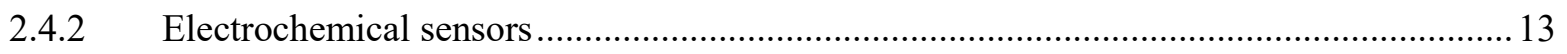

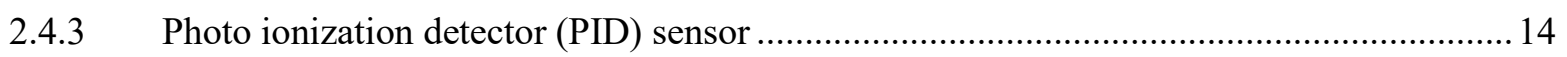

2.4.4 Non-dispersive infra-red radiation absorption ........................................................... 14

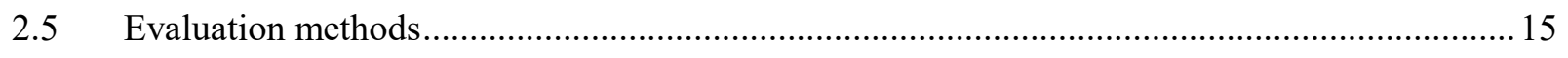

2.5.1 The coefficient of determination (R-square) …............................................................ 15

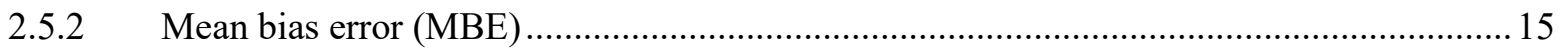

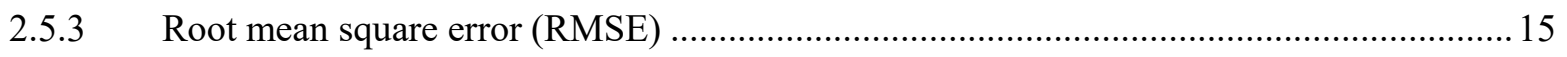

2.5.4 Centered root mean square (CRMSE) .................................................................... 15

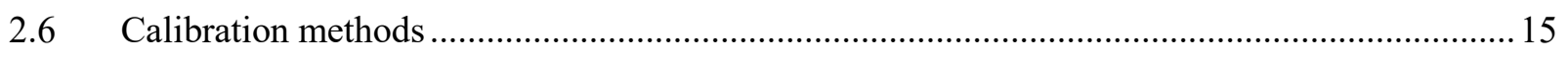

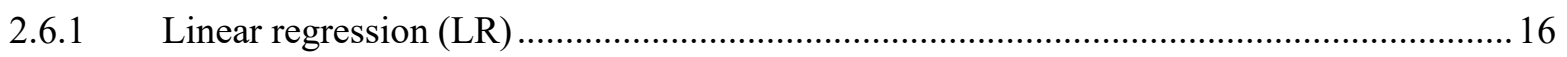

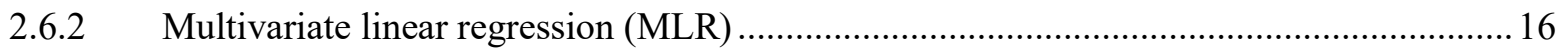

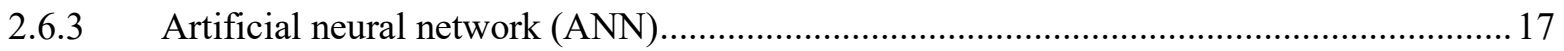




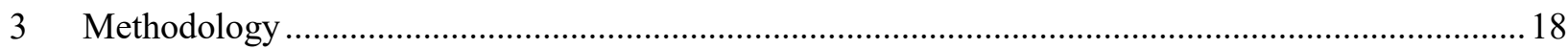

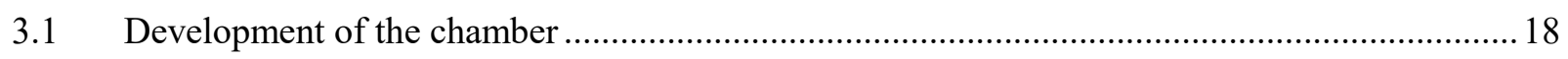

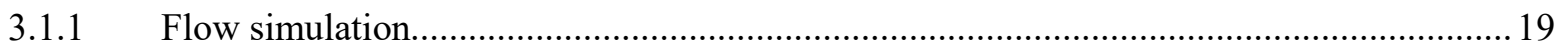

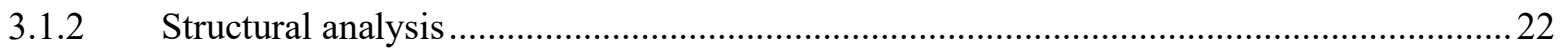

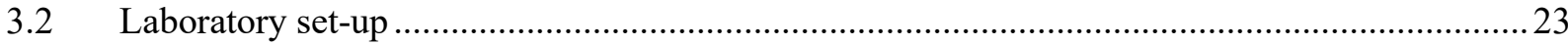

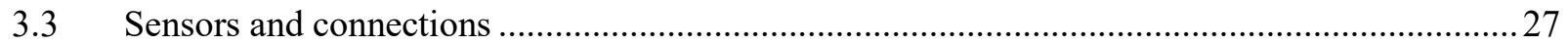

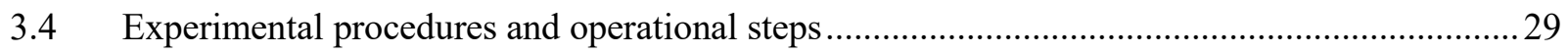

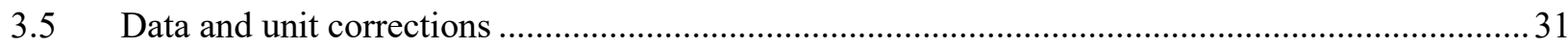

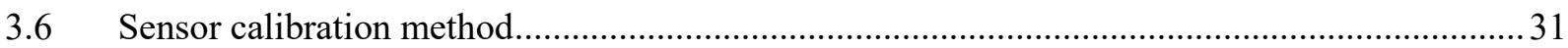

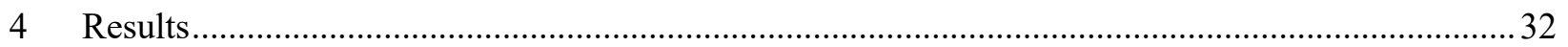

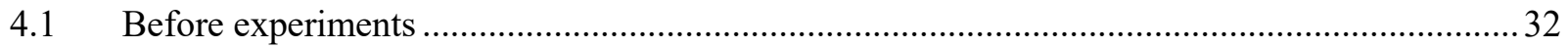

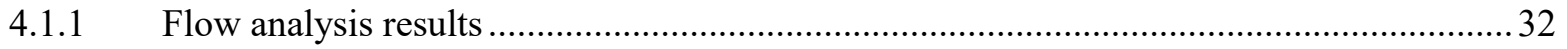

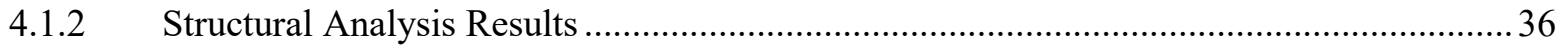

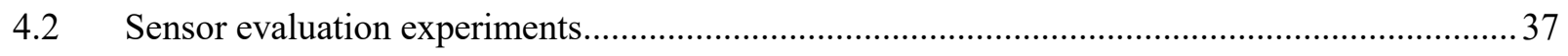

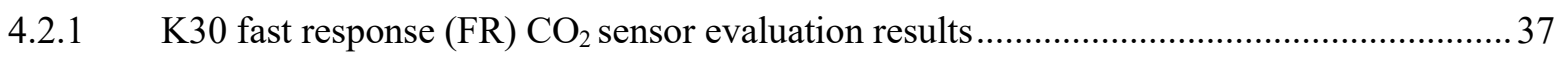

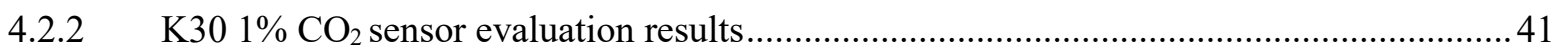

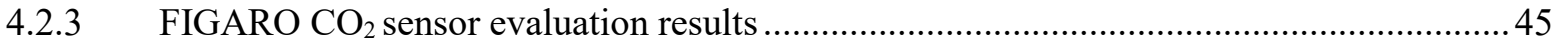

4.2.4 COZIR AMBIENT $\mathrm{CO}_{2}$ sensor evaluation results ................................................... 49

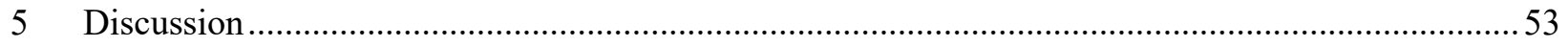

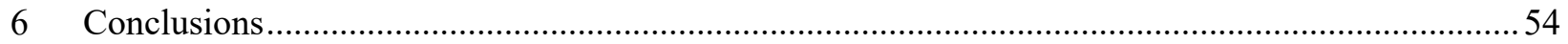

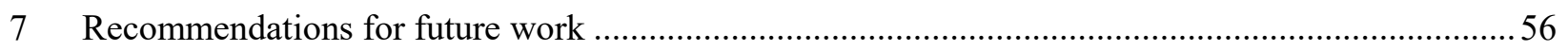

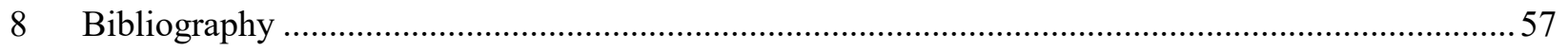

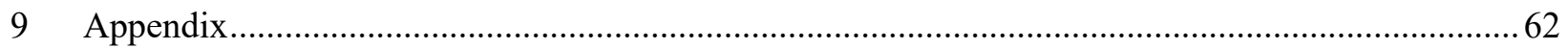

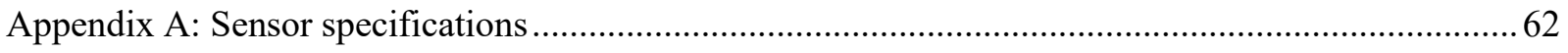

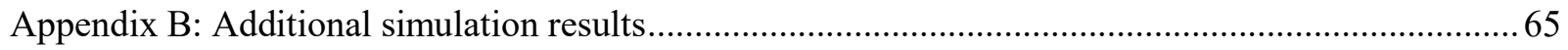

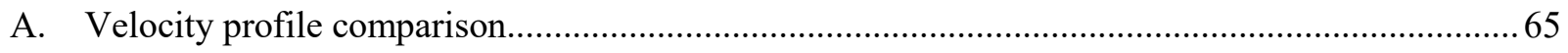

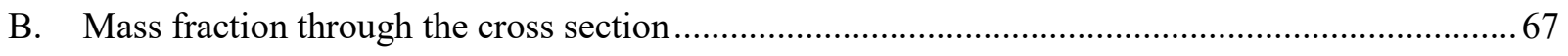


Appendix C: Additional sensor calibration results

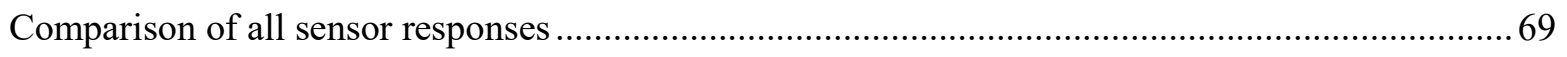




\section{Table of figures}

Figure 1 Typical US EPA stations for monitoring ambient air near highways and selected locations [8]...5

Figure 2 Static volumetric system [15] ..................................................................................... 7

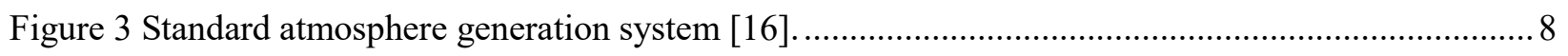

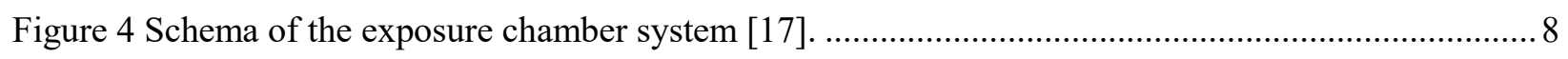

Figure 5 Scheme of the exposure chamber system [18] .................................................................. 9

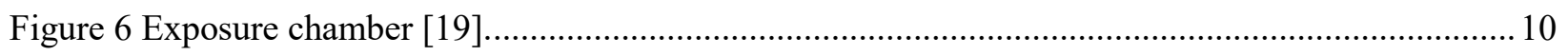

Figure 7 Scheme of the gas mixtures apparatus and mechanical setup as a CAD model [20]................. 11

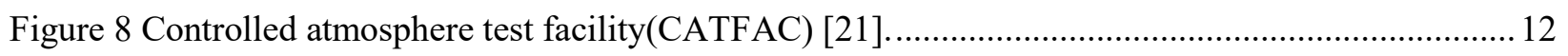

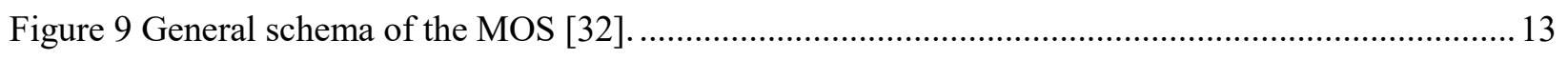

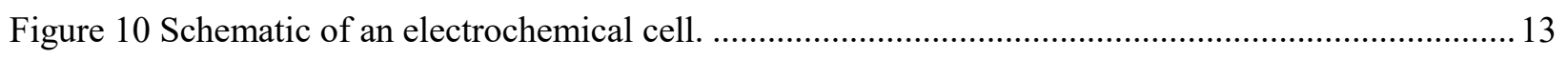

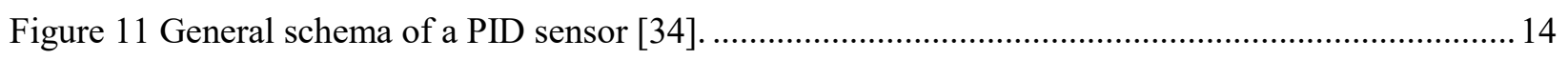

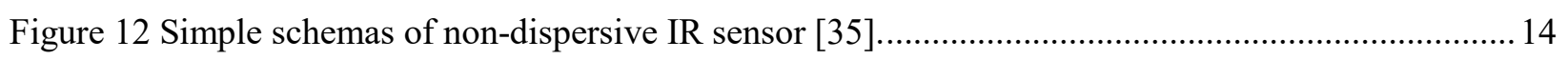

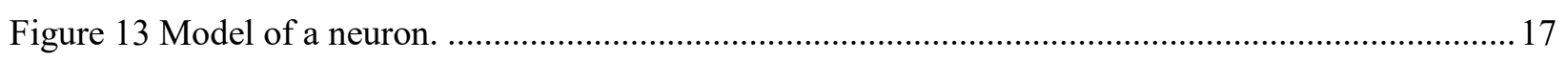

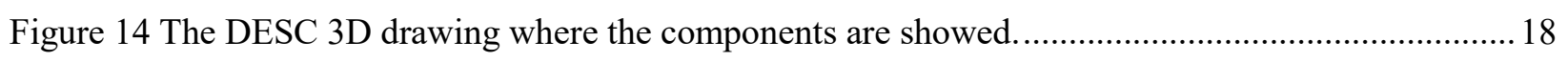

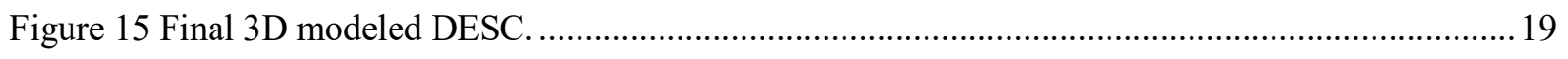

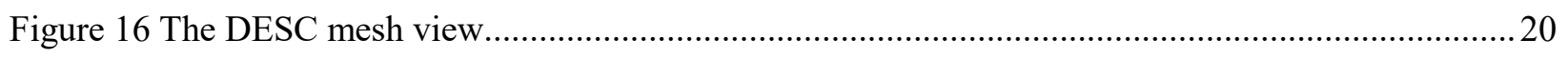

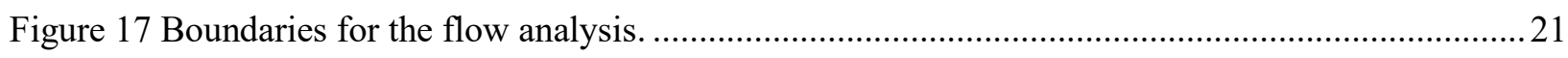

Figure 18 The supported geometry and the location of the pressure load. .............................................22

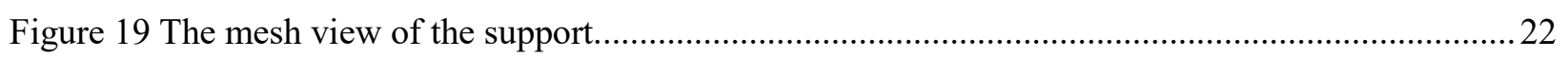

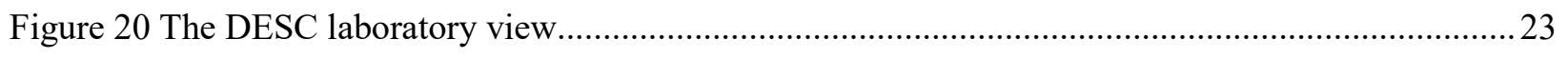

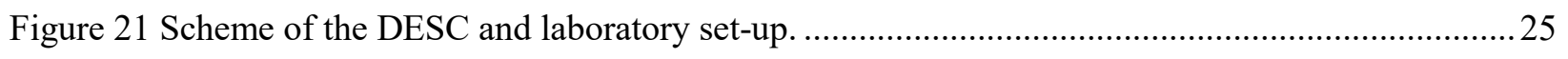

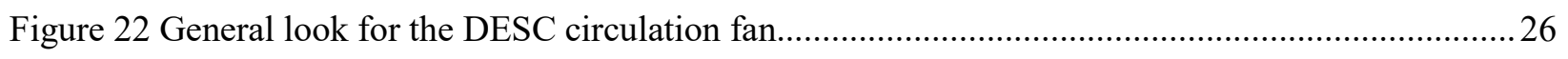

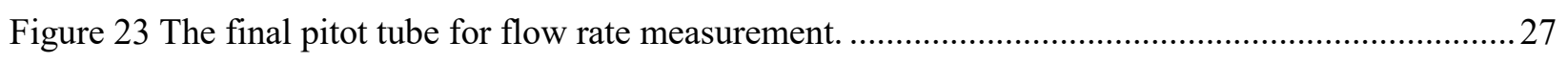

Figure 24 Sensors, sensor connections and sensor place in the DESC . .................................................28

Figure 25 Velocity profile comparison for three cases. Figure a) Velocity profiles at horizontal axis. Figure

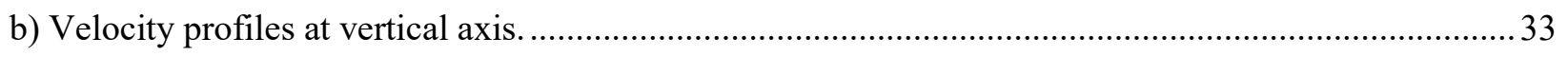

Figure 26 Horizontal velocity profile comparison for low speed level.................................................... 34

Figure 27 Vertical velocity profile comparison for low-speed level. .................................................. 34

Figure $28 \mathrm{CO}_{2}$ mass fraction through the vertical line-high Speed.......................................................35

Figure $29 \mathrm{CO}_{2}$ Mass fraction through the horizontal line-high Speed................................................... 36

Figure 30 The support displacement under $92.1 \mathrm{kPa}$ pressure loads $(6.35 \mathrm{~mm}$ plate)..............................36 
Figure 31 Test 8: K30 FR sensor responses compared to FTIR responses due to increasing concentration

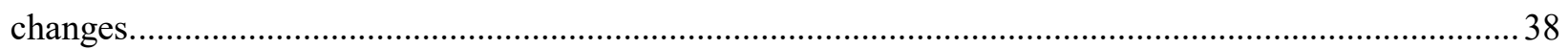

Figure 32 K30 FR -raw measurement relative error compared to corrected measurement relative error (05000ppm)-transient increase.

Figure 33 K30 FR -raw measurement relative error compared to corrected measurement relative error (5000-10000 ppm)- transient increase. 40

Figure 34 Test 8: K30 1\% sensor responses compared to FTIR responses due to increasing concentration changes...... 42

Figure $35 \mathrm{~K} 30$ 1\% -raw measurement relative error compared to corrected measurement relative error ( 0 $5000 \mathrm{ppm})$-transient increase.

Figure 36 K30 1\% -raw measurement relative error compared to corrected measurement relative error (5000-10000ppm)-transient increase.

Figure 37 Test 8: Figaro sensor responses compared to FTIR responses due to increasing concentration changes......

Figure 38 Figaro- raw measurement relative error compared to corrected measurement relative error transient increase. 48

Figure 39 Test 8: COZIR sensor responses compared to FTIR responses due to increasing concentration changes. .50

Figure 40 COZIR -raw measurement relative error compared to corrected measurement relative error transient increase. .51

Figure 41 Representation of a detection limit [52]. 63

Figure 42 Response time to measure $50 \%$ and $90 \%$ of the gas [6]. 63

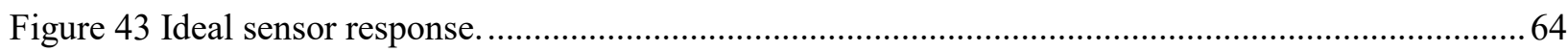

Figure 44 Vertical velocity profile comparison for medium speed level................................................. 65

Figure 45 Vertical velocity profile comparison for high speed level...................................................... 65

Figure 46 Horizontal velocity profile comparison for medium speed level .............................................66

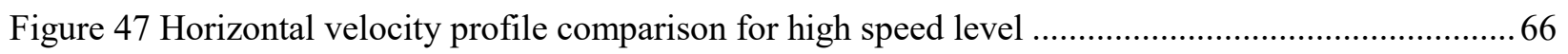

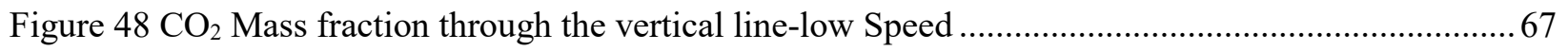

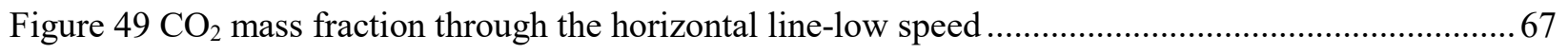

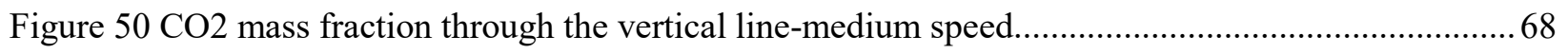

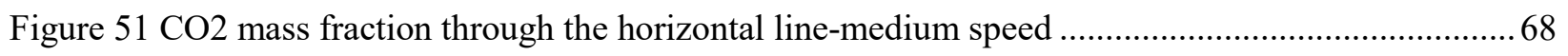

Figure 52 Comparison of the sensor responses with the reference instrument...................................... 69

Figure 53 Test 9: K30 FR sensor responses compared to FTIR responses due to decreasing concentration changes. 
Figure 54 K30 FR- raw measurement relative error compared to corrected measurement relative error (05000ppm)-transient decrease.

Figure 55 K30 FR- raw measurement relative error compared to corrected measurement relative error (5000-10000ppm)-transient increase. 70

Figure 56 Test 7: K30 FR sensor responses compared to FTIR responses due to decreasing concentration changes-step-by-step. .71

Figure 57 K30 FR -raw measurement relative error compared to corrected measurement relative error (05000ppm)-step by step decrease.

Figure 58 K30 FR- raw measurement relative error compared to corrected measurement relative error (5000-10000ppm)-step by step decrease.

Figure 59 Test 9: K30 1\% sensor responses compared to FTIR responses due to decreasing concentration changes. .73

Figure $60 \mathrm{~K} 30$ 1\%- raw measurement relative error compared to corrected measurement relative error (05000ppm)-transient decrease. .73

Figure 61 K30 FR- raw measurement relative error compared to corrected measurement relative error (5000-10000ppm)-transient increase . .74

Figure 62 Test 7: K30 1\% sensor responses compared to FTIR responses due to decreasing concentration changes-step by step.

Figure 63 K30 1\%- raw measurement relative error compared to corrected measurement relative error (05000ppm)-step by step decrease.

Figure 64 K30 1\% -raw measurement relative error compared to corrected measurement relative error (5000-10000ppm)-step by step decrease.

Figure 65 Test 9: Figaro sensor responses compared to FTIR responses due to decreasing concentration changes...

Figure 66 Figaro- raw measurement relative error compared to corrected measurement relative -transient decrease

Figure 67 Test 9: COZIR sensor responses compared to FTIR responses due to decreasing concentration changes. .77

Figure 68 COZIR -raw measurement relative error compared to corrected measurement relative -transient decrease .77 


\section{Tables}

Table 1 Summary of the common air pollutants (The table adapted from EPA Air Sensor Guidebook)..... 4

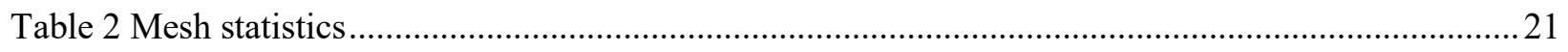

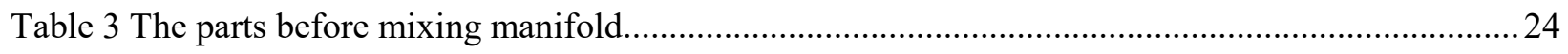

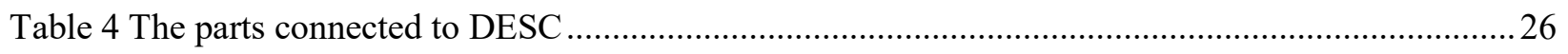

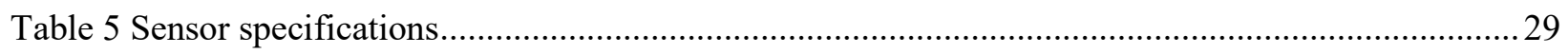

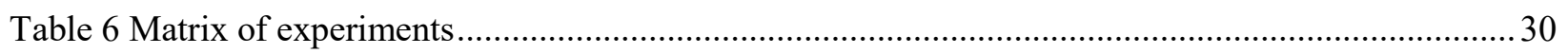

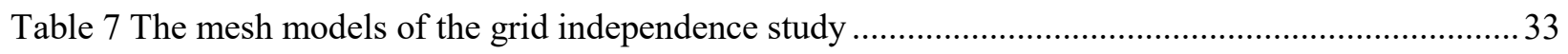

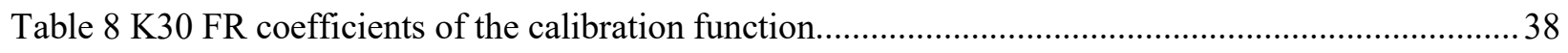

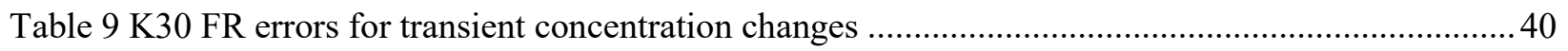

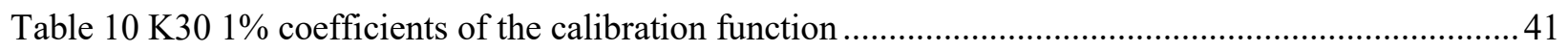

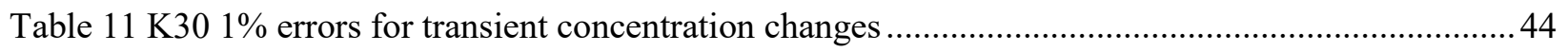

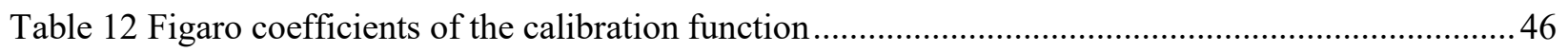

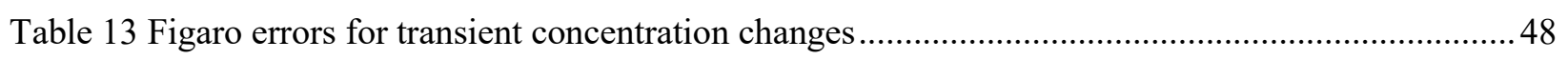

Table 14 COZIR coefficients of the calibration function ....................................................................... 50

Table 15 COZIR errors for transient concentration changes ............................................................. 51 


\section{Introduction}

Ambient air is defined as the proportion of the atmosphere where is publicly accessible, outside of the buildings [1]. Air quality has a significant role in human health and the earth we live in. The technology has been developed within time; thus, the impact of the human sources has been increased on air pollution. Air pollution has a negative influence on mortality, and the evidence shows that pollution increases the number of cardiovascular diseases, lung diseases, cancer, and asthma cases [2]. The studies show the relationship between the mortality and primary pollutions such as Ozone $\left(\mathrm{O}_{3}\right)$, particulate matter $(\mathrm{PM})$, carbon monoxide (CO), Nitrogen dioxide $\left(\mathrm{NO}_{2}\right)$ and sulfur dioxide $\left(\mathrm{SO}_{2}\right)$ [3], [4]. Another study indicates that ambient air quality causes congenital disabilities [5] as well as damages the soil quality and causes climate changes [6].

The World Health Organization (2015) links 3.7 million annual premature deaths as well as other diseases such as heart diseases and lung cancer [7] to the exposure to outdoor fine particulate matter (i.e. PM 2.5). Moreover, exposure to ozone causes around 150000 deaths because of the respiration difficulties. Ozone and soot are also harmful to soil and plantation.

The main pollutions can be linked to stationary and mobile sources which are built by human. The stationary sources are the factories and electric generation plants, and mobile sources are cars and any transportation vehicles. Another reasons for air pollution are natural events such as volcanic explosions, wildfires, etc.

Air pollutants can be divided into two as primary pollutants (i.e. particulate matter (PM), carbon monoxide (CO), carbon dioxide $\left(\mathrm{CO}_{2}\right)$, nitrogen dioxide $\left(\mathrm{NO}_{2}\right)$, sulfur dioxide $\left(\mathrm{SO}_{2}\right)$ and Lead $(\mathrm{Pb})$ ) which are produced directly from stationary and mobile sources; and secondary pollutants which are converted from primary pollutants with chemical reactions such as $\mathrm{O}_{3}$ and other particulate matters (PM) [6].

Because of health and environmental concerns are mentioned above, governments and other organizations are continuously monitoring the ambient air via monitoring stations in favor of estimating the level of pollution and establish regulations. However, the number of the stations cannot cover all the environment due to the cost of the monitoring stations, hence the number of the low-cost ambient air sensor usage is increasing because of the cost-effectivity and simplicity of operation. The sensors have various operating principles such as electrochemical, metal oxide which depends on targeting gases. Although, the quality of low-cost sensors is still increasing, it has not yet reached the quality and accuracy of laboratory grade analyzers. For this reason, many researchers are focused on assessing ambient air quality sensors by counting the effect of environmental conditions and characterize possible cross-sensitivities. 


\subsection{Objective}

Gas sensors are vital for identification of the ambient air quality. The sensors are defined as low-cost sensors $(<\$ 500)$ because they are cost-effective and do not require professional knowledge to be operated by a user. However, the quality of the sensor responses is one of the significant concerns since the sensor responses can be affected by the meteorological events and cross-sensitivity to other gaseous components different from the target gas. Therefore, many researchers evaluated low-cost sensors to validate their responses and characteristics.

The primary objective of this study is to build a testing bench for evaluation of low-cost sensors to assess the sensor responses for meteorological events. In order to evaluate the sensors, the dynamic environmental simulation chamber (DESC) will be designed and constructed at West Virginia University's Center for Alternative Fuel, Engines and Emissions' facilities. The test bench will be capable of simultaneously controlling the concentration of gases, temperature, humidity, pressure, and flow characteristics to simulate different test conditions. Moreover, gas bottles with known concentrations and zero air will be used to avoid the effect of independent variables. The sensor evaluation relies on the comparison between sensor responses versus a reference measurement. In this study, Fourier-transform infrared spectroscopy (FTIR) will be used as reference instrument. Because of the working principals of the FTIR the sampled gas components will not be altered, and thus, the sample stream leaving the FTIR can be feed back into the chamber. Due to this the inner concentration of the chamber will not be affected by the sampling system. The experiments will be performed at several concentration levels over the sensor's full measurement range at the average metrological exposure conditions. The next step will be the identification of significant interferences. The sensors shall be exposed to a controlled environment of standard gas mixtures of selected pollutants in the exposure chamber.

The secondary objective is tuning the sensor's calibration function to increase the sensor accuracy using controlled experimental conditions. The focus of this study are $\mathrm{CO}_{2}$ sensors because carbon dioxide $\left(\mathrm{CO}_{2}\right)$ has been identified to contribute to climate change. $\mathrm{CO}_{2}$ gas sensors were evaluated in the DESC, including, i) a high and low-speed Senseair K30 (range 10000ppm), ii) a FIGARO FG-030 (range 5000ppm), and iii) a COZIR (range 2000ppm). The sensors will be compared to an FTIR and will be calibrated under laboratory conditions using zero air and gaseous components including $\mathrm{CO}_{2}$ and $\mathrm{CO}$. To develop the calibration function, several statistical methods will be applied, specifically, root mean square error (RMSE) calculation and stepwise multilinear regression (MLR). 


\section{Literature review}

\subsection{Air pollution}

Before investigating the ambient air quality, the specifications for gas components need to be understood. The criteria pollutants defined by the US EPA and listed in EPA's air guidebook specifies the detection limits, expected ranges, health effects, and environmental effects for some common air pollutants [6]. NIOSH provides a wide range of additional pollutants that are published in a comprehensive list on their webpage (https://www.cdc.gov/niosh/npg/npgd0103.html).

Table 1 shows the most common air pollutants, detection limit, type, level, range to expect, and average concentration ranges to expect in ambient air in the USA. The type of the pollutants is explained below:

Ozone $\left(\mathrm{O}_{3}\right)$ is a secondary pollutant which is formed by UV (sunlight) from $\mathrm{NO}_{\mathrm{x}}$ and VOCs. Ozone has a crucial role in the ozone layer; however, the abnormal amount is caused by human activities such as fuel combustion sources. Useful detection limits are $10 \mathrm{ppb}$ and the expected range $0-150 \mathrm{ppb}$. Ozone can cause chest pain, breathing problems, and worsen asthma. Besides the health effects, the ozone also damages the vegetation. It is one of the greenhouse gases which commits global warming.

Carbon monoxide $(\mathrm{CO})$ is a primary pollutant which is a product of the fuel combustion, for instance, mobile sources. Carbon monoxide gas is poisonous, colorless, and considers an odorless pollutant. The detection limit is around $0.1 \mathrm{ppm}$, and the expected range is 0-0.3 ppm. Carbon monoxide lowers the amount of oxygen inhaled into the lungs and increases the heart disease symptoms. It helps to the production of $\mathrm{CO}_{2}$ and ozone, which are causing climate changes.

Sulfur dioxide $\left(\mathrm{SO}_{2}\right)$ is another primary pollutant which a product of high-temperature fuel combustion is. Natural events such as volcanic explosions can also produce it. The useful detection limit is around $10 \mathrm{ppb}$, and the expected range is $0-100 \mathrm{ppb}$. Sulfur dioxide worsens the lung diseases indications and can cause to hospitalize for long-term exposure. The environmental effect of $\mathrm{SO}_{2}$ is formed by increasing the acidic level on soil and water, causing damages to vegetation and wildlife.

Nitrogen dioxide $\left(\mathrm{NO}_{2}\right)$ is a primary and secondary pollutant which is produced by fuel combustion mobile sources. The expected range is $0-50 \mathrm{ppb}$, and the detection limit is around $10 \mathrm{ppb}$. The expose of nitrogen dioxide mainly affects kids and older adults' respiration system. $\mathrm{NO}_{2}$ also increases the acidification like $\mathrm{SO}_{2}$ in soil and water. It defects the oxygen in the water, which causes the death of animals.

Carbon dioxide $\left(\mathrm{CO}_{2}\right)$ which is one of the primary pollutants is an odorless and colorless non-toxic greenhouse gas which causes the ocean acidification. It is produced by fuel combustion, which can be seen in, electric facilities and mobile sources. The detection limit is $100 \mathrm{ppm}$, and the expected range is 350-600 ppm.

Particulate Matter (PM includes $P M_{2.5}$ and $P M_{10}$ ) is a primary and secondary pollutant. As a primary pollutant, it is produced by fuel combustion, dust, agriculture, and fire. The useful detection limit of fine 
particulate matter $\left(\mathrm{PM}_{2.5}\right)$ is $5 \mu \mathrm{g} / \mathrm{m}^{3}$, and the expected range is $0-40 \mu \mathrm{g} / \mathrm{m}^{3}$. For Particulate matter $\left(\mathrm{PM}_{10}\right)$ the useful detection limit of fine particulate matter $\left(\mathrm{PM}_{2.5}\right)$ is $5 \mu \mathrm{g} / \mathrm{m}^{3}$, and the expected range is $0-40 \mu \mathrm{g} / \mathrm{m}^{3}$. As a secondary pollutant, it is formed by primary pollutants and sunlight. The health effects of the PM are breathing problems, premature death, cardiovascular and lung diseases, and the environmental effects are deposited onto the surfaces which affect the ecosystem.

Volatile Organic Compounds (VOC) are also primary and secondary pollutants which are produced by fuel combustion operations and gasoline evaporation. The detection limit is $1 \mu \mathrm{g} / \mathrm{m}^{3}$, and total VOC range expected 5-100 $\mu \mathrm{g} / \mathrm{m}^{3}$. VOC's can be separated as non-methane (NMVOCs) and methane $\left(\mathrm{CH}_{4}\right)$. Methane is one of the greenhouse gases. NMVOCs are benzene, toluene, xylene. VOCs can cause cancer and help to the formation of ozone, which effects the atmosphere.

Lead $(P b)$ is a primary pollutant which can be produced by electric facilities and lead-acid manufacturers. The detection limit is $0.05 \mu \mathrm{g} / \mathrm{m}^{3}$, and the expected range is $0-0.1 \mu \mathrm{g} / \mathrm{m}^{3}$. Lead affects the central nervous system and causes cardiovascular diseases. It can cause permanent damages in soil, vegetation, and animals.

Table 1 Summary of the common air pollutants (Adapted from EPA Air Sensor Guidebook).

\begin{tabular}{|c|c|c|c|c|c|}
\hline $\begin{array}{l}\text { Air Pollutant of } \\
\text { Interest }\end{array}$ & Type & Source Example & $\begin{array}{c}\text { Useful } \\
\text { Detection } \\
\text { Limits } \\
\end{array}$ & Range to Expect & Level \\
\hline Ozone $\left(\mathrm{O}_{3}\right)$ & Secondary & $\begin{array}{l}\text { Formed via UV (sunlight) } \\
\text { and pressure of other key } \\
\text { pollutants }\end{array}$ & $10 \mathrm{ppb}$ & $0-150 \mathrm{ppb}$ & 75 ppb (8 hr.) \\
\hline $\begin{array}{l}\text { Carbon monoxide } \\
\text { (CO) }\end{array}$ & Primary & $\begin{array}{l}\text { Fuel combustion - mobile } \\
\text { sources, industrial processes }\end{array}$ & $0.1 \mathrm{ppm}$ & $0-0.3 \mathrm{ppm}$ & $\begin{array}{l}9 \mathrm{ppm}(8 \mathrm{hr} .) \\
35 \mathrm{ppm}(1 \mathrm{hr})\end{array}$ \\
\hline Sulfur dioxide $\left(\mathrm{SO}_{2}\right)$ & Primary & $\begin{array}{l}\text { Fuel combustion - electric } \\
\text { utilities, industrial processes }\end{array}$ & $10 \mathrm{ppb}$ & $0-100 \mathrm{ppb}$ & $\begin{array}{l}75 \mathrm{ppb}(1 \mathrm{hr} .) \\
0.5 \mathrm{ppm}(3 \mathrm{hr})\end{array}$ \\
\hline $\begin{array}{l}\text { Nitrogen dioxide } \\
\quad\left(\mathrm{NO}_{2}\right)\end{array}$ & $\begin{array}{c}\text { Primary and } \\
\text { Secondary }\end{array}$ & $\begin{array}{l}\text { Fuel combustion - mobile } \\
\text { sources, electric utilities, } \\
\text { off-road equipment }\end{array}$ & $10 \mathrm{ppb}$ & $0-50 \mathrm{ppb}$ & $\begin{array}{l}100 \mathrm{ppb}(1 \mathrm{hr} .) \\
53 \mathrm{ppb}(1 \mathrm{yr} .)\end{array}$ \\
\hline $\begin{array}{l}\text { Carbon dioxide } \\
\quad\left(\mathrm{CO}_{2}\right)\end{array}$ & Primary & $\begin{array}{l}\text { Fuel combustion - electric } \\
\text { utilities, mobile sources }\end{array}$ & $100 \mathrm{ppm}$ & $350-600 \mathrm{ppm}$ & None \\
\hline Methane $\left(\mathrm{CH}_{4}\right)$ & Primary & $\begin{array}{c}\text { Industry (e.g., natural gas } \\
\text { operations), agriculture, and } \\
\text { waste management }\end{array}$ & $500 \mathrm{ppb}$ & $1500-2000 \mathrm{ppb}$ & None \\
\hline $\begin{array}{l}\text { Volatile organic } \\
\text { compounds (VOCs) }\end{array}$ & $\begin{array}{c}\text { Primary and } \\
\text { Secondary }\end{array}$ & $\begin{array}{l}\text { Fuel combustion (mobile } \\
\text { sources, industries) gasoline } \\
\text { evaporation; solvents }\end{array}$ & $1 \mu \mathrm{g} / \mathrm{m}^{3}$ & $\begin{array}{c}5-100 \mu \mathrm{g} / \mathrm{m}^{3} \text { (total } \\
\text { VOCs) }\end{array}$ & None \\
\hline $\begin{array}{l}\text { Benzene (an example } \\
\text { of a VOC and air } \\
\text { toxics) }\end{array}$ & Primary & $\begin{array}{l}\text { Gasoline, evaporative losses } \\
\text { from above ground storage } \\
\text { tanks }\end{array}$ & $\begin{array}{c}0.01-10 \\
\mu \mathrm{g} / \mathrm{m}^{3}\end{array}$ & $0-3 \mu \mathrm{g} / \mathrm{m}^{3}$ & None \\
\hline $\begin{array}{l}\text { Fine particulate } \\
\text { matter (PM2.5) }\end{array}$ & $\begin{array}{l}\text { Primary and } \\
\text { Secondary }\end{array}$ & $\begin{array}{c}\text { Fuel combustion (mobile } \\
\text { sources, electric utilities, } \\
\text { industrial processes), dust, } \\
\text { agriculture, fires }\end{array}$ & $\begin{array}{l}5 \mu \mathrm{g} / \mathrm{m}^{3} \\
(24-\mathrm{hr})\end{array}$ & $\begin{array}{l}0-40 \mu \mathrm{g} / \mathrm{m}^{3} \\
(24-\mathrm{hr})\end{array}$ & $\begin{array}{l}35 \mu \mathrm{g} / \mathrm{m}^{3}(24 \mathrm{hr} .) \\
12 \mu \mathrm{g} / \mathrm{m}^{3} \text { (1 yr.) }\end{array}$ \\
\hline
\end{tabular}




\begin{tabular}{|c|c|c|c|c|c|}
\hline $\begin{array}{l}\text { Air Pollutant of } \\
\text { Interest }\end{array}$ & Type & Source Example & $\begin{array}{c}\text { Useful } \\
\text { Detection } \\
\text { Limits }\end{array}$ & Range to Expect & Level \\
\hline $\begin{array}{l}\text { Particulate matter } \\
\text { (PM10) }\end{array}$ & $\begin{array}{l}\text { Primary and } \\
\text { Secondary }\end{array}$ & $\begin{array}{c}\text { Dust, fuel combustion } \\
\text { (mobile sources, industrial } \\
\text { processes), agriculture, fires }\end{array}$ & $\begin{array}{c}10 \mu \mathrm{g} / \mathrm{m}^{3} \\
(24-\mathrm{hr})\end{array}$ & $\begin{array}{c}0-100 \mu \mathrm{g} / \mathrm{m}^{3} \\
(24-\mathrm{hr})\end{array}$ & $150 \mu \mathrm{g} / \mathrm{m}^{3}$ (24 hr.) \\
\hline Lead $(\mathrm{Pb})$ & Primary & $\begin{array}{c}\text { Smelting, aviation gasoline, } \\
\text { waste incinerators, electric } \\
\text { utilities, and lead-acid } \\
\text { battery manufacturers }\end{array}$ & $\begin{array}{l}0.05 \mu \mathrm{g} / \mathrm{m}^{3} \\
\quad(24-\mathrm{hr})\end{array}$ & $\begin{array}{c}0-0.1 \mu \mathrm{g} / \mathrm{m}^{3} \\
(24-\mathrm{hr})\end{array}$ & $0.15 \mu \mathrm{g} / \mathrm{m}^{3}$ (3 mo.) \\
\hline Black carbon (BC) & Primary & $\begin{array}{c}\text { Biomass burning, diesel } \\
\text { engines }\end{array}$ & $0.05 \mu \mathrm{g} / \mathrm{m}^{3}$ & $0-15 \mu \mathrm{g} / \mathrm{m}^{3}$ & None \\
\hline
\end{tabular}

\subsection{Monitoring ambient air}

In order to determine the current ambient air quality and develop new strategies ambient air pollutants have to be monitored. United States Environmental Protection Agency (US EPA) and South Coast Air Quality Management District (SCAQMD) monitors ambient air near the highway, and precise location with monitoring stations with different methods and analyzers adapted to the use for the purpose of these programs. Figure 1 shows the typical monitoring stations. At the stations, laboratory-grade analyzers are used for measuring the ambient air pollution levels. The advantages of these stations are highly reliable data, high accuracy, and long-lifetime. The disadvantages are that the stations cannot be relocated, high cost (higher than $\$ 20 \mathrm{~K}$ ) and for operating these stations, trained personnel is required.
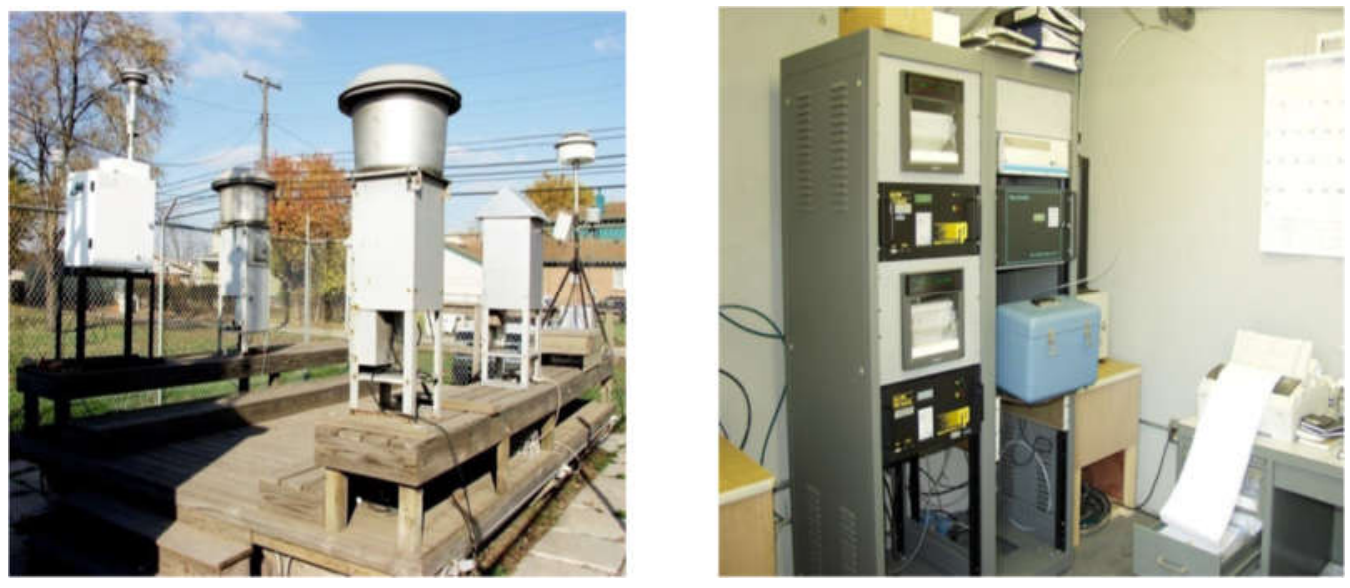

Figure 1 Typical US EPA stations for monitoring ambient air near highways and selected locations

[8].

Within the sensor technology developments, the applicants can reach the commercialized sensors in the market. These sensors can be defined as low-cost $(<\$ 500)$ sensors and are easy to operate due to the simplicity of the sensors; however, low-cost sensor responses and accuracy must be questioned. Many other studies have been completed for the evaluation of the low-cost sensor technologies and compare the sensor responses between laboratory testing versus field monitoring. The sensors have to be evaluated for uncertainty, accuracy, range, response time, and cross-sensitivity [9]. Many researchers focused on ambient 
air monitoring models, sensor calibration and various calibration methods on the sensor for the sensor evaluation and development; the studies are focused on validation of the low-cost ambient air monitoring sensor in laboratory and field conditions. The scope of the studies is wind velocity, humidity, uncertainty, interferences of the other pollutants, response time [10]-[12].

Pang et al. (2018) investigated impacts of the humidity and other pollutants on the low-cost electrochemical gas sensors which are used for monitoring the air quality. Five different gas sensors $\mathrm{O}_{3}, \mathrm{SO}_{2}, \mathrm{CO}, \mathrm{NO}$, $\left.\mathrm{NO}_{2}\right)$ were evaluated in the study for cross-sensitivity of the water vapor and potential pollutants $\left(\mathrm{O}_{3}, \mathrm{SO}_{2}\right.$, $\mathrm{CO}, \mathrm{NO}_{2}, \mathrm{NO}$, and $\mathrm{CO}_{2}$ ). The tests are performed in the laboratory environment with urban background air [13]. Another study focused on the use of semi-conducting oxides for gas sensors. The study points the usual semi-conducting sensor application areas are indoor and inside the passenger cars, however, with the screen printing technology the low-cost sensors can be used for outdoor air monitoring purpose and increase the monitoring station numbers [14].

\subsection{Laboratory experiments}

The set-up of a laboratory is very vital for the sensor evaluation and development process. The primary purpose of the laboratory set up is simulating the ambient air in laboratory condition for the evaluation of the sensor technology with that way metrological, and gas mixtures can be controlled. Different laboratory set-ups were developed in time, and multiple test procedures were performed for various pollutants by the researchers. In laboratory experiments based on generating a homogenous mixture for sensor measurements, a fan placed inside the set-up is mandatory. According to these studies, the atmosphere generation structures can be used for variable sensors evaluation and calibration. Some of the studies are represented below.

Gerboles et al. (1998) studied the uncertainty calculation for $\mathrm{NO}$ and $\mathrm{SO}_{2}$ gas mixtures; the researchers used a static volumetric method for the preparation of the gas mixtures. The vessel set-up is located at the ERLAB laboratories. The study adapted permeation and static volumetric methods and cross-checked the methods [15]. 


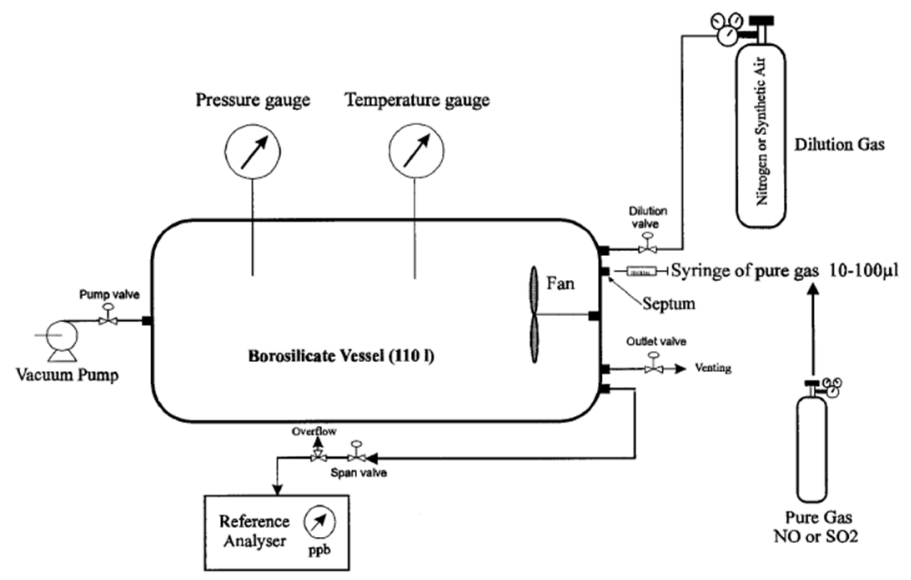

Figure 2 Static volumetric system [15].

Figure 2 shows the static volumetric system. The fan is used for preparing homogeneous mixture inside the vessel $\left(0.11184 \mathrm{~m}^{3}\right)$. The main gas injected by syringe and also. Nitrogen/synthetic air is used for the preparation of the diluted gas mixture. The study concluded the value of the uncertainty for NO and SO2 was calculated around $\pm 0.5 \%$ with $95 \%$ probability with the static volumetric method and with permeation method the uncertainty was around $1 \%$ with $95 \%$ probability and the leading cause of the uncertainty was the syringe volume determination.

Ballesta et al. (1999) investigated ambient air volatile organic compound (VOC) mixtures by using atmosphere generation system. Atmosphere generation system simulates the field conditions by controlling the gas mixture concentration levels, humidity, and temperature. In the study, uncertainty also calculated around $\pm 1.9 \%$. Figure 3 represents the standard atmosphere generation system. The system covers permeation oven for the preparation of VOC's and weighs in specific periods; the exposure chamber contains a fan to generate homogeneous gas mixtures. The study concluded that the main reasons for the uncertainty are weighing the permeation tubes and weighing time, which is linked to the isolation of the weighing procedure [16]. 


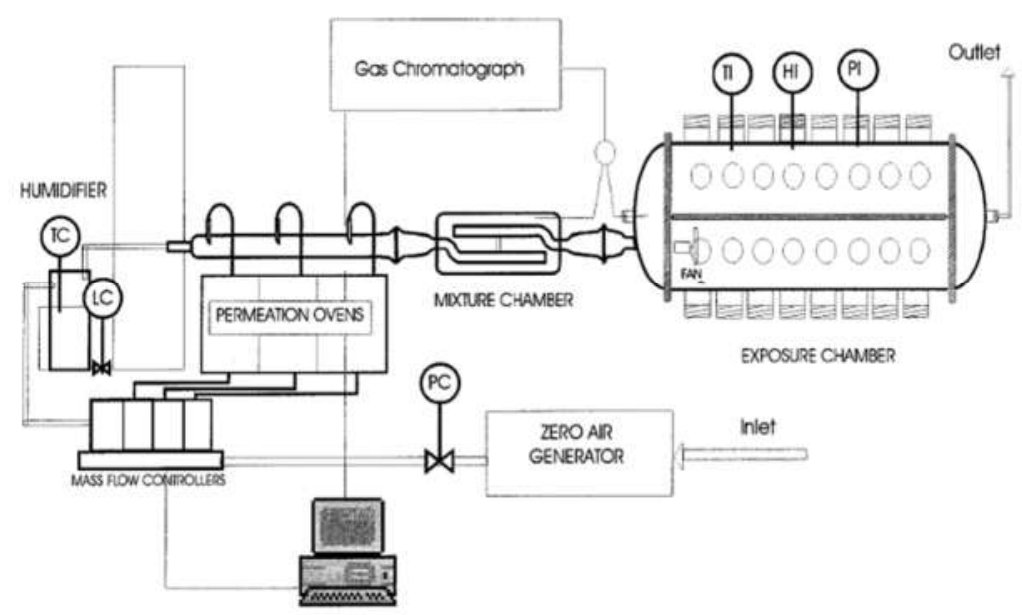

Figure 3 Standard atmosphere generation system [16].

Plaisance et al. (2004) investigated the effects of the meteorological conditions on passive diffusive samplers for $\mathrm{NO}_{2}$ measurements. The researcher had been used the exposure chamber system to simulate and control the meteorological conditions such as wind velocity, humidity, temperature [17].

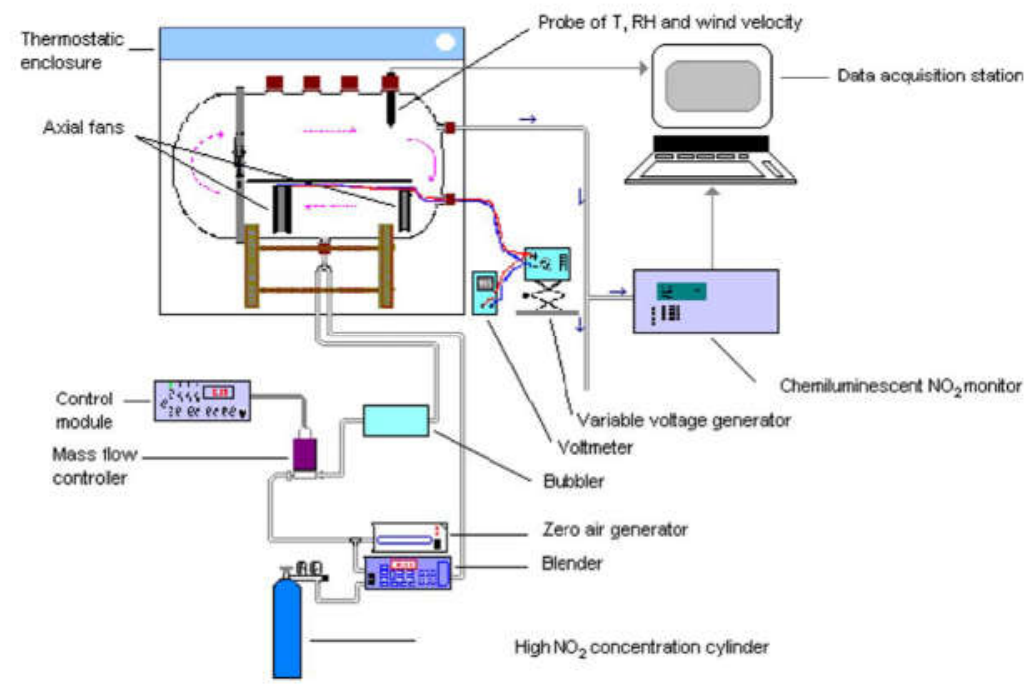

Figure 4 Schema of the exposure chamber system [17].

Figure 4 shows the schema of the exposure chamber. The study concluded that wind speed has a high impact on the sample rate, and the recommendation is protection for the sampler in order to reduce the wind effects. On the other hand, relative humidity $(\mathrm{RH})$ and temperature changes had a low impact on the sampling rate compared to wind speed. Plaisance et al. (2008) used another design of the exposure chamber for the 
estimation of the uncertainty of benzene measurement by using diffusive sampler [18]. The chamber is designed more advanced and controlled, placed in a thermostatic enclosure to sustaining the temperature.

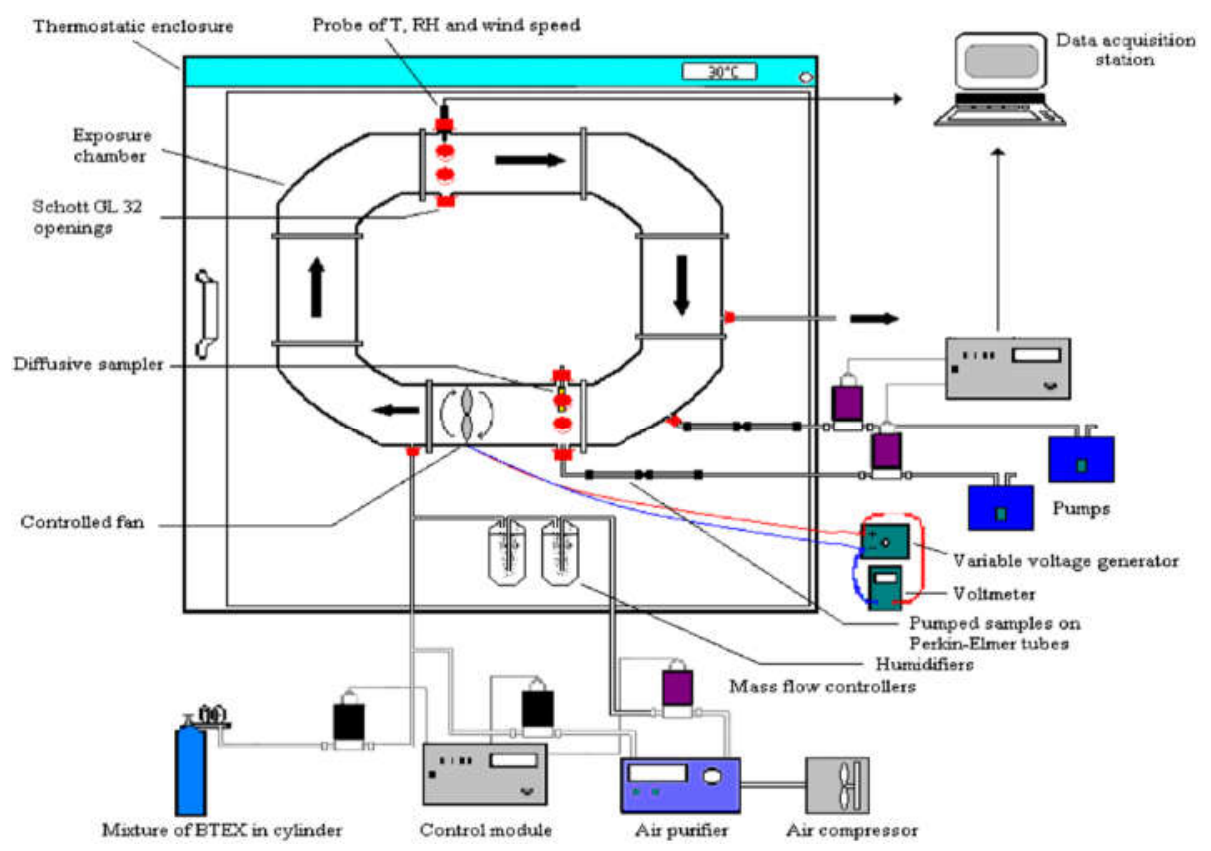

Figure 5 Scheme of the exposure chamber system [18].

Gerboles et al. (2005) studied the preparation and certification of reference materials for $\mathrm{NO}_{2}$ and $\mathrm{SO}_{2}$ in diffusive samplers by using exposure chamber set-up. The exposure chamber allows controlling concentration level, temperature, relative humidity, and wind velocity. The chamber is capable of holding up to 72 samplers. The study concluded that the samplers with cover boxes might have been created turbulence inside the chamber; thus, the specific samplers created bias. Figure 6 represents a schematic view of the exposure chamber [19]. 


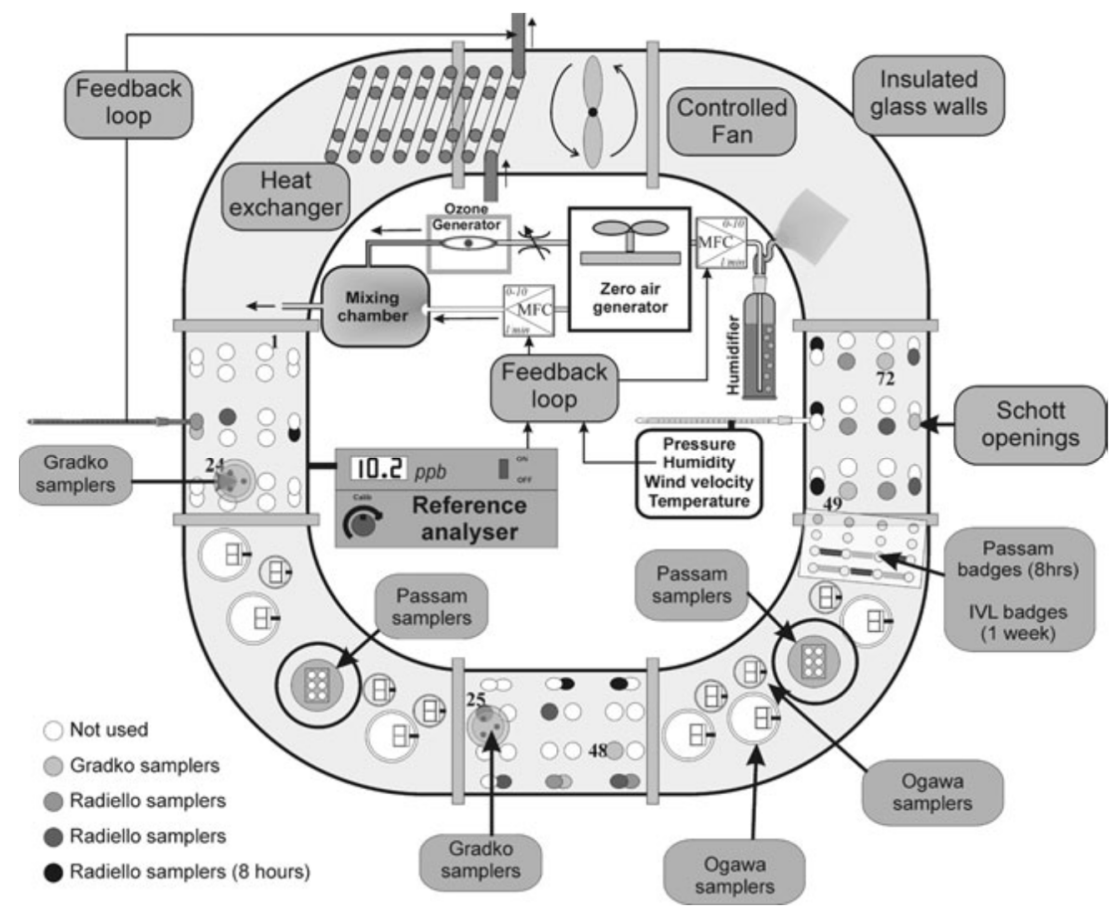

Figure 6 Exposure chamber [19].

Helwig et al. (2014) developed an automated gas mixing system. The focus of the study is a generation of VOCs by using permeation system and pre-dilution of test gases. The system can analyze very low gas concentration and evaluate the sensor responses. The gas mixing apparatus (GMA) adapted the dynamic volumetric methods. The GMA is a combination of 5 parts, gas mixing, humidification, permeation gas generation, gas dilution, and gas measurement. Figure 7 shows the schematic and 3D views of the GMA $[20]$. 

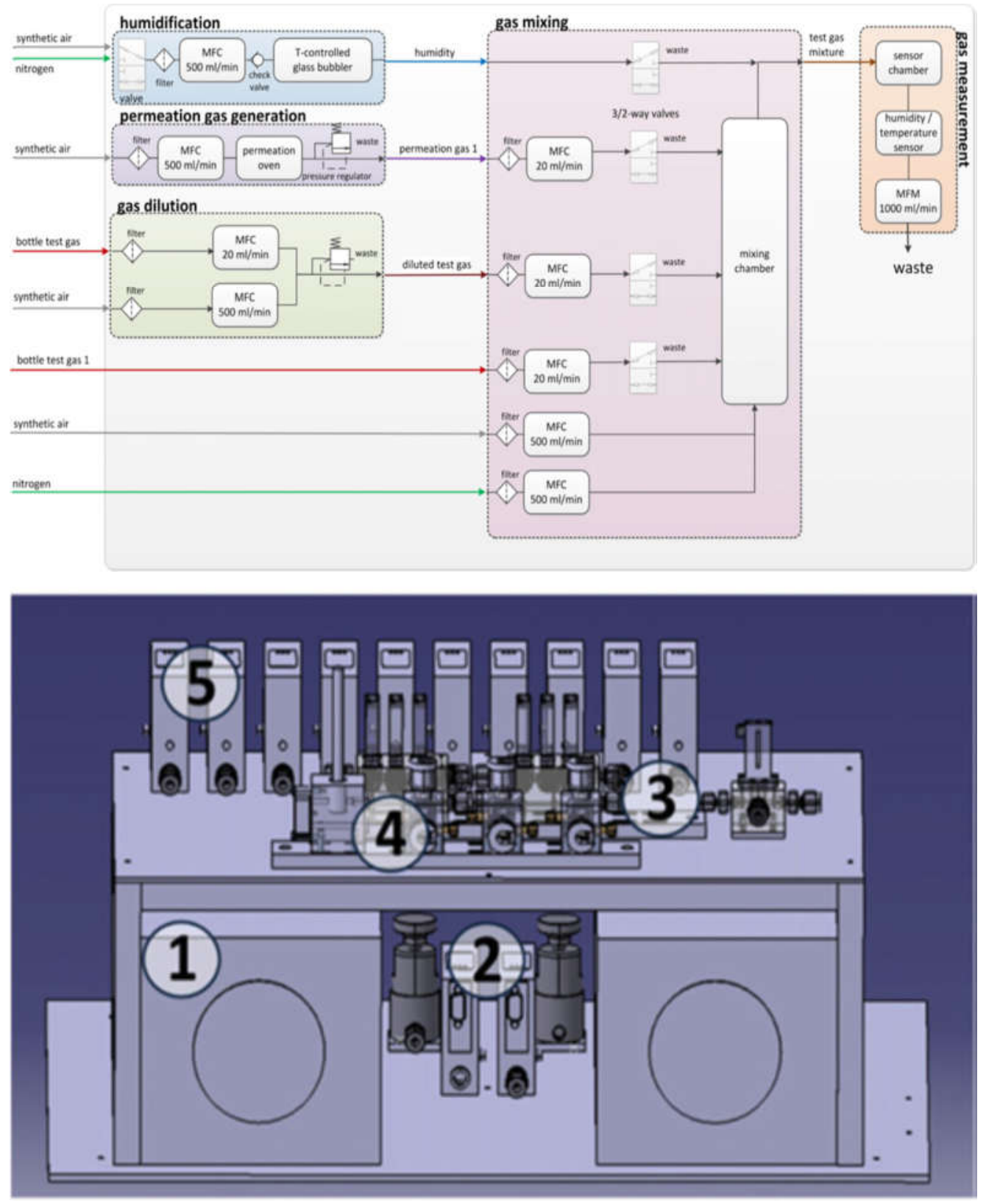

Figure 7 Scheme of the gas mixtures apparatus and mechanical setup as a CAD model [20].

Another study focused on diffusive samplers by Martin et al. in 2003. The researchers developed a controlled atmosphere test facility (CATFAC) to generate VOC atmosphere. The CATFAC can generate various atmosphere. Figure 8 represents the CATFAC system [21]. 


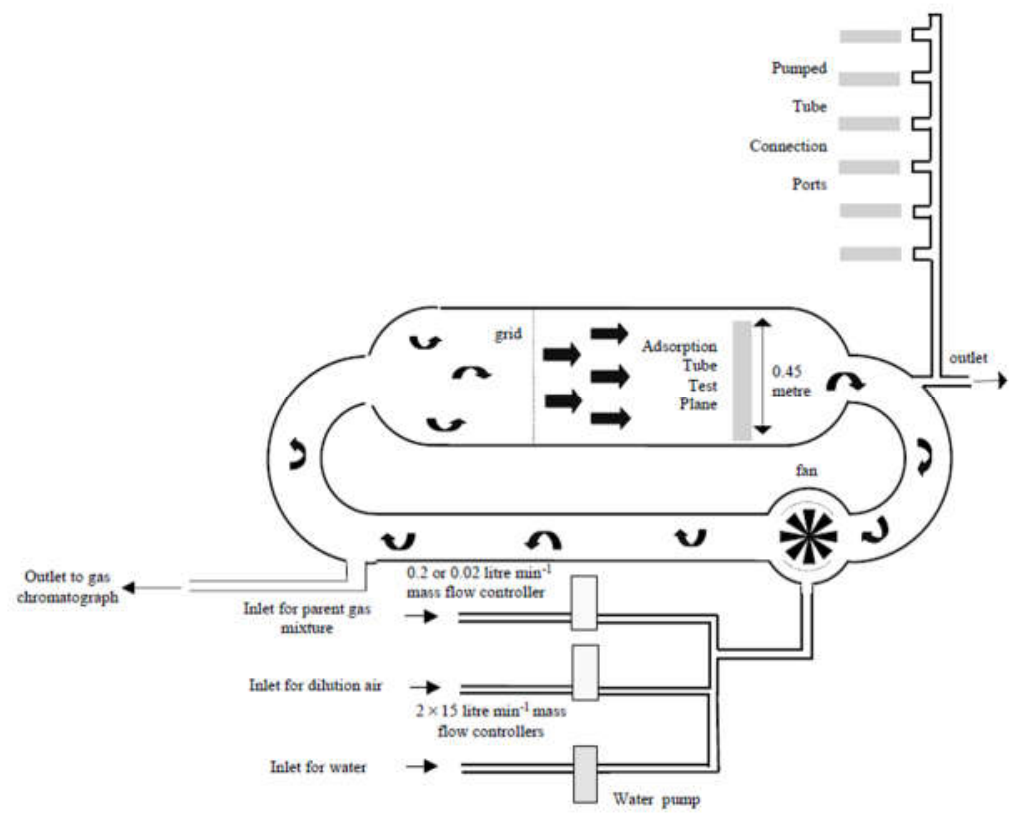

Figure 8 Controlled atmosphere test facility(CATFAC) [21].

South Coast Air Quality Management District (AQMD) has laboratory and field studies performed under the Department of Ambient Quality- Sensor Performance Evaluation Center (AQ-SPEC). The center also focused on low-cost sensor evaluation in the laboratory [22] and field conditions [23].

\subsection{Gas sensor types and sensor technologies}

Due to the cost of the traditional ambient air monitoring stations and requirements of the complex operations, the applicants tended to adopt the low-cost sensors regardless of the quality of the sensors. However, many studies focused on the evaluation of the sensors and calibration methods to increase the data quality of the measurements. The sensor technology is improving; hence, the quality is increasing, and the usage of the low-cost sensor is growing in the market. Another benefit of the low-cost sensors is the coverage of the significant areas; the number of monitoring stations is reducing.

Most common sensor type for ambient air monitoring is electrochemical sensors, Photo Ionization detector sensor (PID), Non-Dispersive infrared radiation absorption (NDIR) and Metal Oxide Sensors. The sensor principals are briefly explained down below. Many researchers focused on the different type of sensor validation [24]-[30].

\subsubsection{Metal oxide sensors}

Metal oxide sensors (MOS) are the most common sensors due to the simplicity of usage and low-cost in production. The MOS working the target gas reacts with the oxygen where it absorbed on the surface of the metal oxide. The reaction determines changes of the sensor resistance, which is recorded as a signal, and 
the signal correlated with the concentration of the target gas. The metal oxide type differs for the reaction gases [31]. The general properties of the sensors, high temperature, sensitive, reacting any volatile, has stability issues. Water consumption lowers the sensor accuracy. However, it depends on the reaction temperature. The study investigates MOS gas sensors benzene as target gas with temperature cycle operation [25]. Metal oxide sensors can also be used for detection of $\mathrm{NO}_{2}, \mathrm{SO}_{2}$. Figure 9 represents the general schema of the metal oxide sensors.

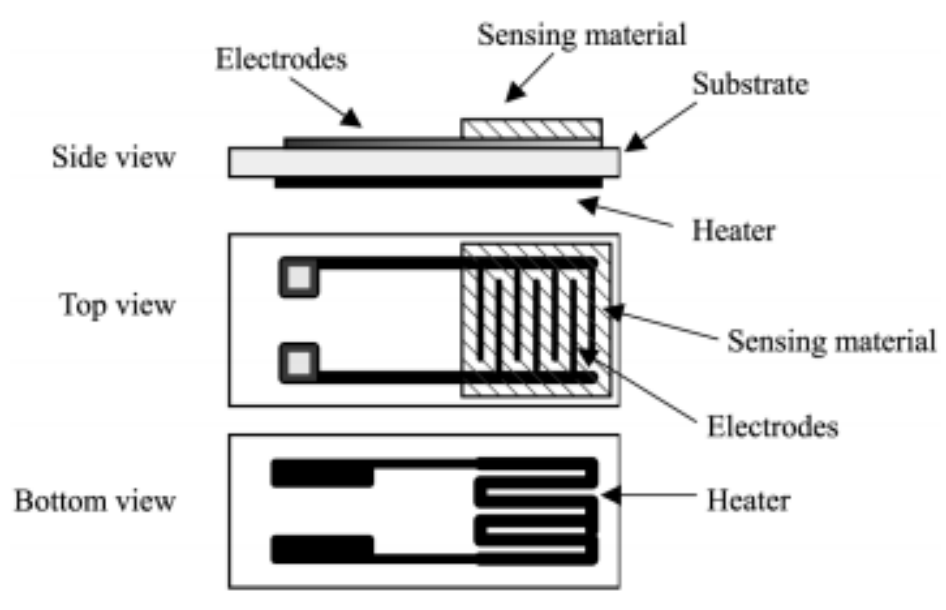

Figure 9 General schema of the MOS [32].

\subsubsection{Electrochemical sensors}

A typical electrochemical gas sensor contains one sensing and one counter electrode, which are divided by a thin layer of electrolyte. Before the target gas contact with the electrode surface, it diffuses through hydrophobic barriers [33]. The barriers are separators, which allow ionic contact between electrodes. The electrochemical sensors are generally used for detection of $\mathrm{CO}_{2}, \mathrm{NO}_{2}, \mathrm{SO}_{2}$. The amplification has to be used due to the sensor electrical current being low. Figure 10 shows electrochemical cell electrodes such as working, reference, and counter electrodes.

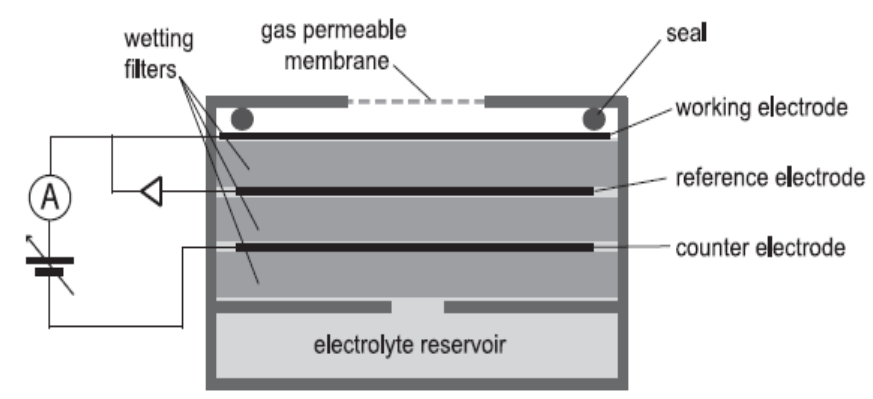

Figure 10 Schematic of an electrochemical cell. 


\subsubsection{Photo ionization detector (PID) sensor}

Photoionization detectors use high energy photons (ultraviolet) to ionize target gas molecules to positive and negative ions. The PID detects the ions or charges generated by the ions; the current is proportional to the gas concentration. Then the ions recombine to reform the sample gas which PIDs do not burn or permanently defects the sample gas. The PID sensors commonly used for detection of the volatile organic compounds (VOCs). The sensor needs frequent calibration [34]. Figure 11 represents the general schema of a PID sensor.

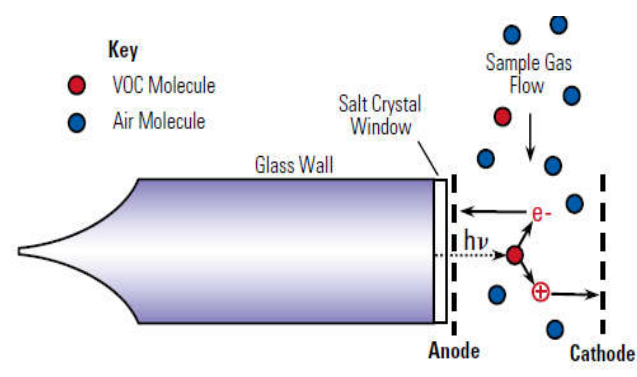

Figure 11 General schema of a PID sensor [34].

\subsubsection{Non-dispersive infra-red radiation absorption}

The Non-Dispersive infrared method is an optical method of gas detection; many target gases absorb specific wavelengths. The amount of absorbed IR lights is proportional to the target gas concentration. The NDIR sensors have the advantage of sensitivity, long-term durability, and power consumption. The detection range of these sensors goes from $5 \%$ vol. to $3000 \mathrm{ppm}$ for hydrocarbon gases and $\mathrm{CO}_{2}$. The NDIR sensors show a too high limit of detection, but some calibrations could be used to lower those limits [26]. Figure 12 shows the simple schema of the NDIR sensor. The NDIR sensors are suitable for detecting $\mathrm{CO}_{2}$ and $\mathrm{CO}$, however, these sensors are sensitive to humidity and temperature.
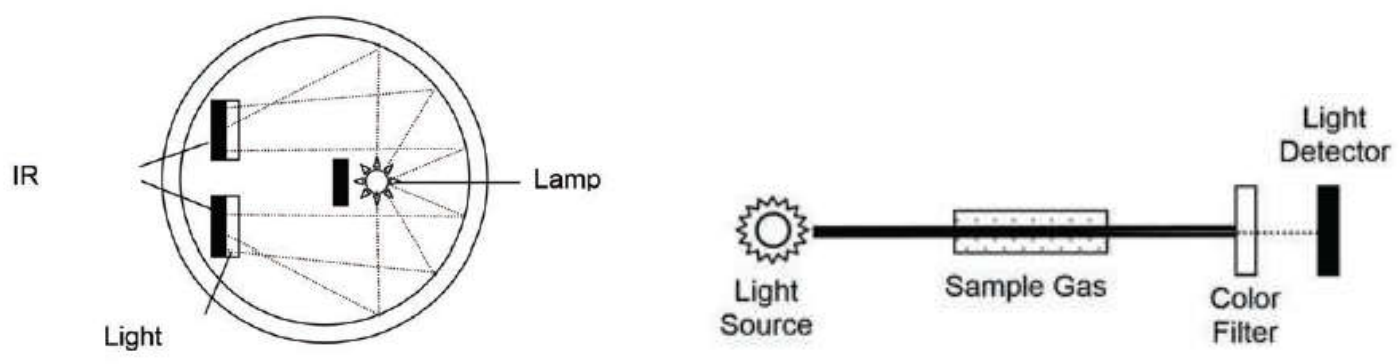

Figure 12 Simple schemas of non-dispersive IR sensor [35]. 


\subsection{Evaluation methods}

Evaluation methods compare the output of calibrated sensor data to a reference instrument. The section defines the primary statistical method, which many studies used these methods for evaluating sensor responses.

\subsubsection{The coefficient of determination (R-square)}

$\mathrm{R}^{2}$ can take a value between 0 to 1 where 0 is poor performance, and 1 is high. The $\mathrm{R}^{2}$ calculation is:

$$
R^{2}=\frac{\sum\left(y_{i}-m\right)^{2}}{\sum\left(x_{i}-m\right)^{2}}
$$

1

Where $\mathrm{y}_{\mathrm{i}}=$ the predicted value, $\mathrm{x}_{\mathrm{i}}=$ the observed value and $\mathrm{m}=$ mean of the observed value.

\subsubsection{Mean bias error (MBE)}

MBE is a measure of overall bias error.

$$
M B E=\frac{1}{n} \sum_{i=1}^{n} \frac{\left(y_{i}-x_{i}\right)^{2}}{x_{i}}
$$

Where $\mathrm{y}_{\mathrm{i}}=$ the predicted value, $\mathrm{x}_{\mathrm{i}}=$ the observed value, and $\mathrm{n}$ is the number of the data.

\subsubsection{Root mean square error (RMSE)}

RMSE is an absolute measure to understand the standard deviation of the unknown factors in variance[36]. RMSE calculation is:

$$
R M S E=\sqrt{\frac{\sum\left(y_{i}-x_{i}\right)^{2}}{n}}
$$

Where $\mathrm{y}_{\mathrm{i}}$ the predicted value, $\mathrm{x}_{\mathrm{i}}=$ the observed value and $\mathrm{n}$ is a number of the data.

\subsubsection{Centered root mean square (CRMSE)}

The method corrects the RMSE method for bias [37].

$$
C R M S E=\sqrt{R M S E^{2}-M B E^{2}}
$$

\subsection{Calibration methods}

The sensor calibration is vital for useful data. Many studies focused on the different calibration methods; most commonly used methods are linear regression, multilinear regression, and artificial neural network(ANN) [38]-[39]. 


\subsubsection{Linear regression (LR)}

Linear regression, the linear model approximates independent variables into a dependent variable. For the calibration function of the sensors, the sensor measurements are assumed to be linear with the reference measurements [40].

$$
y=f(x, \theta)=m x+b
$$

Where $\mathrm{y}$ is a function of and $\mathrm{m}$ is slope and $\mathrm{b}$ is intercept. Then vector of $\theta$ [41],

$$
\theta=\left[\begin{array}{l}
m \\
b
\end{array}\right]
$$

6

The presence of error assumed as

$$
y_{i}=m x_{i}+b+\epsilon_{i}
$$

We use the principle of Least squares regression for increasing the accuracy of the results. The method called minimization of the sum of the squared errors and the function is,

$$
S\left(\left[\begin{array}{c}
m \\
b
\end{array}\right]\right)=\sum_{i=1}^{n} \in_{i}^{2}=\sum_{i=1}^{n}\left(y_{i}-\left(m x_{i}+b\right)\right)^{2}
$$

8

The study where ambient air quality measurements are performed in the Federal District-Brazil. The scope of the study is calibrating Micro-Sensors MiCS-5521 (CO/VOC). For creating the calibration function, LR method is used in order to determine the effect of other parameters [42].

\subsubsection{Multivariate linear regression (MLR)}

Multivariate linear regression is another statistical model which has two or more response variables [43].

$$
y_{\text {corrected }}=\frac{y-b-\left(a_{1} x_{1}\right)-\left(a_{2} x_{2}\right)-\cdots-\left(a_{n} x_{n}\right)}{a_{o}}
$$

Where $\mathrm{y}$ is predicted sensor concentration value, $\mathrm{a}$ and $\mathrm{b}$ are independent variables such as $\mathrm{RH}$, temperatures. The study interest in field ambient air monitoring and creating complex calibration function. The study compares the methods where they defined in this section. During the study, the researchers created calibration models as a function of relative humidity $(\mathrm{RH})$, temperature( $\mathrm{T})$ for various ambient air sensors [44]. 


\subsubsection{Artificial neural network (ANN)}

The artificial neural network is another technique to calibrate the sensors where it simulates the human learning process. The operation of ANNs can be divided into two, first is learning(training) and second generalization(recalling) [45]. ANNs general working schema is like Figure 13.

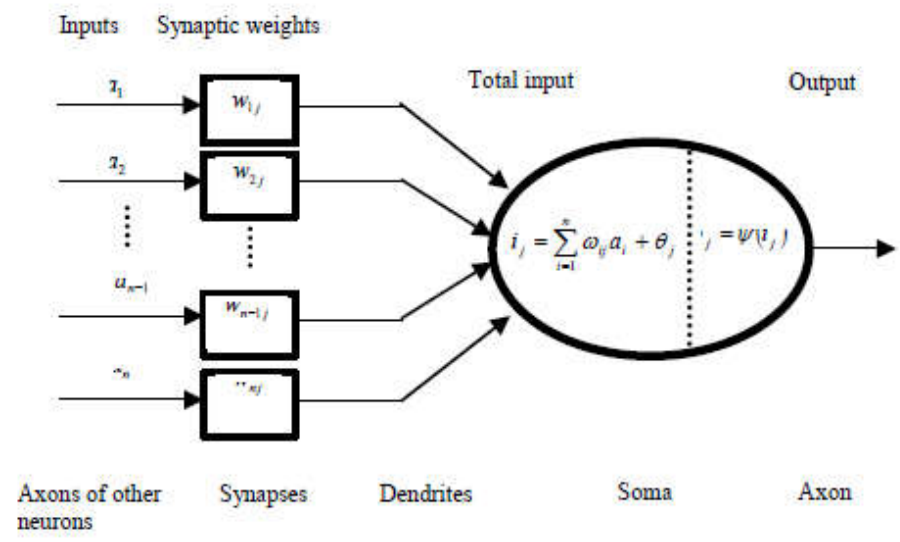

Figure 13 Model of a neuron.

The study, as mentioned earlier, also consider ANN method which is trusts on the training data set. The researchers are used the MLR corrected sensor data set as training data set [44]. 


\section{Methodology}

This section explains the methods for evaluation and calibration steps and shows the details of the DESC laboratory set-up and experiments.

\subsection{Development of the chamber}

Similarly, to the previous studies, the DESC was developed for the purpose of the mixing gas components and creating homogeneous mixtures. The shape of the DESC is adapted from previous studies. The DESC is a loop-shaped tunnel, includes stainless steel four spool pieces and four elbows. The DESC diameter is $254 \mathrm{~mm}$ (10 inches), and the spool piece contains a transparent window in order to place the sensors and visualization into the chamber.

The process has three steps; the first step is a 3D design with a modeling software (SolidWorks). The primary consideration was the weight of the stainless-steel pieces for transportability to the laboratory location. Moreover, another consideration point is suitability to modifications for the possibility of the size changes or any other modifications such as discarded parts; for this reason, the eight pieces design to be assembled. With that design, if needed, any piece can be replaced.

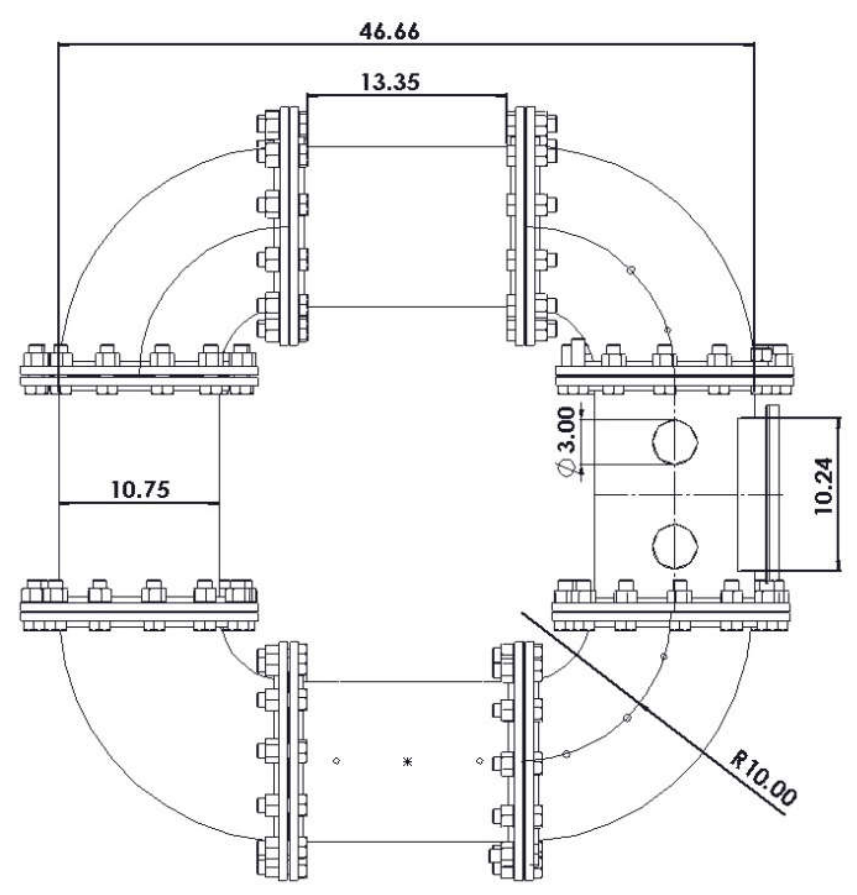

Figure 14 The DESC 3D drawing where the components are showed.

According to $3 \mathrm{D}$ design and calculations, the loop is around $120 \mathrm{~L}$ that is similar to the JRC sensor evaluation chamber [46], and the DESC weight is $300 \mathrm{~kg}$ with bolts.

Moreover, the support legs are also designed in house. The support legs have two parts; first parts directly welded under the spool pieces by Tungsten inert gas (TIG) welding method. Moreover, the Second part is the main leg part. For the leg parts, 2inx2in profiles are used and supported with $2.5 \times 2.5$ profiles and four 
casters used for each leg. Later, the structural analysis performed in order to determine the strength of the support parts. Figure 15 represents the completed version of the 3D design.

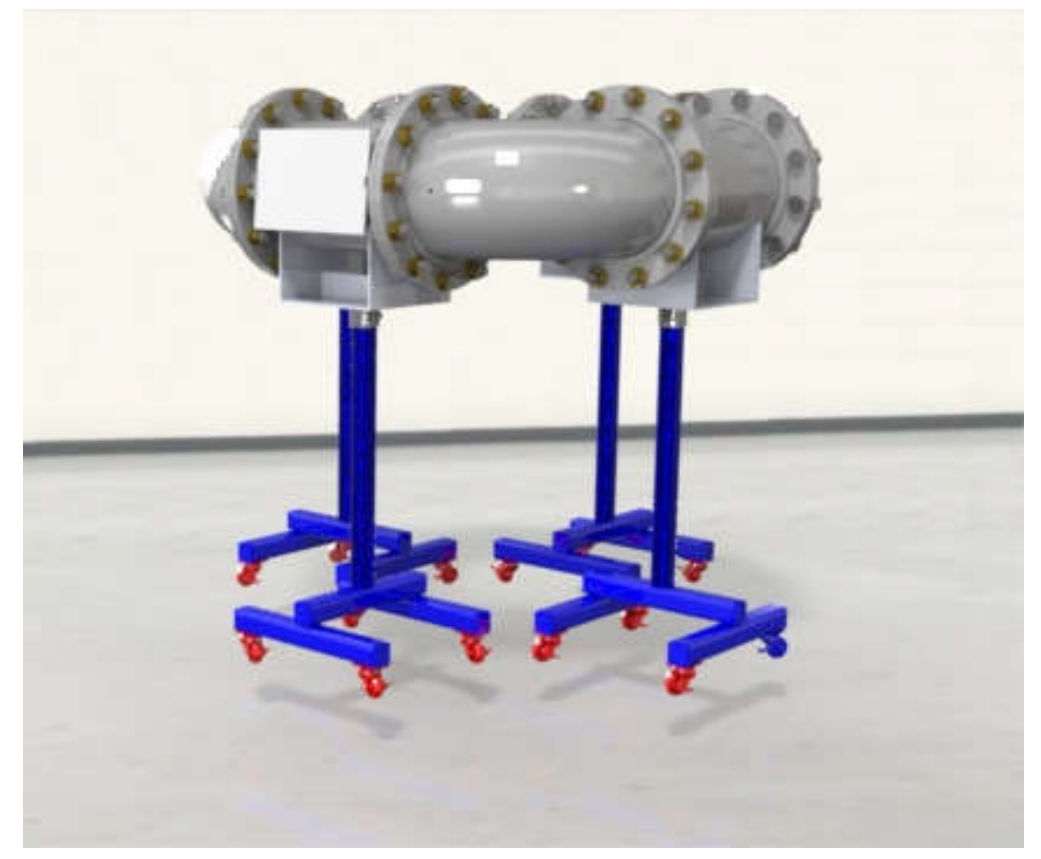

Figure 15 Final 3D modeled DESC.

\subsubsection{Flow simulation}

After the general design parameter and material properties were concluded, the computational flow analysis was performed for to characterization of the flow through the DESC before building up the laboratory. The fan was placed inside the chamber to generate continuous flow and helping to provide for a homogenous gas mixture. The CFD software (ANSYS Fluent) used for the analysis.

The purpose of that particular geometry is creating continuous circulation in the geometry and create a homogenous mixture. The shape of the DESC facilitates the effects of turbulence.

\subsubsection{Turbulent flow analysis numerical approach}

As the turbulence model, the RNG k- $\epsilon$ model used for the reason of the accuracy and wider range than the standard k-€ model. Also, also, the RNG k-€ model gives improved simulations for swirling flows and flow separation [47].

The model is based on the following assumptions;

- the flow is transient, turbulent, incompressible,

- the flow is single phased,

- isothermal. 
Transport equations for the RNG k- $€$ model are represented in partial differential forms as follow:

$$
\begin{gathered}
\frac{\partial}{\partial t}(\rho k)+\frac{\partial}{\partial x_{i}}\left(\rho k u_{i}\right)=\frac{\partial}{\partial x_{i}}\left(\alpha_{k} \mu_{e f f} \frac{\partial k}{\partial x_{j}}\right)+G_{k}+G_{b} \\
-\rho \varepsilon-Y_{M}+S_{k} \\
\frac{\partial}{\partial t}(\rho \varepsilon)+\frac{\partial}{\partial x_{j}}\left(\rho \varepsilon u_{j}\right)=\frac{\partial}{\partial x_{j}}\left(\alpha_{\varepsilon} \mu_{e f f} \frac{\partial \varepsilon}{\partial x_{j}}\right)++C_{1 \varepsilon} \frac{\varepsilon}{k}\left(G_{k}+C_{3 \varepsilon} G_{b}\right) \\
-\rho C_{2 \varepsilon} \frac{\varepsilon_{\dot{*}}^{2}}{k}-R_{\varepsilon}+S_{\varepsilon}
\end{gathered}
$$

Where $G_{k}$ is the generation of mean turbulent kinetic energy that arises mean velocity gradient, $G_{b}$ is the production of the kinetic energy the arises due to the buoyancy, $Y_{M}$ is the contribution of the fluctuating dilatation. $S_{k}$ and $S_{\varepsilon}$ are source terms. $\alpha_{\varepsilon}$ and $\alpha_{\mathrm{k}}$ are inverse effective Prandtl numbers for the turbulent kinetic energy and its dissipation. The default constant values are used for RNG model which are $\mathrm{C}_{\mu}=0.0845, \mathrm{C}_{1 \varepsilon}=1.42, \mathrm{C}_{2 \varepsilon}=1.68, \mathrm{Pr}_{\mathrm{t}}=0.85$.

\subsubsection{Mesh}

For the meshing process, the default mesh properties are used. Figure 16 shows the meshed geometry in ANSYS. Table 2 shows the mesh statistics of the DESC. This study also performed grid independency study to understand that simulation accuracy is independent from the grid resolution at the section 4.1.1.1

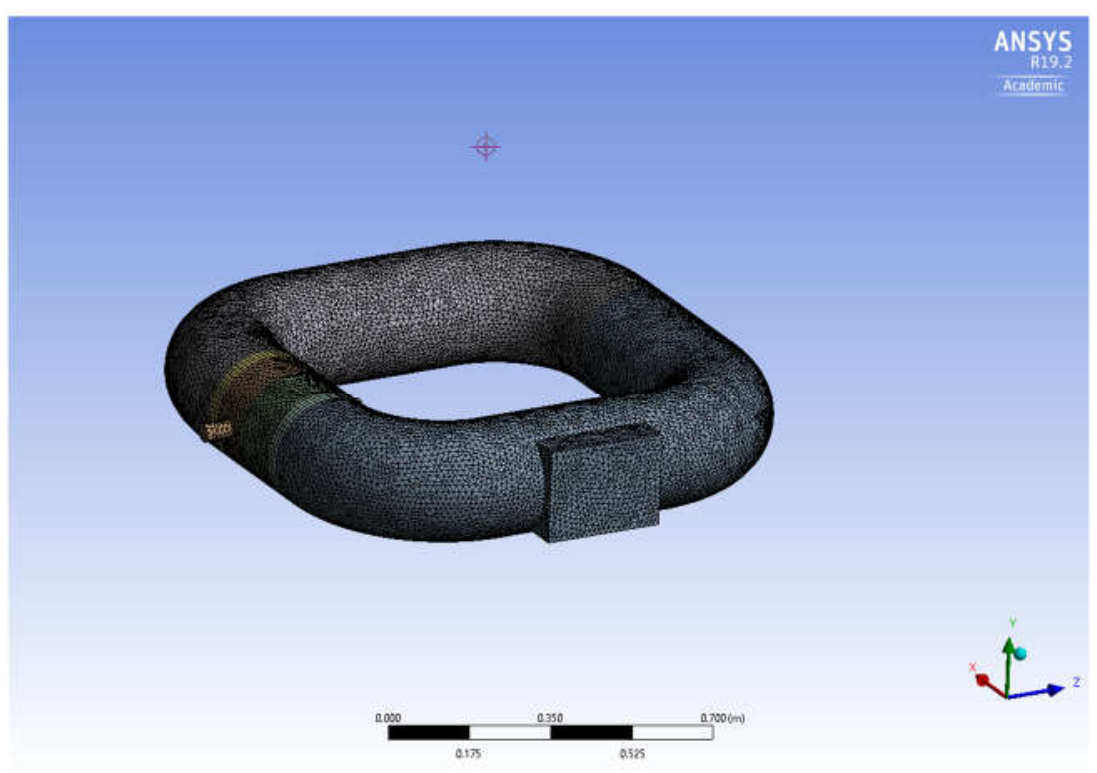

Figure 16 The DESC mesh view. 
Table 2 Mesh characteristics and statistics.

\begin{tabular}{|l|c|}
\hline Number of Nodes & 107138 \\
\hline Number of Elements & 509775 \\
\hline Tetrahedra & 499739 \\
\hline Wedges & 68 \\
\hline Pyramids & 4418 \\
\hline Hexahedra & 5550 \\
\hline Polyhedra & 0 \\
\hline
\end{tabular}

\subsubsection{Boundary conditions}

The DESC flow simulation solver type is pressure based, absolute velocity and transient, and also gravity accounted to simulation. The simulation models are viscous- RNG k- $€$ model for turbulent flow and species transport model used for creating the proper mixture, the mixture contains air, water vapor $\left(\mathrm{H}_{2} \mathrm{O}\right)$ and $\mathrm{CO}_{2}$ as a fraction of the mixture to determine $\mathrm{CO}_{2}$ mass fraction as a result of the mixing effect of the turbulent flow.

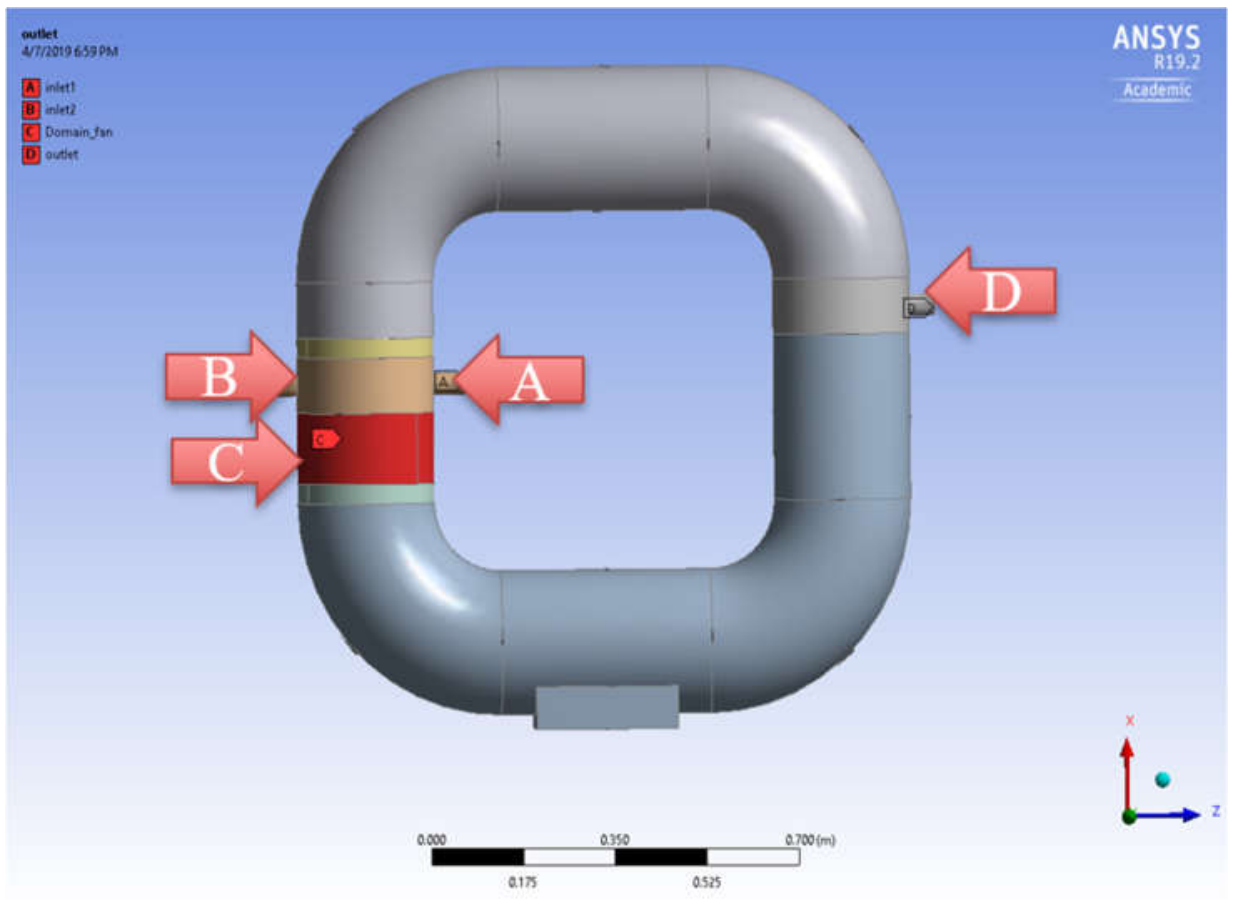

Figure 17 Boundaries for the flow analysis.

As boundaries shown at Error! Reference source not found. the boundaries are inlet 1 is A, inlet 2 B, fan domain $\mathrm{C}$ and outlet is $\mathrm{D}$. The fan defined as rotational speed source (frame motion) and the speed defined 
$1000 \mathrm{rpm}, 600 \mathrm{rpm}$ and $500 \mathrm{rpm}$. In the analysis, heat transfer is neglected, focused on the velocity profile in the chamber.

\subsubsection{Structural analysis}

The software calculates the design weight; it estimated around $300 \mathrm{~kg}$ of four support parts must carry the weight equally. The support parts have four pieces each. In order to decide the piece thickness structural analysis (ANSYS Mechanical) performed and calculated estimated displacement for $6.35 \mathrm{~mm}$ plates under $92.1 \mathrm{kPa}$ pressure. The pressure applied to $0.0017202 \mathrm{~m}^{2}$ where the spool piece welded-showed as red color in Figure 18 and Figure 19 show the mesh of the support where default mesh properties are used

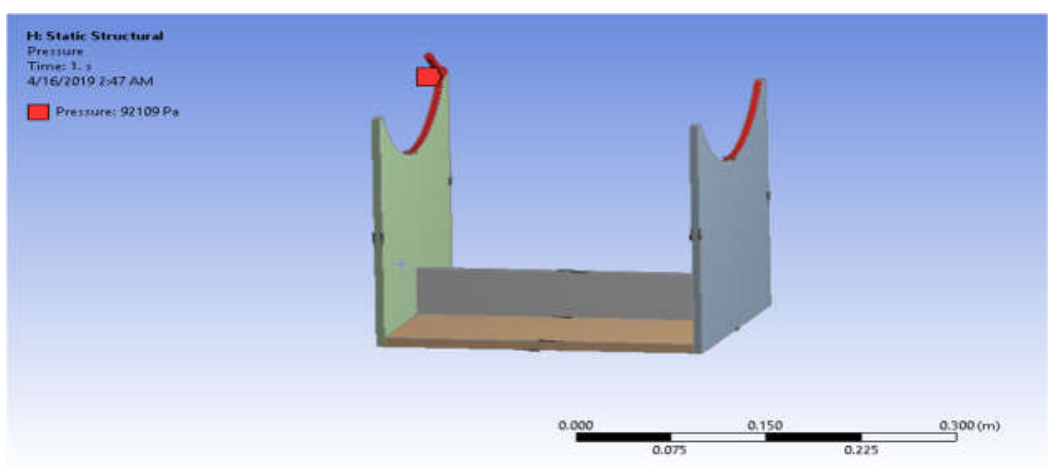

Figure 18 The supported geometry and the location of the pressure load.

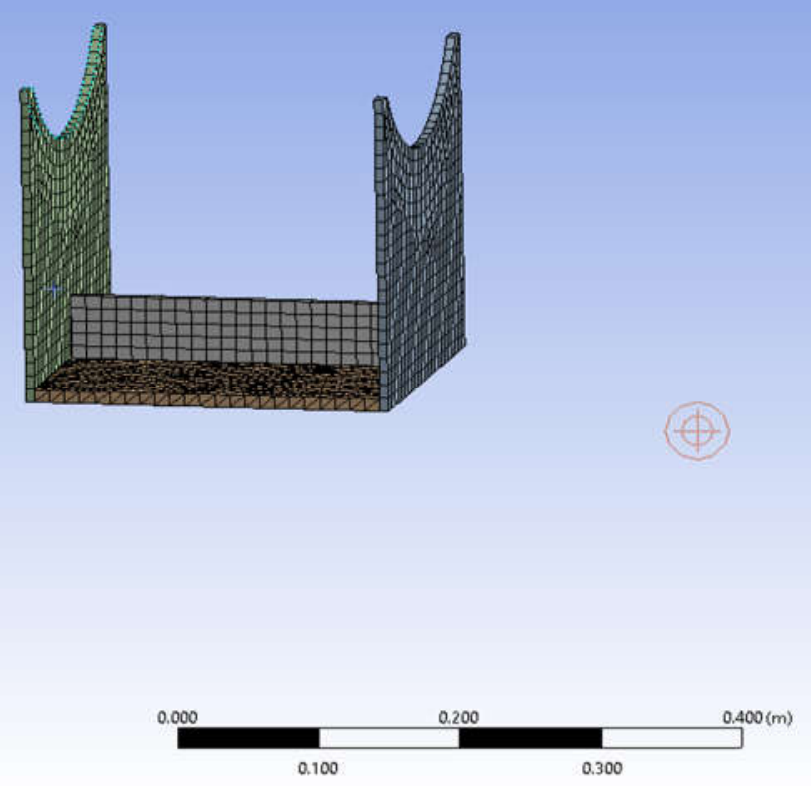

Figure 19 The mesh view of the support. 


\subsection{Laboratory set-up}

The DESC was placed at the sensor laboratory at West Virginia University's CAFEE facility. As mentioned before, the chamber contains eight separated pieces and four spool parts has the support legs for the purpose of transportation and increase the height. Figure 20 shows the test set-up in the facility. The study focused on $\mathrm{CO}_{2}$ sensors although the testing bench is capable of holding various ambient air sensors to evaluate them.

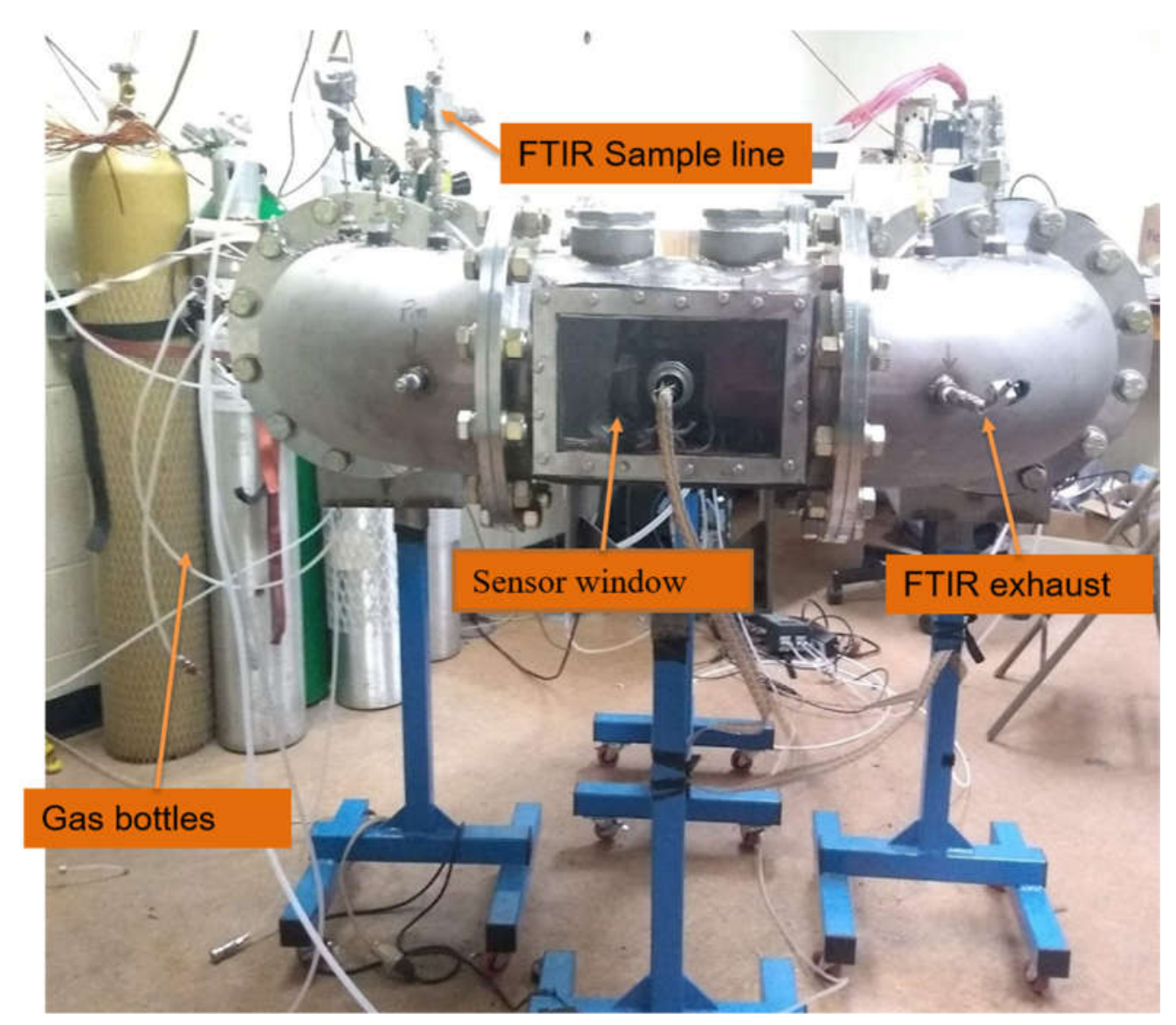

Figure 20 The DESC laboratory view.

Figure 21 represents a schema of the laboratory set-up. The set-up has two portions, with the first part being the mixing chamber before the DESC. A manifold used for the mixing gas components flow including air generated by Parker Balston zero air generator. At zero air generation line, before zero air generator, a chiller connected in order to drop water content in compressed air. The generated airflow through the Alicat mass flow controllers. Water-vapor is produced by a Honeywell humidifier and is used as a source of humidity. The communication and control are provided with an in-house software for the humidifier and the thermocouples used for measurement of the chamber temperature. An ICP-CON used for digital input 
and output, and $12 \mathrm{~V}$ power supply used for the ICP-CON. For the humidifier control set-up, a solid-state relay is connected to allow for water-vapor injection control. Table 3 shows the components before the mixing manifold. $\mathrm{CO}_{2}$ and $\mathrm{CO}$ gas bottles are used for the source of gas concentration and interference test components.

Table 3 The parts before mixing manifold.

\begin{tabular}{|c|c|c|c|c|}
\hline Name & Manufacturer & Model & \multicolumn{2}{|l|}{ Specifications } \\
\hline Chiller & Dominick Hunter & & & \\
\hline Zero Air Generator & Parker Balston & HPZA-3500 & & \\
\hline Humidifier & Honeywell & HM750A1000 & $\begin{array}{l}\text { Water Supply: } 30-100 \text { PSIG } \\
\text { HM750 produces } 11 \text { gallons per day } \\
\text { (GPD) }\end{array}$ & \\
\hline Mass Flow Controller & AliCat & MC-Series & $\begin{array}{c} \pm(0.8 \% \text { of Reading }+0.2 \% \text { of Full Scale }) \\
\pm 0.2 \% \text { Full Scale }\end{array}$ & Air \\
\hline Mass Flow Controller & AliCat & MC-Series & $\begin{array}{c} \pm(0.8 \% \text { of Reading }+0.2 \% \text { of Full Scale }) \\
\pm 0.2 \% \text { Full Scale }\end{array}$ & $\mathrm{CO}_{2}$ \\
\hline Mass Flow Controller & AliCat & MC-Series & $\begin{array}{c} \pm(0.8 \% \text { of Reading }+0.2 \% \text { of Full Scale }) \\
\pm 0.2 \% \text { Full Scale }\end{array}$ & $\mathrm{CO}$ \\
\hline
\end{tabular}




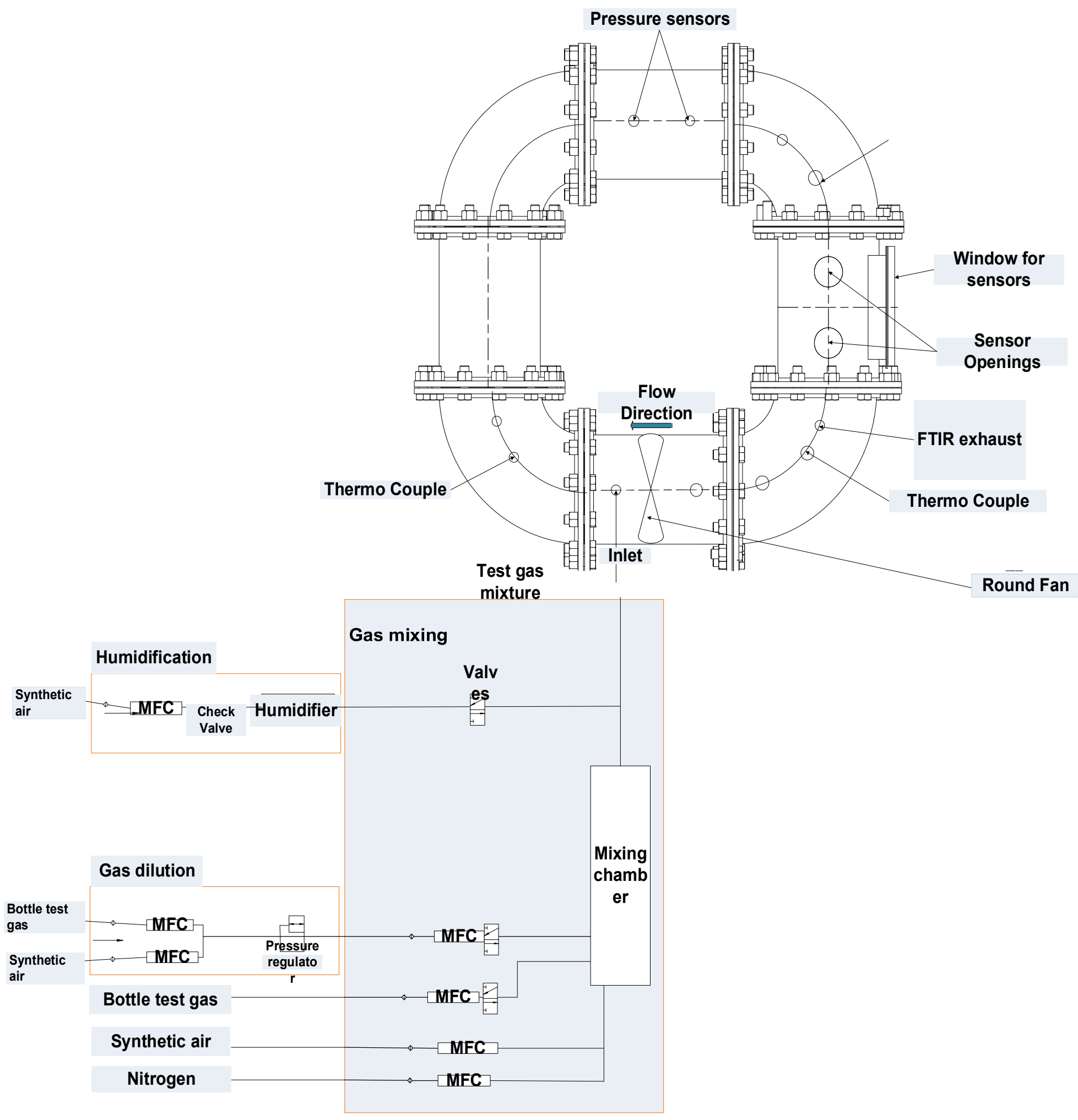

Figure 21 Scheme of the DESC and laboratory set-up. 
The second part is the dynamic environmental simulation chamber (DESC) where the mixed gas components with water vapor injected. In the chamber, a fan located in favor of creating a homogenous mixture and circulate it. Figure 22 shows the fan which placed into the chamber.

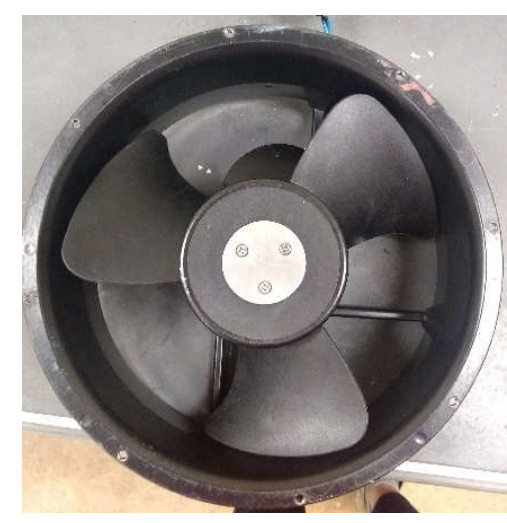

Figure 22 General look for the DESC circulation fan.

For control the chamber humidity control and feedback, Dew Point Hygrometer is connected to the chamber for monitoring relative humidity in the DESC. A small pump supplied the sample to dew prime. Two lines are connected one for sample out and one for sample into the chamber for the reason to maintain the inner concentration constant. Table 4 shows the components which are connected directly to DESC.

Table 4 The parts connected to DESC.

\begin{tabular}{|c|c|c|c|c|}
\hline Name & Manufacturer & Model & \multicolumn{2}{|c|}{ Specifications } \\
\hline Fan & $\begin{array}{l}\text { Mechatronics Fan } \\
\text { Group }\end{array}$ & UF25GC & $\begin{array}{l}\text { Voltage: } 115 \text { VAC } \\
\text { Round } 254 \text { mm Dia. (10.0 Dia) }\end{array}$ & $\begin{array}{l}\text { AirFlow:550 CFM } \\
\left(15.40 \mathrm{~m}^{3} / \mathrm{min}\right) \\
\text { RPM: } 1650 \mathrm{RPM}\end{array}$ \\
\hline Fan Controller & Yescom & & $\begin{array}{l}\text { Router Speed Controller, fuse } \\
\text { controlled }\end{array}$ & $\begin{array}{l}\text { Low, Medium, or } \\
\text { High speed }\end{array}$ \\
\hline Dew Point Hygrometer & EdgeTech & $\begin{array}{l}2000 \text { Dew } \\
\text { Prime II }\end{array}$ & $\begin{array}{l}\text { Relative Humidity } \\
\text { Accuracy: } \pm 0.50 \%\end{array}$ & $\begin{array}{l}\text { Flow rate: } 0.25 \mathrm{~L} / \mathrm{m} \text { to } \\
2.5 \mathrm{~L} / \mathrm{m}\end{array}$ \\
\hline Air velocity Probe & Kanomax & 0963-00 & Uni-directional & \\
\hline Air Flow Transducer & Kanomax & 6332 & & \\
\hline Handheld Digital Calibrator & Heise & PTE-1 & $\begin{array}{l}\text { AP module: } \\
\text { DP module: }\end{array}$ & \\
\hline FT-IR gas analyzers & MKS MultiGas & MG2000 & $\begin{array}{l}\text { Sample Temperature: Ambient to } \\
191^{\circ} \mathrm{C} \text { (calibration temperature } \\
\text { dependent) }\end{array}$ & $\begin{array}{l}\text { Sample Flow } 0.2-20 \\
\text { L/min Sample } \\
\text { Pressure } 0.01-4 \mathrm{~atm}\end{array}$ \\
\hline
\end{tabular}

The chamber contains multiple pieces which they create concerns about the leak through the chamber connection and bolts. The leak check performed by injecting air and creating pressure in the chamber and the measured pressure monitored. The leaks where are they spotted are closed by sealing products.

In order to measure the volumetric flow rate and air speed inside the DESC, four different pitot tubes are 
tested on a flow bench. A NIST-traceable Laminar Flow Element (LFE, Merriam) is used for comparison and linearization.

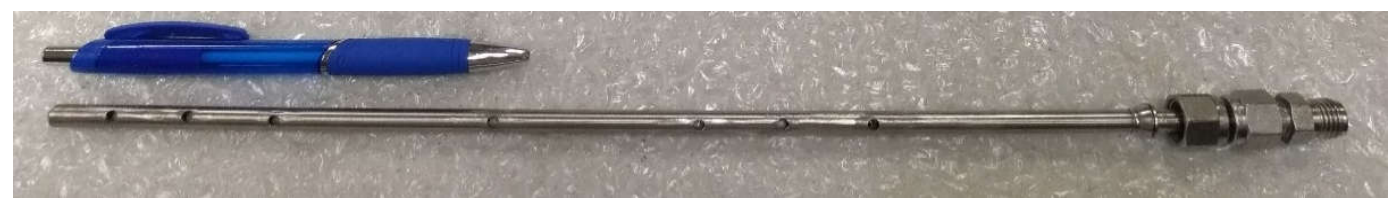

Figure 23 The final pitot tube for flow rate measurement.

The velocity profile measured by a Kanomax air velocity probe was compared to the velocity profile simulated by ANSYS simulations. The simulations were performed in order to understand velocity profile before testing and used for locating the ambient air sensors. The fan has three levels of speed which is controlled by Yescom variable speed controller (VFC). The window section gives a chance to visualize the sensors and the inner section of the chamber. Moreover, also, at the top of the DESC, two more openings added for more sensor locations and additional probes. A heating cable is wrapped around the chamber as a heating source in order to control the testing temperature.

\subsection{Sensors and connections}

The $\mathrm{CO}_{2}$ gas sensors were evaluated in the DESC, including, i) a high (K30 FR) and low-speed Senseair K30 (range 10000ppm), ii) a FIGARO FG-030 (range 5000ppm), and iii) a COZIR (range 2000ppm). The evaluated $\mathrm{CO}_{2}$ sensors were all based on nondispersive infrared detection (NDIR) technology which has interference with $\mathrm{CO}$, humidity, and temperature.

$\mathrm{K} 30 \mathrm{CO}_{2}$ sensors manufacturer specifications, the sensor measurement range is $0-10,000 \mathrm{ppm}$, the accuracy $\pm 30 \mathrm{ppm} \pm 3 \%$ of the measured value within specifications $(0-5,000 \mathrm{ppm}$ in spec), operating temperature limits are $0{ }^{\circ} \mathrm{C}$ to $+50{ }^{\circ} \mathrm{C}$, and operating humidity range is 0 to $95 \% \mathrm{RH}$ non-condensed. FIGARO FG-030 $\mathrm{CO}_{2}$ sensor manufacturer specifications, the measurement range, is 300-5,000 ppm within specifications. Sensor accuracy: $\pm 50 \mathrm{ppm} \pm 3 \%$ of the measured value within specifications. Operating temperature range is 0 to $+\% 50 \mathrm{C}$ and operating humidity range is 0 to $85 \% \mathrm{RH}$ non-condensed. COZIR ambient $\mathrm{CO}_{2}$ sensor has the lowest measurement range which is $0-2000 \mathrm{ppm}$. The sensor accuracy is $\pm 50 \mathrm{ppm} \pm 3 \%$ of the measured value within specifications, and operating temperature range is 0 to $+50{ }^{\circ} \mathrm{C}$, and operating humidity range is 0 to $95 \% \mathrm{RH}$ non-condensed.

As Figure 24 shows, the sensors are mounted on a transparent plate then placed into the DESC. The sensor location can hold up more than 20 sensors, and for more sensor, additional mounting plates can be added. 

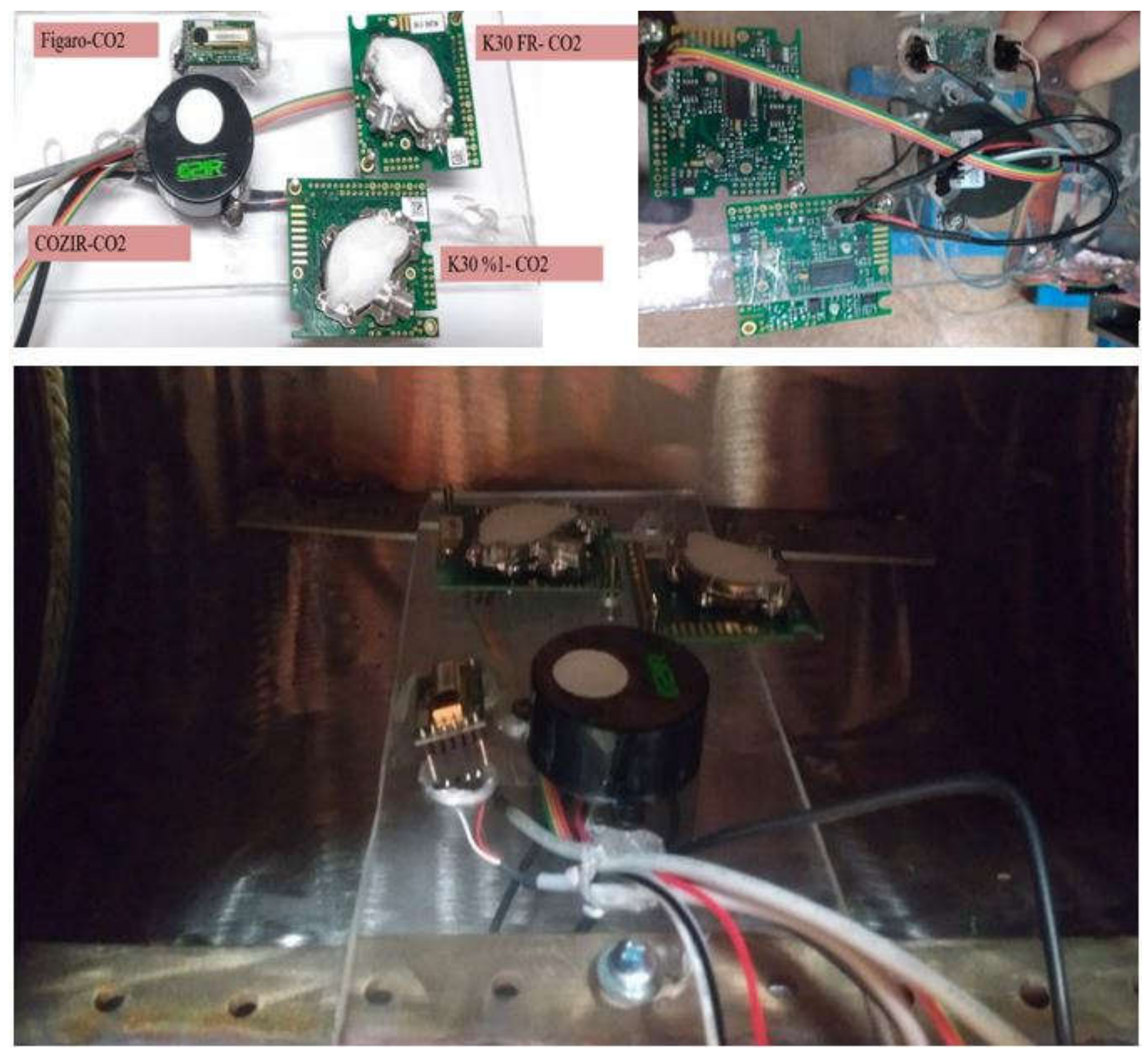

Figure 24 Sensors, sensor connections and sensor place in the DESC. 
Table 5 Sensor specifications.

\begin{tabular}{|c|c|c|c|c|}
\hline Name & Manufacturer & Model & \multicolumn{2}{|l|}{ Specifications } \\
\hline K30 & SENSE AIR & $\begin{array}{c}\text { Fast } \\
\text { Response } \\
\text { (FR) }\end{array}$ & $\begin{array}{l}\text { Measurement Range: } 0-5,000 \mathrm{ppm} \text { within specifications } \\
\text { Accuracy: } \pm 30 \mathrm{ppm} \pm 3 \% \text { of the measured value within } \\
\text { specifications } \\
\text { Response time t90: } 2 \text { seconds } @ .5 \mathrm{l} / \mathrm{min} \text { tube gas flow } \\
\text { Rate of Measurement: } 2 \text { seconds } \\
\text { Operating temperature } ; 0 \text { to }+50 \mathrm{C} \\
\text { Operating Humidity: } 0 \text { to } 95 \% \mathrm{RH} \text { non-condensed }\end{array}$ & $\mathrm{CO}_{2} \mathrm{NDIR}$ \\
\hline K30 & SENSE AIR & $1 \%$ & $\begin{array}{c}\text { Measurement Range }: 0-10,000 \mathrm{ppm}(0-5,000 \mathrm{ppm} \text { within } \\
\text { specifications) Accuracy: } \pm 30 \mathrm{ppm} \pm 3 \% \text { of measured value } \\
\text { within specifications Response time t90: } 2 \text { seconds @ } .51 / \text { min tube } \\
\text { gas flow } \\
\text { Rate of Measurement: } 2 \mathrm{~Hz} \\
\text { Operating temperature: } 0 \text { to }+50 \mathrm{C} \\
\text { Operating Humidity: } 0 \text { to } 95 \% \text { RH non-condensed }\end{array}$ & $\mathrm{CO}_{2} \mathrm{NDIR}$ \\
\hline $\begin{array}{l}\text { FIGARO } \\
\text { FG-030 }\end{array}$ & FIGARO & CDM7160 & $\begin{array}{c}\text { Measurement Range: } 300-5,000 \mathrm{ppm} \text { within specifications } \\
\text { Accuracy: } \pm 50 \mathrm{ppm} \pm 3 \% \text { of measured value within specifications } \\
\text { Response time t } 90: 2 \mathrm{~min} \\
\text { Rate of Measurement: } 2 \text { seconds } \\
\text { Operating temperature: } 0 \text { to }+\% 50 \mathrm{C} \\
\text { Operating Humidity: } 0 \text { to } 85 \% \text { RH non-condensed }\end{array}$ & $\mathrm{CO}_{2} \mathrm{NDIR}$ \\
\hline Cozir & $\begin{array}{c}\text { GAS SENSING } \\
\text { SENSOR }\end{array}$ & Ambient & $\begin{array}{c}\text { Measurement Range: } 0-2,000 \mathrm{ppm} \text { within specifications } \\
\text { Accuracy: } \pm 50 \mathrm{ppm} \pm 3 \% \text { of measured value } \\
\text { within specifications } \\
\text { Rate of Measurement: } 2 \text { seconds } \\
\text { Operating temperature: } 0 \text { to }+50 \mathrm{C} \\
\text { Operating Humidity: } 0 \text { to } 95 \% \text { RH non-condensed }\end{array}$ & $\mathrm{CO}_{2} \mathrm{NDIR}$ \\
\hline
\end{tabular}

\subsection{Experimental procedures and operational steps}

In this section, laboratory operations and the procedures followed for the experiments will be explained. For tuning the calibration function, the test matrix is created. Various experiments are performed for each independent variables. Table 6 shows the test matrix for the testing sensors. The testing matrix designed consideration of the possible interference and variables such as temperature, pressure, humidity.

The laboratory limits are temperature $\left(25-110{ }^{\circ} \mathrm{C}\right)$, relative humidity $(0-95 \%)$, and wind speed $(0-5 \mathrm{~m} / \mathrm{s})$ instantly. Still, the laboratory limitations can be changed if needed for other sensor applications. 
Table 6 Matrix of experiments.

\begin{tabular}{|c|c|c|c|c|c|c|}
\hline Test ID & Test Spec & $\begin{array}{c}\text { Test } \mathrm{CO}_{2} \text { range } \\
(\mathrm{ppm})\end{array}$ & $\begin{array}{l}\text { Temperature } \\
\left({ }^{\circ} \mathrm{C}\right)\end{array}$ & Humidity (RH) & CO level & Pressure (Psi) \\
\hline 1 & High Speed & $1000 \pm 50 \mathrm{ppm}$ & $23 \pm 0.2$ & $16 \pm 2$ & $1 \mathrm{ppm}$ & \\
\hline 2 & Medium Speed & $1000 \pm 50 \mathrm{ppm}$ & $23 \pm 0.2$ & 15 & $1 \mathrm{ppm}$ & \\
\hline 3 & Low Speed & $950 \pm 50 \mathrm{ppm}$ & $23 \pm 0.2$ & 13 & $1 \mathrm{ppm}$ & \\
\hline 4 & Zero Speed & $970 \pm 80 \mathrm{ppm}$ & $23 \pm 0.2$ & 12 & $1.5 \mathrm{ppm}$ & \\
\hline 5 & All Speed & $970 \pm 80 \mathrm{ppm}$ & $23 \pm 0.2$ & $10 \pm 0.6$ & $1 \mathrm{ppm}$ & \\
\hline 6 & $\begin{array}{c}\text { Step by Step } \mathrm{CO}_{2} \text { concentration } \\
\text { increase ( } 40 \text { levels })\end{array}$ & $900-9000$ ppm & $26 \pm 2$ & $7.2 \pm 1.5$ & $7 \pm 6 \mathrm{ppm}$ & $14.3 \pm 0.2$ \\
\hline 7 & $\begin{array}{c}\text { Transient } \mathrm{CO}_{2} \text { concentration } \\
\text { decrease }\end{array}$ & $9000-500 \mathrm{ppm}$ & 27 & $7.2 \pm 1.5$ & $8 \pm 2 \mathrm{ppm}$ & $14.3 \pm 0.2$ \\
\hline 8 & $\begin{array}{c}\text { Transient } \mathrm{CO}_{2} \text { concentration } \\
\text { increase }\end{array}$ & $\begin{array}{l}500 p p m- \\
10000 p p m\end{array}$ & 28 & 26 & $4 \pm 2 \mathrm{ppm}$ & 14.15 \\
\hline 9 & $\begin{array}{c}\text { Transient } \mathrm{CO}_{2} \text { concentration } \\
\text { decrease }\end{array}$ & $10000-800$ ppm & $28 \pm 2$ & $30 \pm 2$ & $4 \pm 2 \mathrm{ppm}$ & 14.15 \\
\hline 10 & Temp increase & $600 \pm 50 \mathrm{ppm}$ & $25-50$ & $4 \pm 2$ & $5 \pm 2$ & 14 \\
\hline 12 & Temp decrease & $1100 \pm 50 \mathrm{ppm}$ & $36-28$ & $5 \pm 2$ & $5 \pm 2$ & 14 \\
\hline 13 & $\begin{array}{c}\text { CO concentration increase (3 } \\
\text { level) }\end{array}$ & $1250 \pm 100$ & $27.21 \pm 0.5$ & $8.2 \pm 0.2$ & $\begin{array}{c}5-650-800 \\
\text { ppm }\end{array}$ & 14 \\
\hline 14 & Humidity change (3 level) & $1709 \pm 120$ & 31 & $6-30-60$ & $11 \mathrm{ppm}$ & 13.9 \\
\hline 15 & Pressure change & $1500 \mathrm{ppm}$ & 24 & 8 & $1 \mathrm{ppm}$ & $14.5-14.33$ \\
\hline
\end{tabular}

All the experiments are performed for only one independent variable; other variables are kept constant in the testing set-up limits. For the fan speed tests, the concentration and other meteorological and interference components are stabilized during the testing process. The step by step $\mathrm{CO}_{2}$ concentration test is recorded, but throughout the testing procedure, first, the $\mathrm{CO}_{2}$ concentration is increased until the desired level then holds until FTIR starts to read stably. Then the stable measurement sections are established as the sampling measurement, 40 concentration level considered for the test

For the transient concentration changes, the $\mathrm{CO}_{2}$ gas injected continuously while the evacuation valve is open; therefore, the DESC inner pressure will stay constant. The concentration increased until the sensor detection limitation ranges; however, COZIR ambient sensor is stopped recording because the $\mathrm{CO}_{2}$ concentration exceeds after $2,000 \mathrm{ppm}$. The temperature properties tests, the heating cable is used, the cable is capable of heating $110{ }^{\circ} \mathrm{C}$ however, during the tests experimental temperature is increased until $50{ }^{\circ} \mathrm{C}$ because high temperature might damage the circulation fan because it is the maximum operational temperature up to $65^{\circ} \mathrm{C}$ and the sensors which have the maximum operational temperature up to $50{ }^{\circ} \mathrm{C}$.

$\mathrm{CO}$ considered as an only cross-sensitivity entity; three concentration levels are measured during the experiment. The concentration level increased to the aspired limit then the gas injection is stopped and hold 
until FTIR reading starts to read stable CO concentration. Three levels considered as sample reading. Highest $\mathrm{CO}$ level is $650 \mathrm{ppm}$ which is exceeding the EPA limits. The purpose of measuring the high concentration is observing the effects on the sensor.

The humidity experiments are also considered; three levels of humidity are investigated to see the impact on the sensors. The chamber humidity increased to the specific level then hold until Dew Prime starts to read the desired level of the humidity.

\subsection{Data and unit corrections}

K30 FR, low-speed Senseair K30, and COZIR recording frequency are kept at $1 \mathrm{~Hz}$, and Figaro and FTIR recording frequency are at $5 \mathrm{~Hz}$. After the experiments, the recorded data processed for time alignment and the frequency up/down sampling. The recorded data corrected, and the sampling frequency became $2 \mathrm{~Hz}$ for all which is belong to the sensors, FTIR and other measurement recorded by in-house software.

For the humidity corrections, Dew Prime humidity output unit is relative humidity. The unit converted to water content. The water content is calculated by the EPA CFR 1065.645 [48]. The section explains how to calculate the amount of water content in an ideal gas.

$$
\begin{aligned}
& \log _{10}\left(P_{H 2 O}\right)=10.79574 .\left(1-\frac{273.16}{T_{\text {sat }}}\right)-5.02800 \cdot \log _{10}\left(\frac{T_{\text {sat }}}{273.16}\right)+1.50475 \cdot 10^{-4} \cdot\left(1-10^{-8.2969 \cdot\left(\frac{T_{\text {sat }}}{273.16-1}\right)}\right)+ \\
& 0.42873 .10^{-3} \cdot\left(10^{4.76955 \cdot\left(1-\frac{273.16}{T_{\text {sat }}}\right)}-1\right)-0.2138602
\end{aligned}
$$

Where $P_{H 2 O}(\mathrm{kPa})$ is water vapor pressure at the saturation point and $T_{\text {sat }}(\mathrm{K})$ is saturation temperature of water at measured conditions.

$$
X_{H 2 O}=\frac{R H \% \cdot P_{H 2 O}}{P_{a b s}}
$$

Where $X_{H 2 O}$ is water content in ideal gas, $\mathrm{RH} \%$ is relative humidity, $P_{H 2 O}$ is water vapor pressure at 100 $\%$ relative humidity at the location, $P_{a b s}$ is wet static absolute pressure.

\subsection{Sensor calibration method}

As described in the literature review, the researchers are used various calibration method. In this study, the Multilinear regression method will be used for multiple variables with stepwise.

As the first step, zero and span corrections will be completed after drift correction for reference analyzer. Then, for the independent variables, the multilinear regression method applied individually. For one independent variable, the method applied then after the variable correction the method repeated for the next variable if the new variable has a contribution to calibration accuracy then the variable applied to the process [49]. The generated calibration function is as shown in Equation 14 in section 2.6. 


\section{Results}

This section contains two parts; the first part contains the results which are generated before the DESC is developed for the purpose of the design and material selections such as fan selection and deciding to sensor locations. The second part comprises the sensor validation results after the calibration function had been generated as a function of pressure $(\mathrm{P})$, temperature $(\mathrm{T})$, water content $(\mathrm{H})$ and $\mathrm{CO}$ interference.

\subsection{Before experiments}

At the early stage of this work, after the design process completed, the simulations are generated for the sake of understanding the velocity profile during gas injection and the fan circulation. Moreover, also, structural analysis is performed in order to determine the strength of the support legs because of the weight concerns since the overall chamber set-up is around $300 \mathrm{~kg}$.

The CFD simulation results consist of velocity profile compared with the experimental velocity profile where it is measured from the horizontal and vertical axis of the sensor window. Moreover, the mass fraction linearity is considered as another topic for concerning about the mixing time in the chamber even though the gas mixture generated in the small manifold. Still generating homogeneous mixture is concerned.

Another experimental work is accomplished for the sake of preparing accurate pitot tube. The calibrated pitot tube and calibration coefficients are used for calculating the flow rate during the circulation and flow rate are monitored at the testing procedure.

\subsubsection{Flow analysis results}

Flow simulations are performed as they described in section 3.1.1. The experimental and calculated results are compared to experimental results as showed below. The center line of the pipe is taken as the origin on the coordinate system; however, Y-axis origin intersection point might vary which depends on the velocity values.

\subsubsection{Grid independence study}

Another important point is grid independence study. Fine mesh requirements cause to high computational time [50]. Coarse grid significantly decreases the computational time; however, it may affect our simulation results and the early design decisions. In order to optimizing the grid resolution versus the accuracy of the simulation, grid independence study is performed. 
Table 7 The mesh models of the grid independence study.

\begin{tabular}{|c|c|c|}
\hline Case & Number of nodes & Number of the elements \\
\hline Mesh 1 (Case 1) & 101307 & 509775 \\
\hline Mesh 2 (Case 2) & 476831 & 2411646 \\
\hline Mesh 3 (Case 3) & 26266 & 128081 \\
\hline
\end{tabular}

Table 7 shows the three cases that have been used for the high-level speed simulations and the results are compared for three cases in order to conclude the effects of the grid resolution to simulation accuracy.
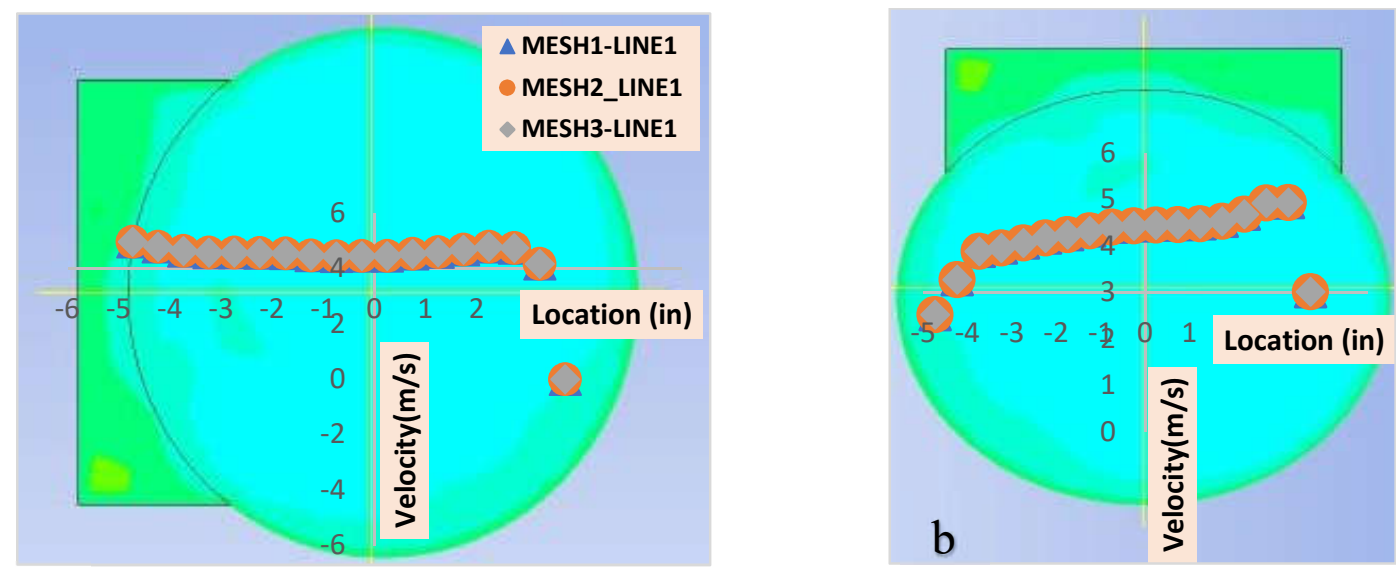

Figure 25 Velocity profile comparison for three cases. Figure a) Velocity profiles at horizontal axis. Figure b) Velocity profiles at vertical axis.

Figure $25 \mathrm{a}$ and $\mathrm{b}$ represent the velocity profile comparisons at horizontal and vertical axis. The grid independence study shows the grid resolution is not dependent to simulation accuracy since three grid resolution results have no difference. And also, the experimental results are confirmed simulation results.

\subsubsection{Velocity profile results}

The velocity profile results compared to the experimental result. For the rest of the results, the figures show the comparison of the experimental and simulation results and the background of the figures are applied to help visualization of the sampling location 3D model and also experiments. The purple circle shows the location where the Kanomax probe also inserted the yellow line shows the sampling line for the simulation. The transient flow simulation solved for $100 \mathrm{~s}$. X-axis represents the sampling locations(in) through the cross-sectional area. Y-axis shows the velocity values $(\mathrm{m} / \mathrm{s})$.

Figure 26 shows the horizontal velocity profile comparison between experimental and theoretical results through the cross-section. The experimental and simulated velocity profiles, both show the non-linear trend through the section except, the location between -4(in) to +3 (in). At these locations' velocity profiles have linear behavior if compared to the rest of the location. 


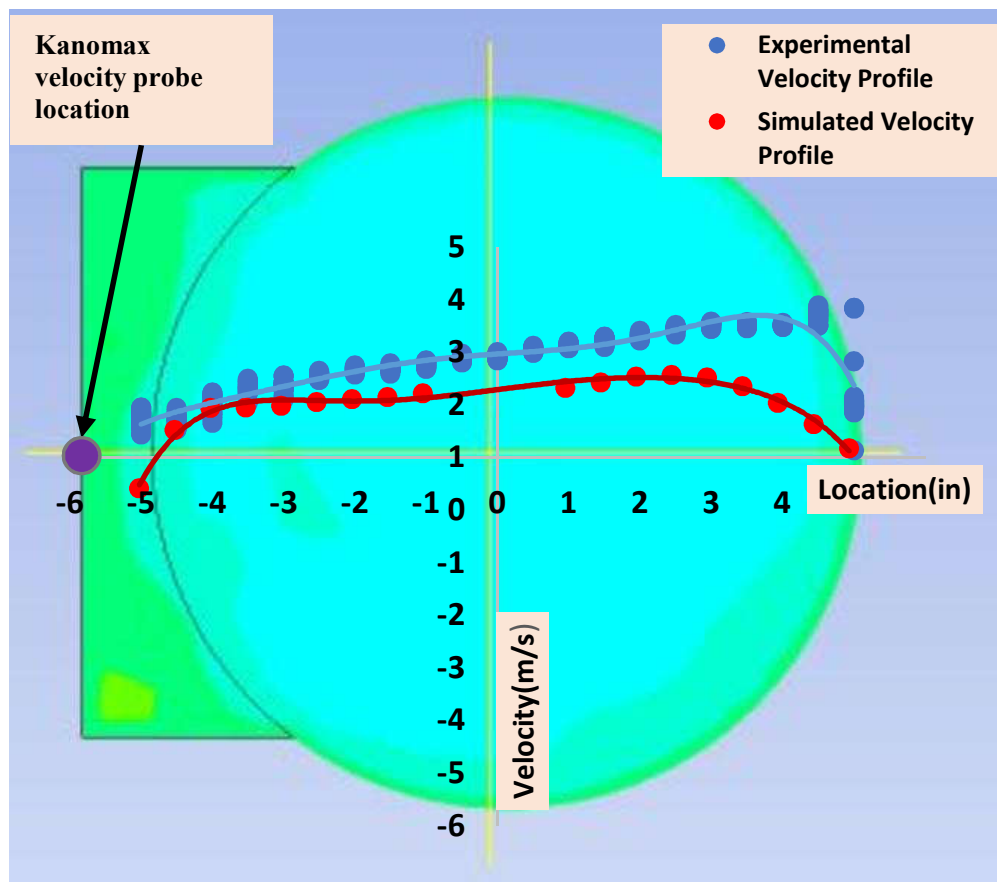

Figure 26 Horizontal velocity profile comparison for low speed level.

Figure 27 shows the vertical velocity profile comparison between experimental and theoretical results through the cross-section. The experimental and simulated velocity profiles, both show the non-linear trend through the section except, the location between -5 (in) to +4 (in). In this part, velocity linearly increased compared to rest.

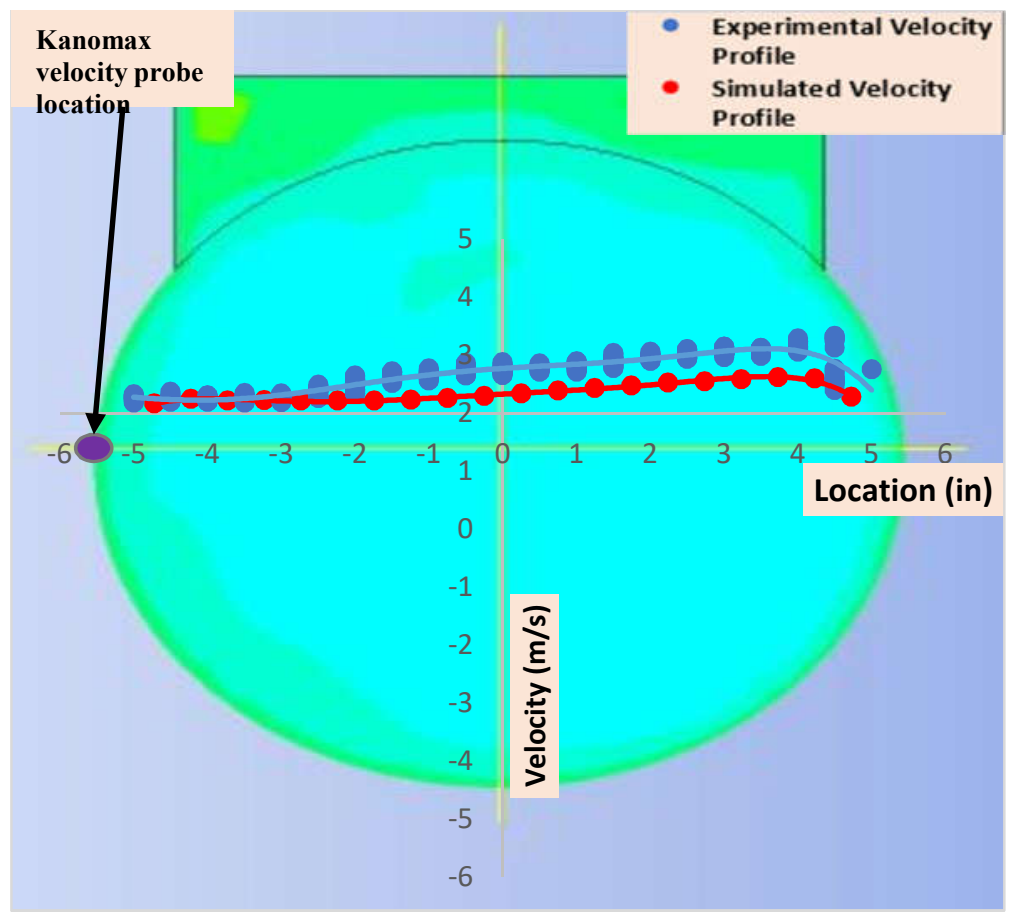

Figure 27 Vertical velocity profile comparison for low-speed level. 
The additional results are shown in Appendix B: Additional simulation results for the velocity profile comparison for medium and high-speed levels.

\subsubsection{Simulated mass fraction through the cross sections}

This section shows the mass fraction across the pipe diameter as a result of the simulation. The plot background represents the cross-sectional area of the chamber at the sensor window. The $\mathrm{x}$-axis represents the sampling locations in the chamber where it is the horizontal axis of the DESC and Y-axis show the mass fraction of $\mathrm{CO}_{2}$ at the end of the solution time.

Figure 28 and Figure 29 show $\mathrm{CO}_{2}$ mass fraction through the vertical and horizontal line at high-speed fan simulation. The mass fractions are linear through the cross section, which the $\mathrm{CO}_{2}$ mass fraction calculated around 0.006 through the sampling area.

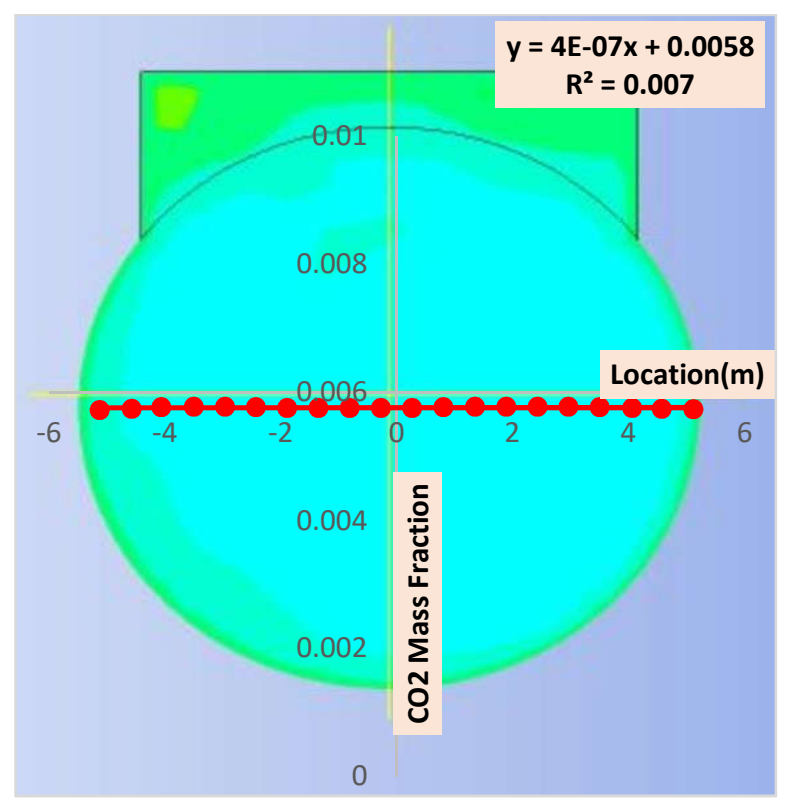

Figure $28 \mathrm{CO}_{2}$ mass fraction through the vertical line-high Speed. 


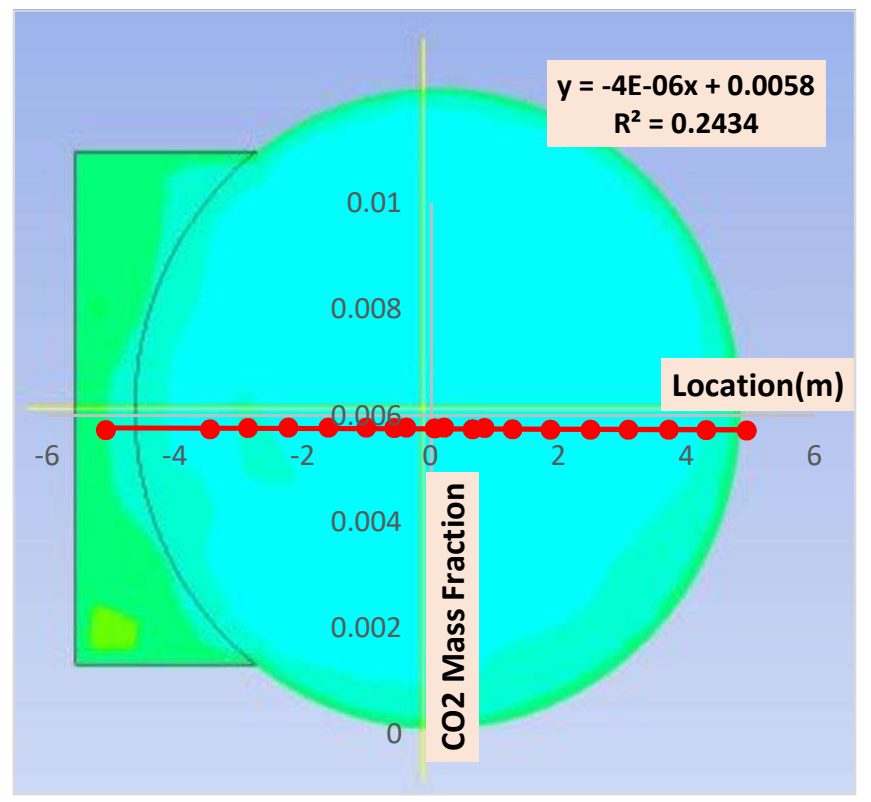

Figure $29 \mathrm{CO}_{2}$ Mass fraction through the horizontal line-high Speed.

\subsubsection{Structural Analysis Results}

This section shows the structural analysis of the support part which is designed for connecting the carrying legs with the DESC. Figure 30 represents the displacement of the support after $92.1 \mathrm{kPa}$ loaded to welding points. The simulation shows a maximum $0.002979 \mathrm{~mm}$ displacement after the pressure load applied.

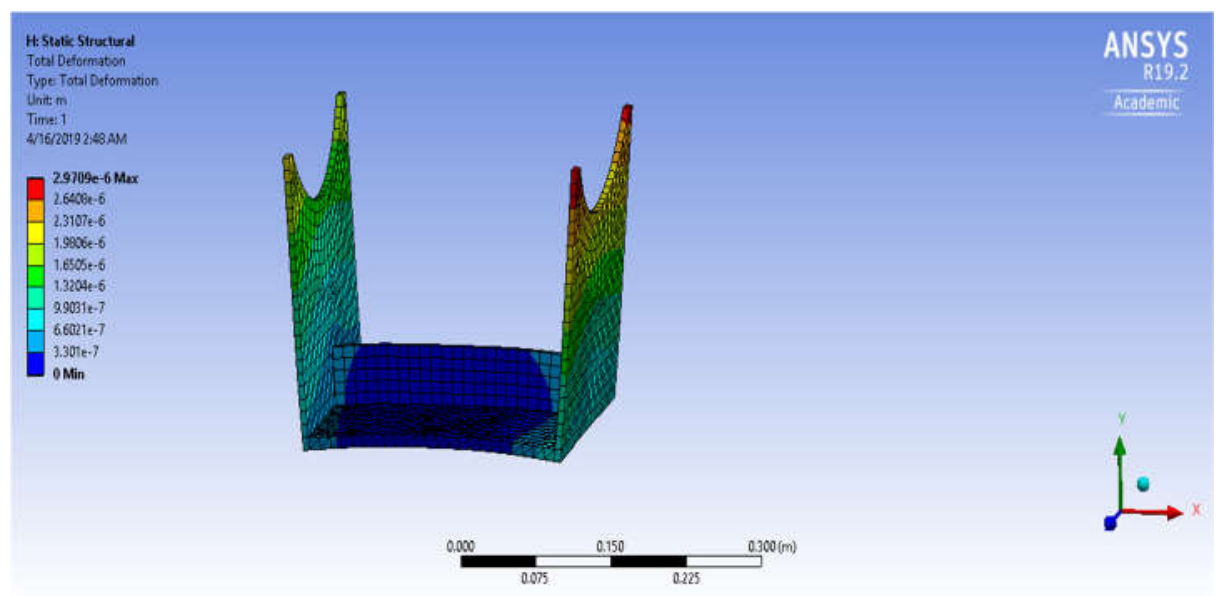

Figure 30 The support displacement under $92.1 \mathrm{kPa}$ pressure loads (6.35 mm plate).

Error! Reference source not found. shows the support after the chamber assembly is completed. The support does not show displacement or any damage which can be detected which can cause to balance issues after the weight applied. 


\subsection{Sensor evaluation experiments}

In this section, the sensor responses are shown which are corrected responses and raw sensor responses. The plots show corrected response linearity at the left side, and raw response linearity at the left side and also best-fit line showed in order visualize the sensor response difference. Y-axis represents the sensor readings in ppm, X-axis shows FTIR readings in ppm. Before starting to correct sensor responses. Drift corrections are performed for the reference analyzer.

The sensor calibration models are performed in order zero, span, environmental corrections. After the correction coefficients are generated, they are applied to test 7,8 and 9.

The general calibration function is shown below. However, the function may vary to sensor responses such as the environmental responses may not be linear.

$Y_{\text {corr }}=(Y * a+b)+($ Temp $* c+d)+(H u m * f+g)+(P * h+i)+(C O * j+k)$

Where;

$Y_{\text {corr }}$ : Corrected sensor response (ppm).

Y: Raw sensor response.

Temp: Temperature $\left({ }^{\circ} \mathrm{C}\right)$.

Hum: Water content.

$\mathrm{CO}$ : CO concentration (ppm).

P: Pressure (Psi).

\subsubsection{K30 fast response (FR) $\mathrm{CO}_{2}$ sensor evaluation results}

In this part, K30 FR corrected responses compared to raw measurements. At the sensor manual, the measurement range within 0 to $5000 \mathrm{ppm}$. During the experiments, $\mathrm{CO}_{2}$ concentration increased up to $10000 \mathrm{ppm}$. The calibration function generated up to $10000 \mathrm{ppm}$. The calibration exceeds the range which can be used for high concentration more than 5000ppm.

The calibration function for K30 FR is shown below;

$Y_{\text {corr }}=(Y * a+b)+(T e m p * c+d)+\left(H u m^{2} * e+H u m * f+g\right)+(P * h+i)+(C O * j+k)$

As the function shows, the variables have a direct contribution to sensor responses. However, humidity variable has a non-linear contribution. Table 8 shows the calibration function coefficients. 
Table 8 K30 FR coefficients of the calibration function.

\begin{tabular}{|c|c|}
\hline $\mathbf{a}$ & 0.064905 \\
\hline $\mathbf{b}$ & -469.78 \\
\hline $\mathbf{c}$ & 0.090632 \\
\hline $\mathbf{d}$ & 248.0868 \\
\hline $\mathbf{e}$ & -65.7754 \\
\hline $\mathbf{f}$ & 234.493 \\
\hline $\mathbf{g}$ & 3.958974 \\
\hline $\mathbf{h}$ & -18.2869 \\
\hline $\mathbf{i}$ & 0 \\
\hline $\mathbf{j}$ & -0.00124 \\
\hline $\mathbf{k}$ & 165.0875 \\
\hline
\end{tabular}

The coefficients show the most affecting parameter is pressure, and it has a negative impact on the sensor response, the temperature is influencing the sensor positively, and also humidity has a positive impact but fairly lower than temperature effect. CO interference is lower than all the other parameters.

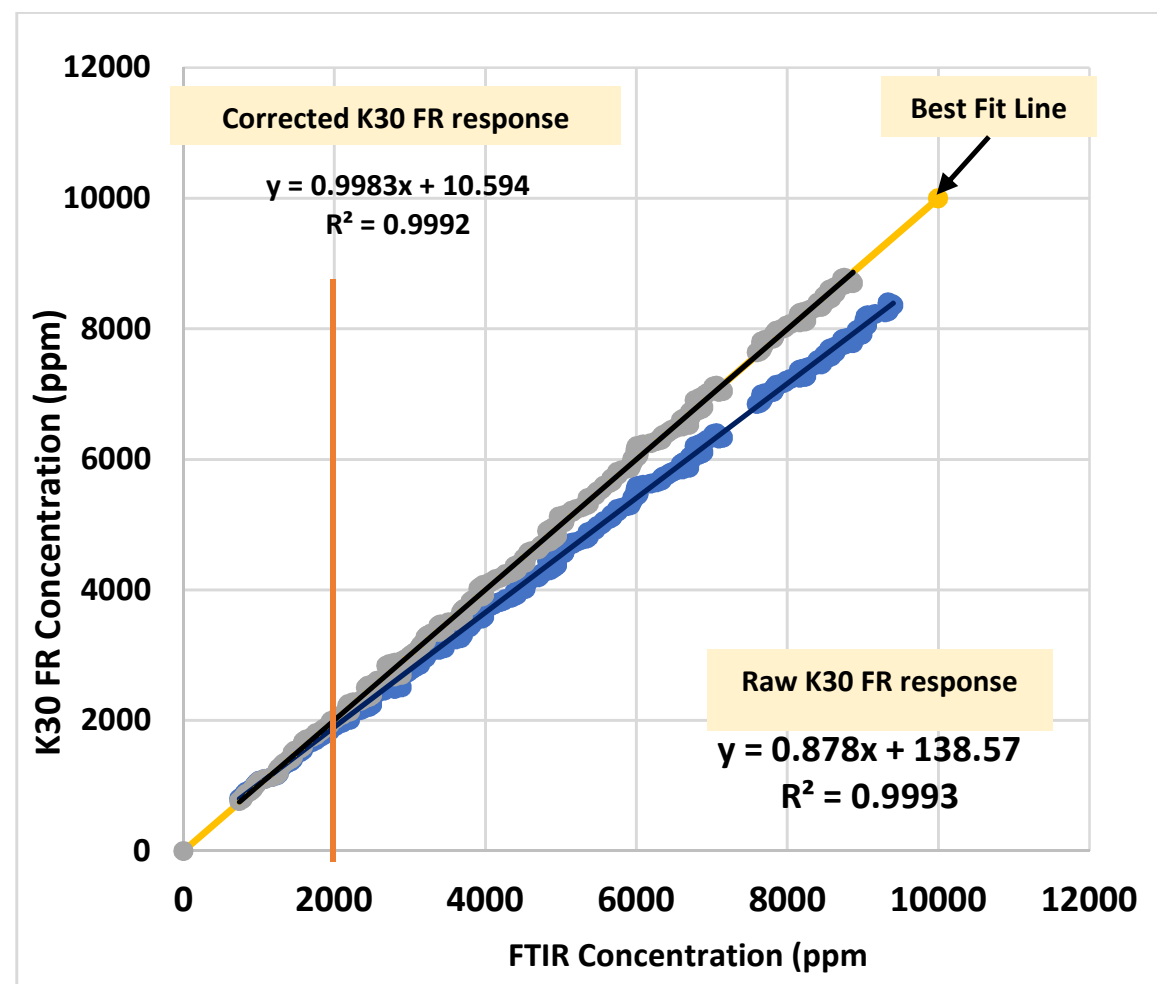

Figure 31 Test 8: K30 FR sensor responses compared to FTIR responses due to increasing concentration changes. 
Figure 31 shows corrected, and raw sensor responses compared to FTIR responses. The best fit line gives the ability to see the difference and compare raw and corrected responses. The plot shows the calibration model corrected measurement has better agreement with FTIR response

Appendix C: Additional sensor calibration results. The error plots are divided into two; the parts are lower than $5000 \mathrm{ppm}$ and higher $5000 \mathrm{ppm}$.

Figure 32 shows error plots; the concentration is lower than $5000 \mathrm{ppm}$. The sensor response has high relative error lower than $2000 \mathrm{ppm}$. Figure 33 shows error plots; the concentration is higher than $5000 \mathrm{ppm}$.

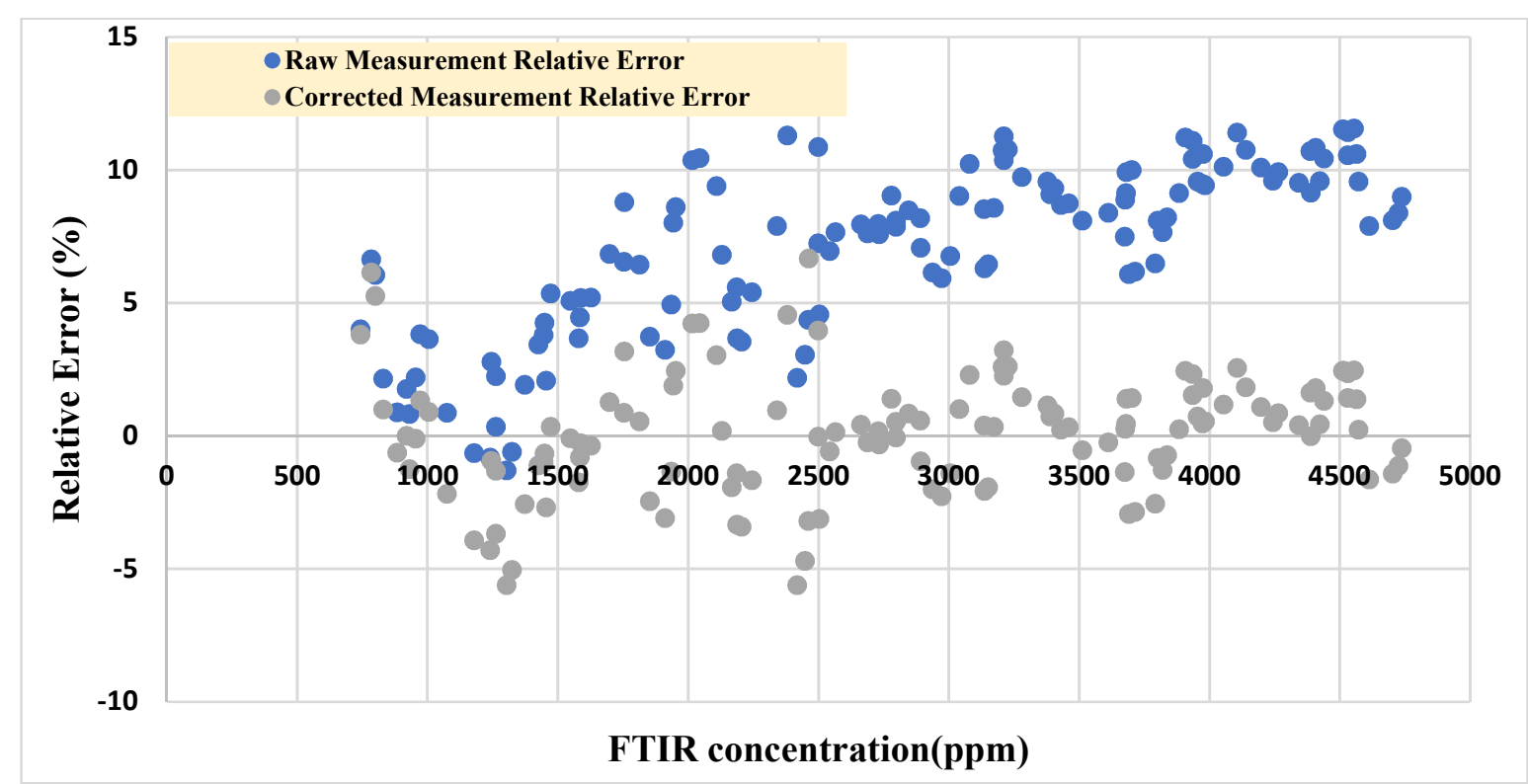

Figure 32 K30 FR -raw measurement relative error compared to corrected measurement relative error (0-5000ppm)-transient increase.

The error lower than $5000 \mathrm{ppm}$ is showed at

Figure 32. The model decreased the error closer when it compared to raw measurement, however the error band is still high. And the error lower than $2000 \mathrm{ppm}$ is fairly higher when it compared to the portion higher than $2000 \mathrm{ppm}$. The reason is assumed because of the FTIR analyser noise might be causing to that problem. The study suggests further analysis for the range lower than $2000 \mathrm{ppm}$. 


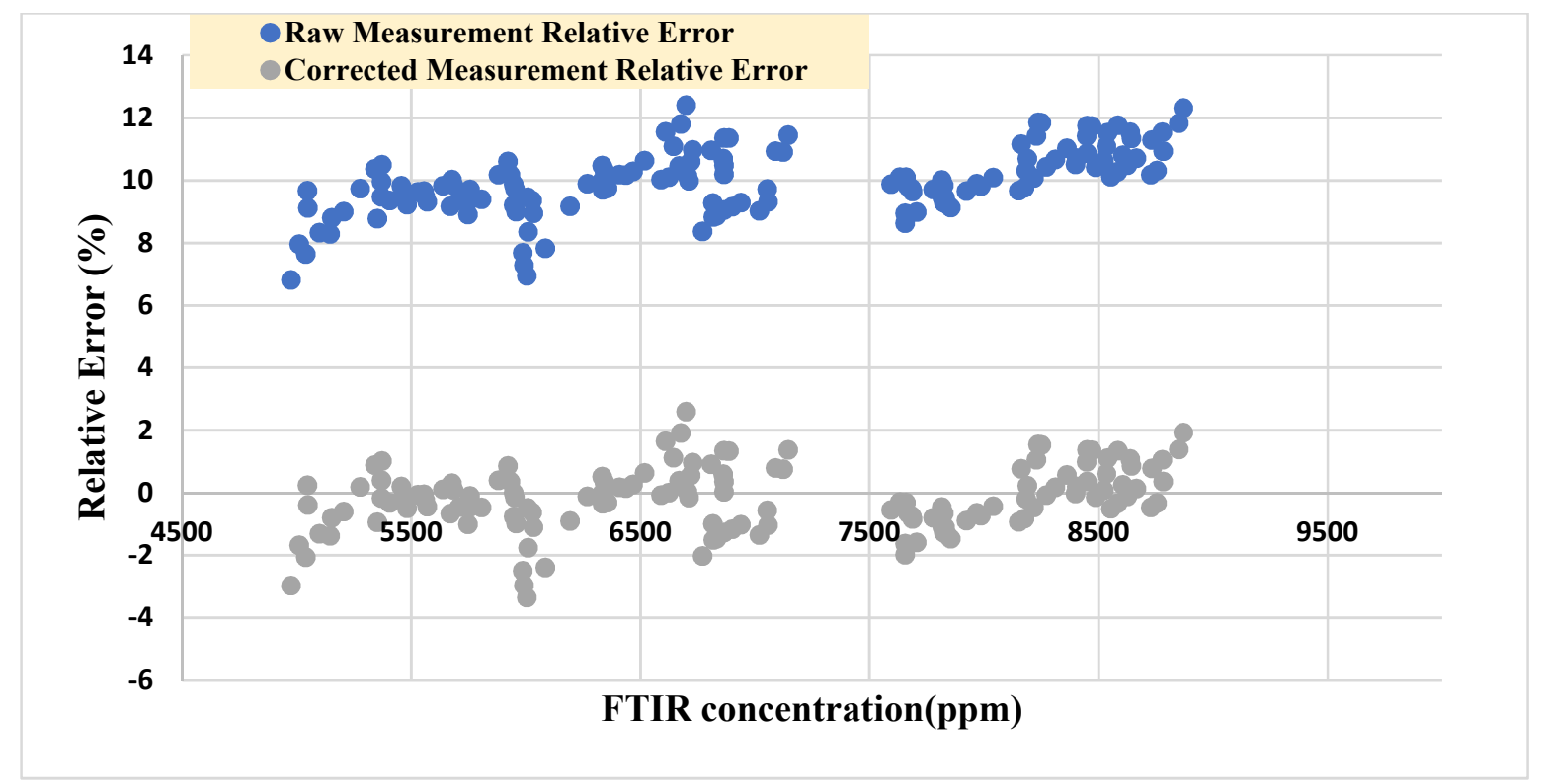

Figure 33 K30 FR -raw measurement relative error compared to corrected measurement relative error (5000-10000 ppm)- transient increase.

The relative error is showed in Figure 33. The model decreased the relative error when it compared to raw measurements. The model has a better response to high concentration. The relative error for overall test results is shown in Table 9.

Table 9 K30 FR errors for transient concentration changes.

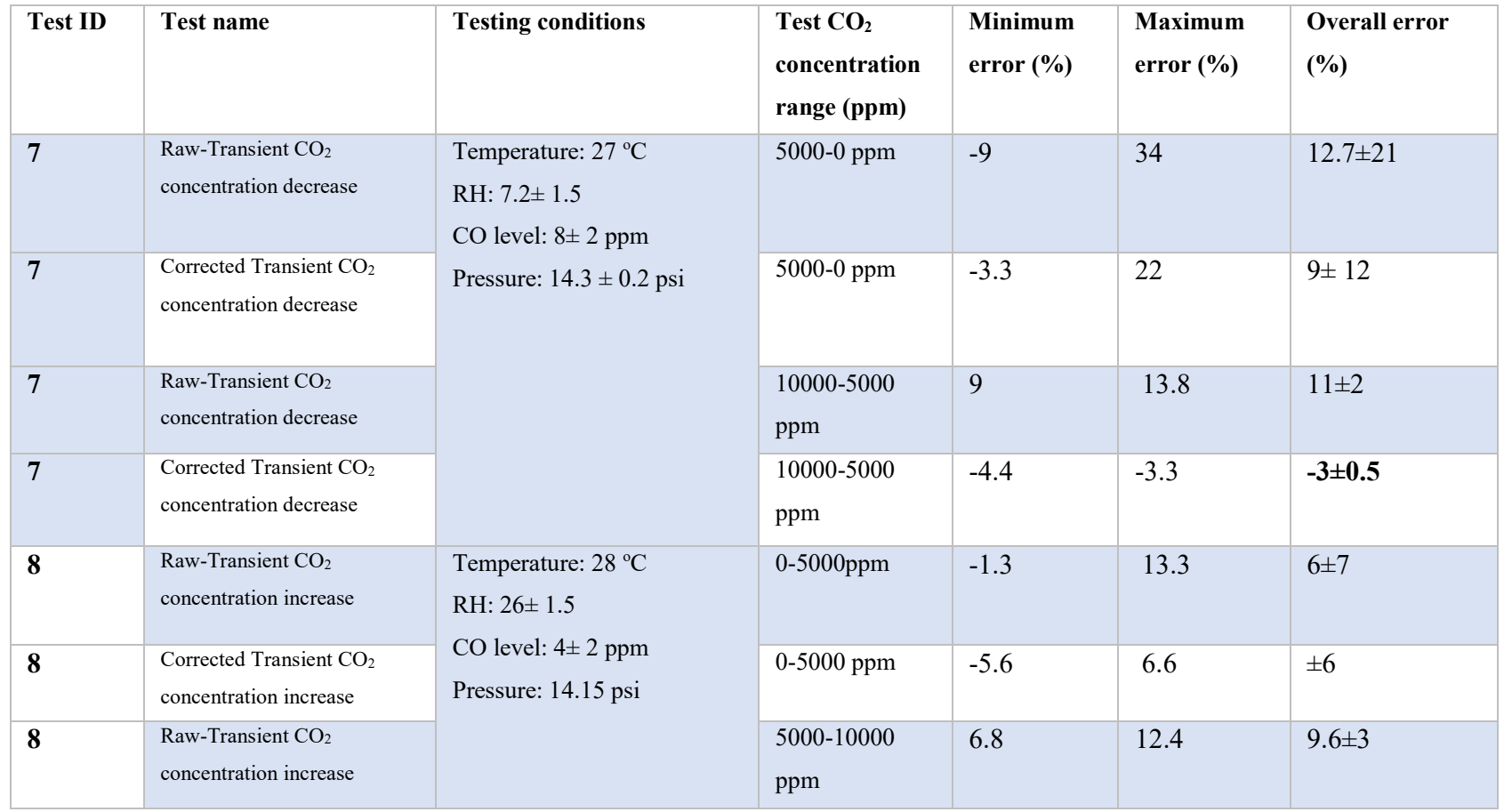




\begin{tabular}{|c|c|c|c|c|c|c|}
\hline 8 & $\begin{array}{l}\text { Corrected Transient } \mathrm{CO}_{2} \\
\text { concentration increase }\end{array}$ & & $\begin{array}{l}5000-10000 \\
\text { ppm }\end{array}$ & -3.3 & 2.5 & \pm 3 \\
\hline 9 & $\begin{array}{l}\text { Raw-Transient } \mathrm{CO}_{2} \\
\text { concentration decrease }\end{array}$ & \multirow{3}{*}{$\begin{array}{l}\text { Temperature: } 28 \pm 2{ }^{\circ} \mathrm{C} \\
\text { RH: } 30 \pm 2 \\
\text { CO level: } 4 \pm 2 \mathrm{ppm} \\
\text { Pressure: } 14.15 \mathrm{psi}\end{array}$} & $5000-0 \mathrm{ppm}$ & 9.7 & 35 & $22 \pm 12$ \\
\hline 9 & $\begin{array}{l}\text { Corrected Transient } \mathrm{CO}_{2} \\
\text { concentration decrease }\end{array}$ & & 5000-0 ppm & -10 & 12.6 & \pm 11 \\
\hline 9 & $\begin{array}{l}\text { Raw-Transient } \mathrm{CO}_{2} \\
\text { concentration decrease }\end{array}$ & & $\begin{array}{l}10000-5000 \\
\text { ppm }\end{array}$ & 11.5 & 14.5 & $13 \pm 1.5$ \\
\hline
\end{tabular}

K30 FR responses are compared before and after corrections for the tests at the 0 to $5000 \mathrm{ppm}$ level. The comparison of the relative error is represented in Table 9 which the table shows, Raw measurement relative errors are $-9 \%$ to $34 \%$ for Test 7 under 5000ppm level. For same concentration level, raw measurement the relative error $-1.3 \%$ to $13.3 \%$ at Test 8 and $9.7 \%$ to $35 \%$ at Test 9 . The corrected measurement relative errors are $-3.3 \%$ to $22 \%$ at Test $7,-6 \%$ to $6 \%$ at Test $8,-11 \%$ to $11 \%$ at Test 9 . The raw measurement relative errors are $9 \%$ to $13 \%$ for Test 7 above 5000ppm level. For the same concentration level, the raw measurement the relative error $6.8 \%$ to $12.4 \%$ at Test 8 and $11.5 \%$ to $14.5 \%$ at Test 9 . The corrected measurement relative errors are $-3 \pm 0.5 \%$ at Test $7, \pm 3 \%$ at Test $8, \pm 2 \%$ at Test 9 .

Overall, K30 FR $\mathrm{CO}_{2}$ sensor responses faster when it compared the other $\mathrm{CO}_{2}$ sensor which they are investigated at this study however the sensor significantly affected by temperature,humidity, and pressure in the experimental range. The sensor should be calibrated to working environmental range.

\subsection{2 $\mathrm{K30} 1 \% \mathrm{CO}_{2}$ sensor evaluation results}

The same procedure is followed as K30 FR since both sensors have a similar structure and working principles and the same non-linear behavior to humidity. The parameters have similar behavior for K30 1\% $\mathrm{CO}_{2}$ sensor. $Y_{\text {corr }}=Y * a+b$ ? $+($ Temp $* c+d)+\left(H_{u m^{2}} * e+H u m * f+g\right)+(P * h+i)+(C O * j+k)$

16 is used for the sensor. Table 10 shows the calibration coefficients for the sensor.

Table $10 \mathrm{K30} 1 \%$ coefficients of the calibration function.

\begin{tabular}{|c|c|}
\hline $\mathrm{a}$ & 0.018011 \\
\hline $\mathrm{b}$ & 58.53 \\
\hline $\mathrm{c}$ & -0.99711 \\
\hline $\mathrm{d}$ & 171.1353 \\
\hline $\mathrm{e}$ & -46.1508 \\
\hline
\end{tabular}




\begin{tabular}{|c|c|}
\hline $\mathrm{f}$ & 195.4114 \\
\hline $\mathrm{g}$ & 35.68038 \\
\hline $\mathrm{h}$ & 31.88192 \\
\hline $\mathrm{i}$ & -697.929 \\
\hline $\mathrm{j}$ & -0.01062 \\
\hline $\mathrm{k}$ & -5.69851 \\
\hline
\end{tabular}

The coefficients show the most affecting parameter is pressure and it has negative impact on the sensor response, the temperature is influencing the sensor positively and also humidity has positive impact but fairly lower than temperature effect as it observed for K30 FR. CO interference is lower than all the other parameters. However, the K30 1\% is slower when it compared to K30 FR.

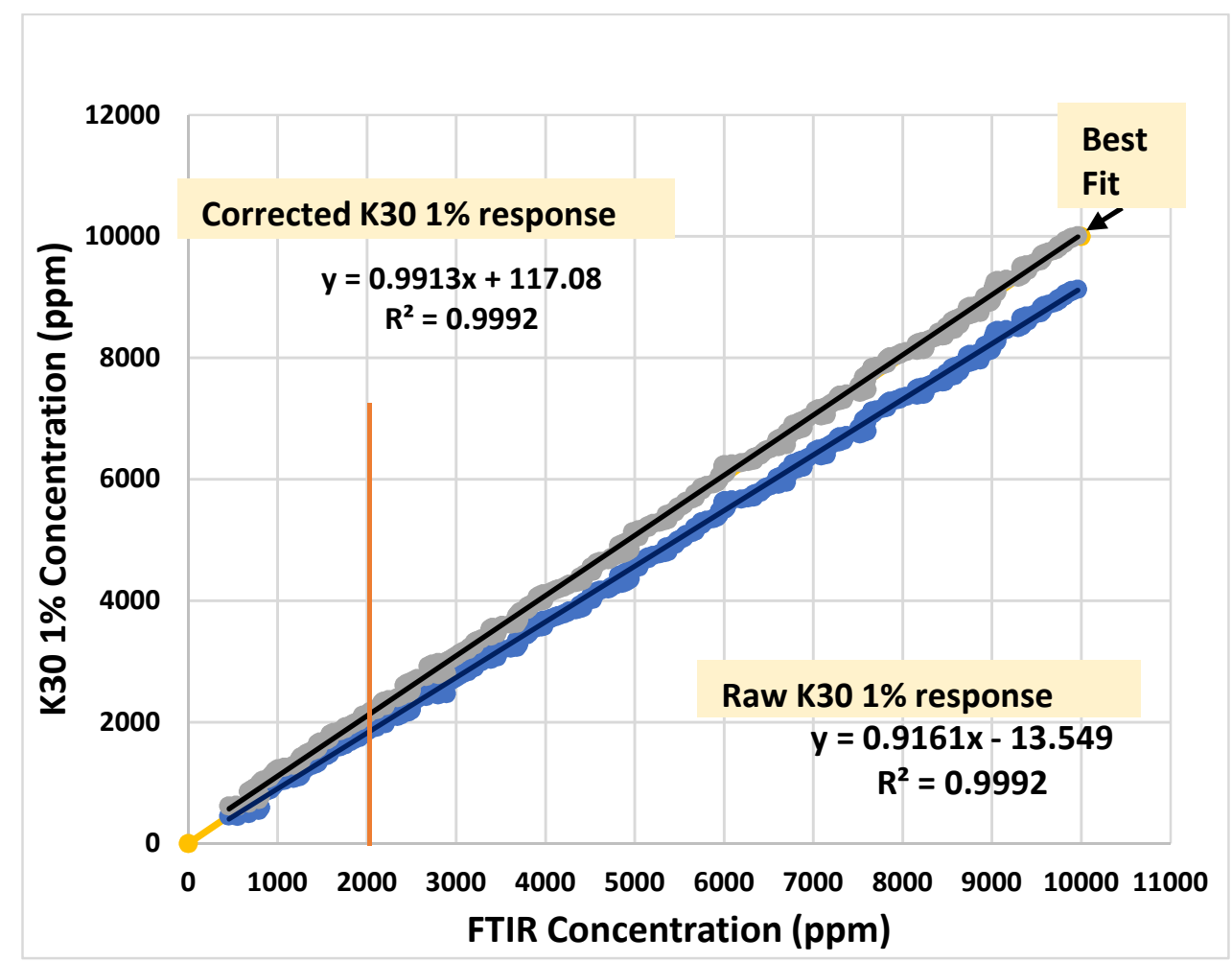

Figure 34 Test 8: K30 1\% sensor responses compared to FTIR responses due to increasing concentration changes.

Figure 34 shows corrected, and raw sensor responses compared to FTIR responses. The best fit line gives the ability to see the difference and compare raw and corrected responses. The plot shows that the calibration model corrected measurement has better agreement with FTIR response 
Appendix C: Additional sensor calibration results. The error plots are divided into two; the parts are lower than $5000 \mathrm{ppm}$ and higher $5000 \mathrm{ppm}$. Figure 35 shows error plots; the concentration is lower than 5000 ppm. The sensor response has high relative error lower than 2000 ppm. Figure 36 shows error plots; the concentration is higher than $5000 \mathrm{ppm}$. The relative error for overall test results is shown in Table 10. As it mentioned earlier, K30 $1 \%$ and K30 FR sensors are similar.

The model decreased the error closer when it compared to raw measurement, however the error band is still high. And the error lower than $2000 \mathrm{ppm}$ is fairly higher when it compared to the portion higher than $2000 \mathrm{ppm}$. The reason is assumed because of the FTIR analyser noise might be causing to that problem. The study suggests further analysis for the range lower than $2000 \mathrm{ppm}$.

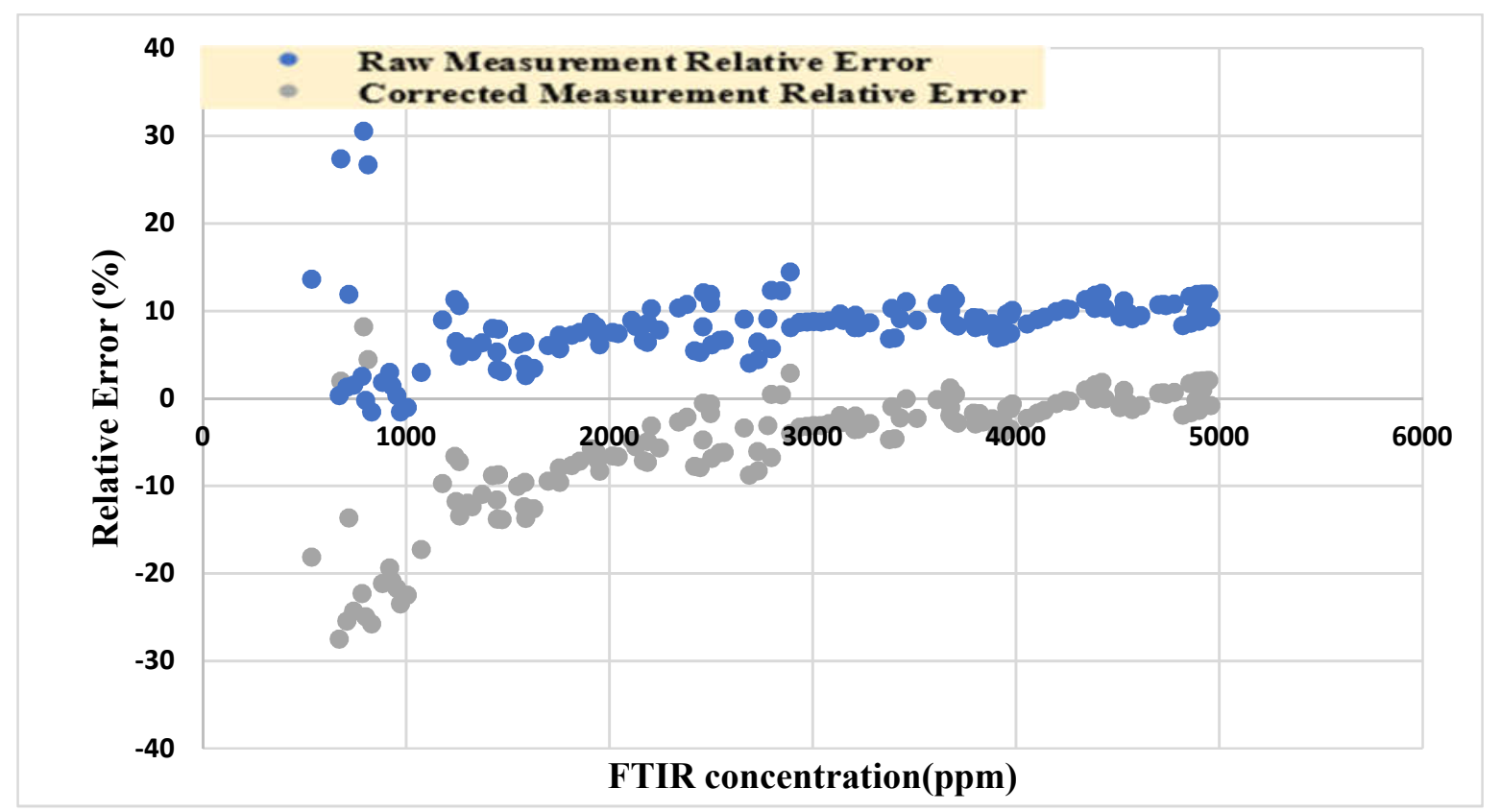

Figure $35 \mathrm{~K} 30$ 1\% -raw measurement relative error compared to corrected measurement relative error (0-5000ppm)-transient increase. 


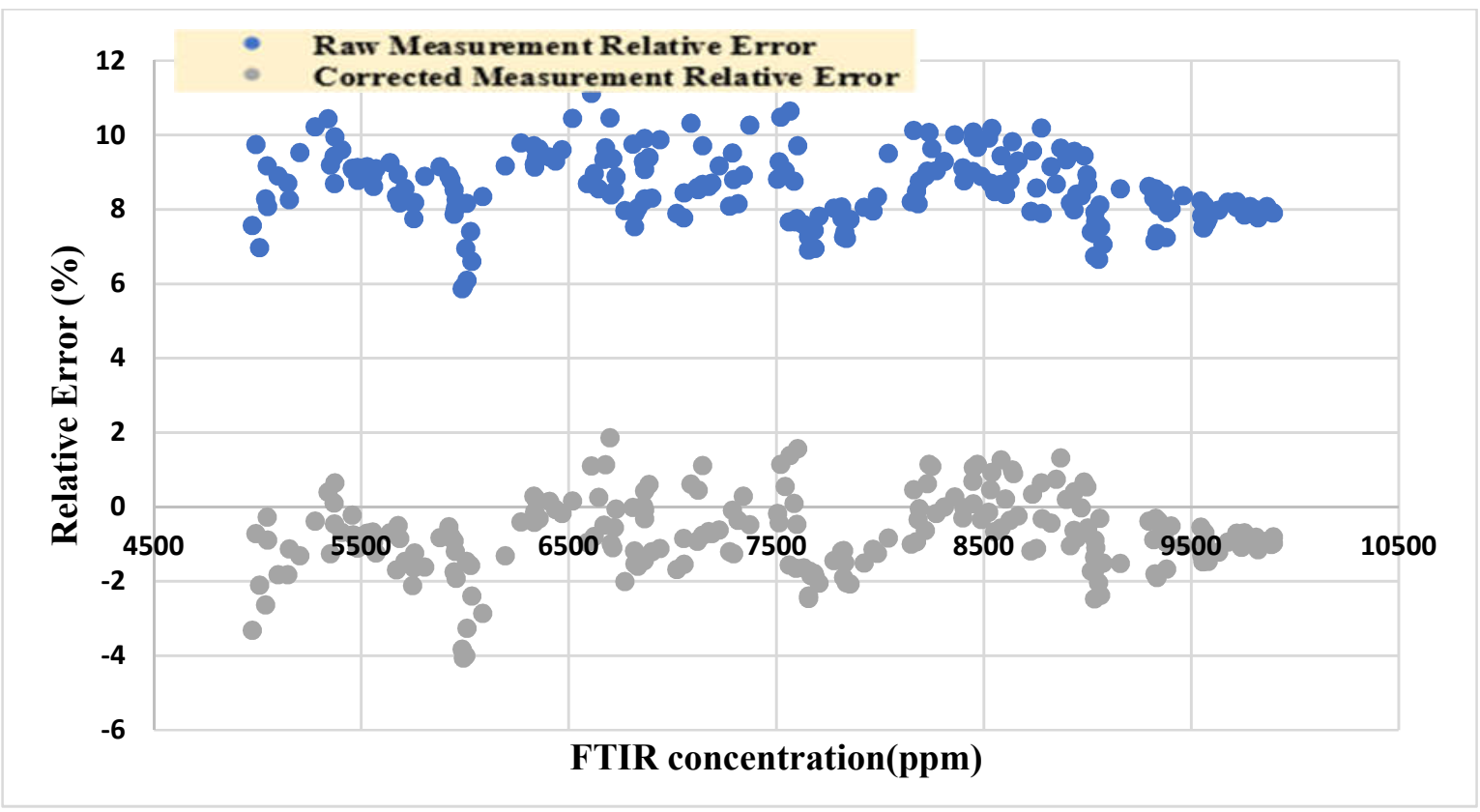

Figure $36 \mathrm{K30}$ 1\% -raw measurement relative error compared to corrected measurement relative error (5000-10000ppm)-transient increase.

The relative error is shown in Figure 35 and Figure 36. The model decreased the relative error when it compared to raw measurements. The model has better response to high concentration. The relative error for overall test results is shown in Table 11.

Table 11 K30 1\% errors for transient concentration changes.

\begin{tabular}{|c|c|c|c|c|c|c|}
\hline Test ID & Test name & Testing conditions & $\begin{array}{l}\text { Test } \mathrm{CO}_{2} \\
\text { concentration } \\
\text { range (ppm) }\end{array}$ & $\begin{array}{l}\text { Minimum } \\
\text { error (\%) }\end{array}$ & $\begin{array}{l}\text { Maximum } \\
\text { error (\%) }\end{array}$ & $\begin{array}{l}\text { Overall error } \\
(\%)\end{array}$ \\
\hline 7 & $\begin{array}{l}\text { Raw-Transient } \mathrm{CO}_{2} \\
\text { concentration decrease }\end{array}$ & \multirow{4}{*}{$\begin{array}{l}\text { Temperature: } 27^{\circ} \mathrm{C} \\
\text { RH: } 7.2 \pm 1.5 \\
\text { CO level: } 8 \pm 2 \mathrm{ppm} \\
\text { Pressure: } 14.3 \pm 0.2 \mathrm{psi}\end{array}$} & $5000-0 \mathrm{ppm}$ & -12 & 31 & $9.5 \pm 22$ \\
\hline 7 & $\begin{array}{l}\text { Corrected Transient } \mathrm{CO}_{2} \\
\text { concentration decrease }\end{array}$ & & $5000-0 \mathrm{ppm}$ & -27 & 22 & \pm 25 \\
\hline 7 & $\begin{array}{l}\text { Raw-Transient } \mathrm{CO}_{2} \\
\text { concentration decrease }\end{array}$ & & $\begin{array}{l}10000-5000 \\
\mathrm{ppm}\end{array}$ & 3 & 8.7 & $6 \pm 2.7$ \\
\hline 7 & $\begin{array}{l}\text { Corrected Transient } \mathrm{CO}_{2} \\
\text { concentration decrease }\end{array}$ & & $\begin{array}{l}10000-5000 \\
\mathrm{ppm}\end{array}$ & -4.1 & 1.45 & $-1 \pm 3$ \\
\hline 8 & $\begin{array}{l}\text { Raw-Transient } \mathrm{CO}_{2} \\
\text { concentration increase }\end{array}$ & \multirow{2}{*}{$\begin{array}{l}\text { Temperature: } 28^{\circ} \mathrm{C} \\
\text { RH: } 26 \pm 1.5 \\
\text { CO level: } 4 \pm 2 \mathrm{ppm}\end{array}$} & $0-5000 \mathrm{ppm}$ & -1.5 & 30.5 & $14 \pm 17$ \\
\hline 8 & $\begin{array}{l}\text { Corrected Transient } \mathrm{CO}_{2} \\
\text { concentration increase }\end{array}$ & & $0-5000 \mathrm{ppm}$ & -36 & 8 & $-14 \pm 22$ \\
\hline
\end{tabular}




\begin{tabular}{|c|c|c|c|c|c|c|}
\hline 8 & $\begin{array}{l}\text { Raw-Transient } \mathrm{CO}_{2} \\
\text { concentration increase }\end{array}$ & \multirow[t]{2}{*}{ Pressure: 14.15 psi } & $\begin{array}{l}5000-10000 \\
\text { ppm }\end{array}$ & 5.8 & 11 & $\% 8.5 \pm 2.5$ \\
\hline 8 & $\begin{array}{l}\text { Corrected Transient } \mathrm{CO}_{2} \\
\text { concentration increase }\end{array}$ & & $\begin{array}{l}5000-10000 \\
\text { ppm }\end{array}$ & -4 & 2 & \pm 3 \\
\hline 9 & $\begin{array}{l}\text { Raw-Transient } \mathrm{CO}_{2} \\
\text { concentration decrease }\end{array}$ & \multirow{4}{*}{$\begin{array}{l}\text { Temperature: } 28 \pm 2{ }^{\circ} \mathrm{C} \\
\text { RH: } 30 \pm 2 \\
\text { CO level: } 4 \pm 2 \mathrm{ppm} \\
\text { Pressure: } 14.15 \mathrm{psi}\end{array}$} & $5000-0 \mathrm{ppm}$ & 8 & 33 & $20 \pm 12$ \\
\hline 9 & $\begin{array}{l}\text { Corrected Transient } \mathrm{CO}_{2} \\
\text { concentration decrease }\end{array}$ & & $5000-0 \mathrm{ppm}$ & -9 & 12.3 & \pm 11 \\
\hline 9 & $\begin{array}{l}\text { Raw-Transient } \mathrm{CO}_{2} \\
\text { concentration decrease }\end{array}$ & & $\begin{array}{l}10000-5000 \\
\text { ppm }\end{array}$ & 7 & 11 & $9 \pm 2$ \\
\hline 9 & $\begin{array}{l}\text { Corrected Transient } \mathrm{CO}_{2} \\
\text { concentration decrease }\end{array}$ & & $\begin{array}{l}10000-5000 \\
\text { ppm }\end{array}$ & -1 & 2.8 & \pm 2 \\
\hline
\end{tabular}

K30 1\% responses are compared before and after corrections for the tests at the 5,000 to 10,000 ppm level. The comparison of the relative error is represented in Table 9 which the table shows, Raw measurement relative errors are $-12 \%$ to $31 \%$ for Test 7 higher than 5000ppm level. For same concentration level, raw measurement the relative error $-1.5 \%$ to $30.5 \%$ at Test 8 and $8 \%$ to $33 \%$ at Test 9 . The corrected measurement relative errors are $-27 \%$ to $22 \%$ at Test $7,-36 \%$ to $8 \%$ at Test $8,-11 \%$ to $11 \%$ at Test 9 .

The raw measurement relative errors are $3 \%$ to $8.7 \%$ for Test 7 above 5000ppm level. For the same concentration level, the raw measurement the relative error $5.8 \%$ to $11 \%$ at Test 8 and $7 \%$ to $11 \%$ at Test 9. The corrected measurement relative errors are $-4.1 \%$ to $1.45 \%$ at Test $7, \pm 3 \%$ at Test $8, \pm 2 \%$ at Test 9 .

Overall, $\mathrm{K} 301 \% \mathrm{CO}_{2}$ sensor responses faster when it compared the other $\mathrm{CO}_{2}$ sensor which they are investigated at this study however the sensor significantly affected by temperature, humidity, and pressure in the experimental range. The sensor should be calibrated to working environmental range.

\subsubsection{FIGARO $\mathrm{CO}_{2}$ sensor evaluation results}

This section shows Figaro responses compared to raw measurements. The sensor range is up to $10000 \mathrm{ppm}$ however, in the sensor manual the manufacturer's accuracy limit is up to $5000 \mathrm{ppm}$.

Figaro $\mathrm{CO}_{2}$ sensor has different response than $\mathrm{K} 30$ sensors this reason the calibration function is different than $\mathrm{K} 30$ sensors such as the sensor response is not linear for $\mathrm{CO}$ interference but for the humidity it has linear response. Since Figaro has slower than K30 sensors and the response is fluctuating during the measurements, the averaging time increased by 5 times for the sensor.

$Y_{\text {corr }}=(Y * a+b)+($ Temp $* c+d)+(H u m * e+f)+(P * g+h)+\left(\mathrm{CO}^{\wedge} 2 * i+C O * j+k\right) \quad 17$ 
Where;

$Y_{\text {corr }}$ : Corrected sensor response (ppm).

Y: Raw sensor response.

Temp: Temperature $\left({ }^{\circ} \mathrm{C}\right)$.

Hum: Water content.

$\mathrm{CO}$ : CO concentration (ppm).

P: Pressure (Psi).

As the function shows, the variables have a direct contribution to sensor responses. However, $\mathrm{CO}$ variable has a non-linear contribution. Table 12 shows the calibration function coefficients.

Table 12 Figaro coefficients of the calibration function.

\begin{tabular}{|c|c|}
\hline $\mathbf{a}$ & -0.0164 \\
\hline $\mathbf{b}$ & -40.1951 \\
\hline $\mathbf{c}$ & -2.38954 \\
\hline $\mathbf{d}$ & 136.0133 \\
\hline $\mathbf{e}$ & 104.5417 \\
\hline $\mathbf{f}$ & 125.2024 \\
\hline $\mathbf{g}$ & 543.679 \\
\hline $\mathbf{h}$ & -8033.9 \\
\hline $\mathbf{i}$ & 0.002601 \\
\hline $\mathbf{j}$ & -1.95101 \\
\hline $\mathbf{k}$ & 292.088 \\
\hline
\end{tabular}

Pressure has the highest impact on the sensor which is affected negatively. The second most influencing parameter is the $\mathrm{CO}$ interference which the sensor is affected positively, humidity variable follows pressure and $\mathrm{CO}$ inference. Temperature effect is lower than the other parameters. 


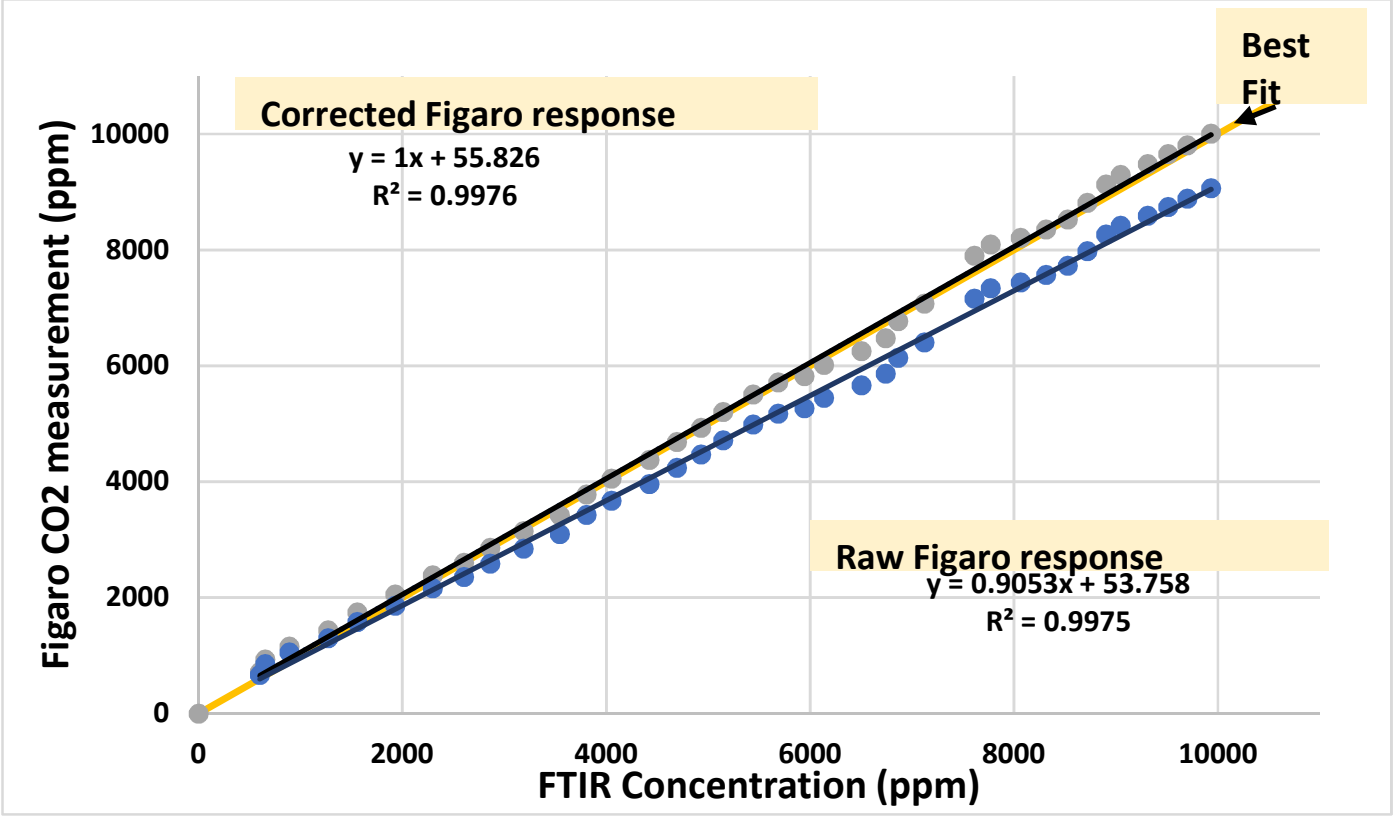

Figure 37 Test 8: Figaro sensor responses compared to FTIR responses due to increasing concentration changes.

Figure 37 shows corrected, and raw sensor responses compared to FTIR responses. The best fit line gives the ability to see the difference and compare raw and corrected responses. Appendix C: Additional sensor calibration results. The plot shows the calibration model corrected measurement has better agreement with FTIR response. 


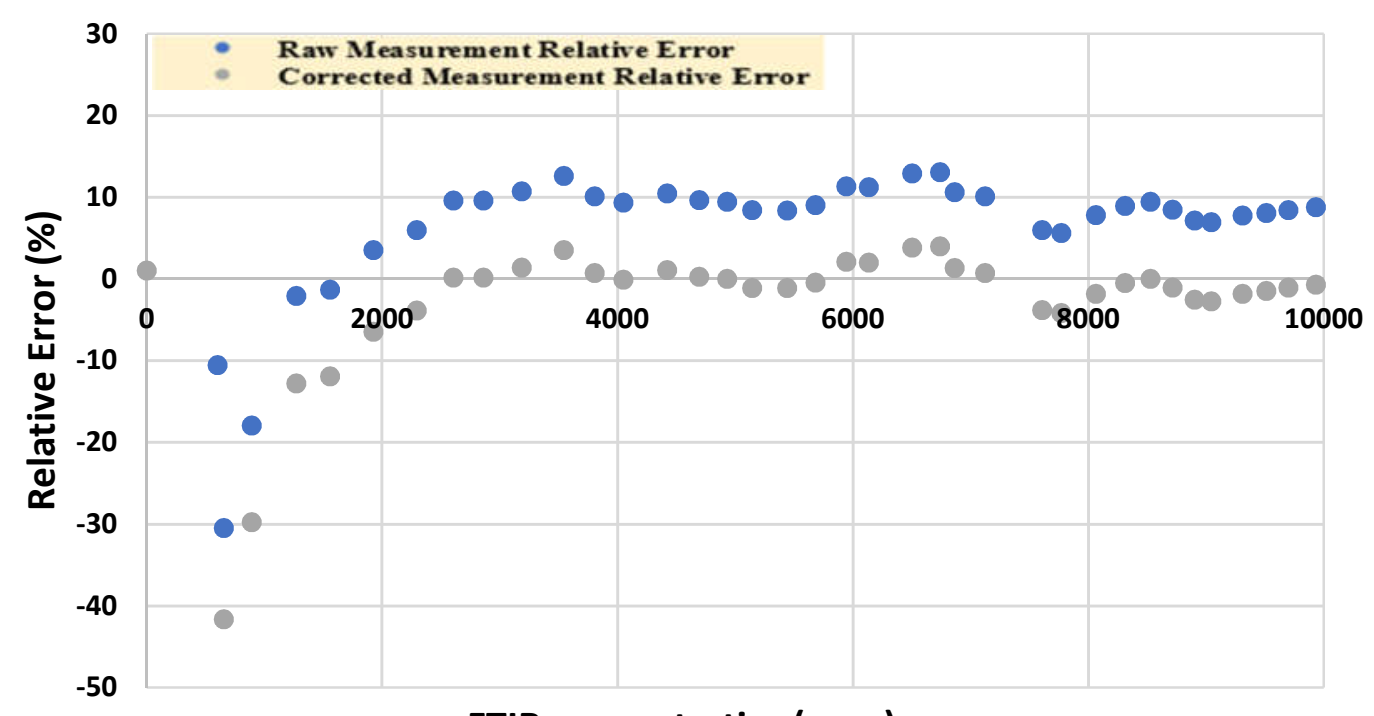

FTIR concentration(ppm)

Figure 38 Figaro- raw measurement relative error compared to corrected measurement relative error -transient increase.

The Figure 38 represents the relative error plots for raw and corrected measurements. The model significantly decreased the relative error. However, as it observed at K30 sensor responses, the sensor has higher error when the concentration is lower than $2000 \mathrm{ppm}$.

Table 13 Figaro errors for transient concentration changes.

\begin{tabular}{|c|c|c|c|c|c|c|}
\hline Test ID & Test name & Testing conditions & $\begin{array}{l}\text { Test } \mathrm{CO}_{2} \\
\text { concentration } \\
\text { range }(\mathrm{ppm})\end{array}$ & $\begin{array}{l}\text { Minimum } \\
\text { error }(\%)\end{array}$ & $\begin{array}{l}\text { Maximum } \\
\text { error }(\%)\end{array}$ & $\begin{array}{l}\text { Overall error } \\
(\%)\end{array}$ \\
\hline 8 & $\begin{array}{l}\text { Raw-Transient } \mathrm{CO}_{2} \\
\text { concentration increase }\end{array}$ & $\begin{array}{l}\text { Temperature: } 28^{\circ} \mathrm{C} \\
\text { RH: } 26 \pm 1.5 \\
\text { CO level: } 4 \pm 2 \text { ppm }\end{array}$ & 0-2000ppm & -30 & 3.5 & $-13 \pm 16$ \\
\hline 8 & $\begin{array}{l}\text { Corrected Transient } \mathrm{CO}_{2} \\
\text { concentration increase }\end{array}$ & Pressure: 14.15 psi & 0-2000ppm & -41 & -6 & $-24 \pm 18$ \\
\hline 8 & $\begin{array}{l}\text { Raw-Transient } \mathrm{CO}_{2} \\
\text { concentration increase }\end{array}$ & & $\begin{array}{l}2000-10000 \\
\text { ppm }\end{array}$ & 6 & 13 & $9 \pm 4$ \\
\hline 8 & $\begin{array}{l}\text { Corrected Transient } \mathrm{CO}_{2} \\
\text { concentration increase }\end{array}$ & & $\begin{array}{l}2000-10000 \\
\text { ppm }\end{array}$ & -4 & 4 & \pm 4 \\
\hline 9 & $\begin{array}{l}\text { Raw-Transient } \mathrm{CO}_{2} \\
\text { concentration decrease }\end{array}$ & $\begin{array}{l}\text { Temperature: } 28 \pm 2{ }^{\circ} \mathrm{C} \\
\mathrm{RH}: 30 \pm 2\end{array}$ & 2000-0ppm & 8 & 42 & $25 \pm 17$ \\
\hline
\end{tabular}




\begin{tabular}{|c|c|c|c|c|c|c|}
\hline 9 & $\begin{array}{l}\text { Corrected Transient } \mathrm{CO}_{2} \\
\text { concentration decrease }\end{array}$ & $\begin{array}{l}\text { CO level: } 4 \pm 2 \text { ppm } \\
\text { Pressure: } 14.15 \text { psi }\end{array}$ & 2000-0ppm & -2 & 35 & $16 \pm 19$ \\
\hline 9 & $\begin{array}{l}\text { Raw-Transient } \mathrm{CO}_{2} \\
\text { concentration decrease }\end{array}$ & & $\begin{array}{l}10000-2000 \\
\text { ppm }\end{array}$ & 5 & 18 & $12 \pm 6$ \\
\hline 9 & $\begin{array}{l}\text { Corrected Transient } \mathrm{CO}_{2} \\
\text { concentration decrease }\end{array}$ & & $\begin{array}{l}10000-2000 \\
\text { ppm }\end{array}$ & -4 & 9 & $2 \pm 5$ \\
\hline
\end{tabular}

Figaro responses are compared before and after corrections for the tests at the 0 to $2000 \mathrm{ppm}$ level. The comparison of the relative error is represented in Table 13 . The concentration level, raw measurement the relative error $-30 \%$ to $3.5 \%$ at Test 8 and $8 \%$ to $42 \%$ at Test 9 . The corrected values are $-41 \%$ to $-6 \%$ at Test 8 and $-2 \%$ to $35 \%$ at Test 9 .

The raw measurement relative errors are $6 \%$ to $13 \%$ at Test $8,5 \%$ to $18 \%$ at Test 9 . The corrected measurement relative errors are $-4 \%$ to $9 \%$ for Test 8 and $-4 \%$ to $9 \%$ above $2000 \mathrm{ppm}$ level.

Over all the model has improved the sensor response if it is compared to raw measurement however lower than $2000 \mathrm{ppm}$ level needs to further investigation for better understanding. The figaro $\mathrm{CO}_{2}$ sensor has sensitivity to meteorological events so the sensor needs calibration for desired working range.

\subsubsection{COZIR AMBIENT $\mathrm{CO}_{2}$ sensor evaluation results}

The sensor's working range is up to $2000 \mathrm{ppm}$ described at the sensor manual. The sensor cannot detect higher than $2000 \mathrm{ppm}$. The experiments are performed with the other sensors but the COZIR stopped measuring after $2000 \mathrm{ppm}$ level and gave constant number. The environmental, zero and span corrections are performed on the sensor responses and compared to FTIR measurements.

The calibration function is shown as below;

$Y_{\text {corr }}=(Y * a+b)+($ Temp $* c+d)+(H u m * f+g)+(P * h+i)+(C O * j+k)$

Where;

$Y_{\text {corr }}$ : Corrected sensor response (ppm).

Y: Raw sensor response.

Temp: Temperature $\left({ }^{\circ} \mathrm{C}\right)$.

Hum: Water content.

$\mathrm{CO}$ : CO concentration (ppm).

P: Pressure (Psi).

As the function shows, all the parameters have linear effect on the sensors. Table 14 shows the calibration function coefficients. 
Table 14 COZIR coefficients of the calibration function.

\begin{tabular}{|l|c|}
\hline $\mathbf{a}$ & 0.038134 \\
\hline $\mathbf{b}$ & -413.363 \\
\hline $\mathbf{c}$ & -0.85023 \\
\hline $\mathbf{d}$ & 101.0813 \\
\hline $\mathbf{f}$ & 234.493 \\
\hline $\mathbf{g}$ & -84.696 \\
\hline $\mathbf{h}$ & 873.9422 \\
\hline $\mathbf{i}$ & -12622.5 \\
\hline $\mathbf{j}$ & -0.08841 \\
\hline $\mathbf{k}$ & 349.828 \\
\hline
\end{tabular}

As the coefficients are showing, CO interference has significance positive impact on the sensor, pressure has also high impact on the sensor negatively. Temperature and humidity have lower impact when they compared to other parameters.

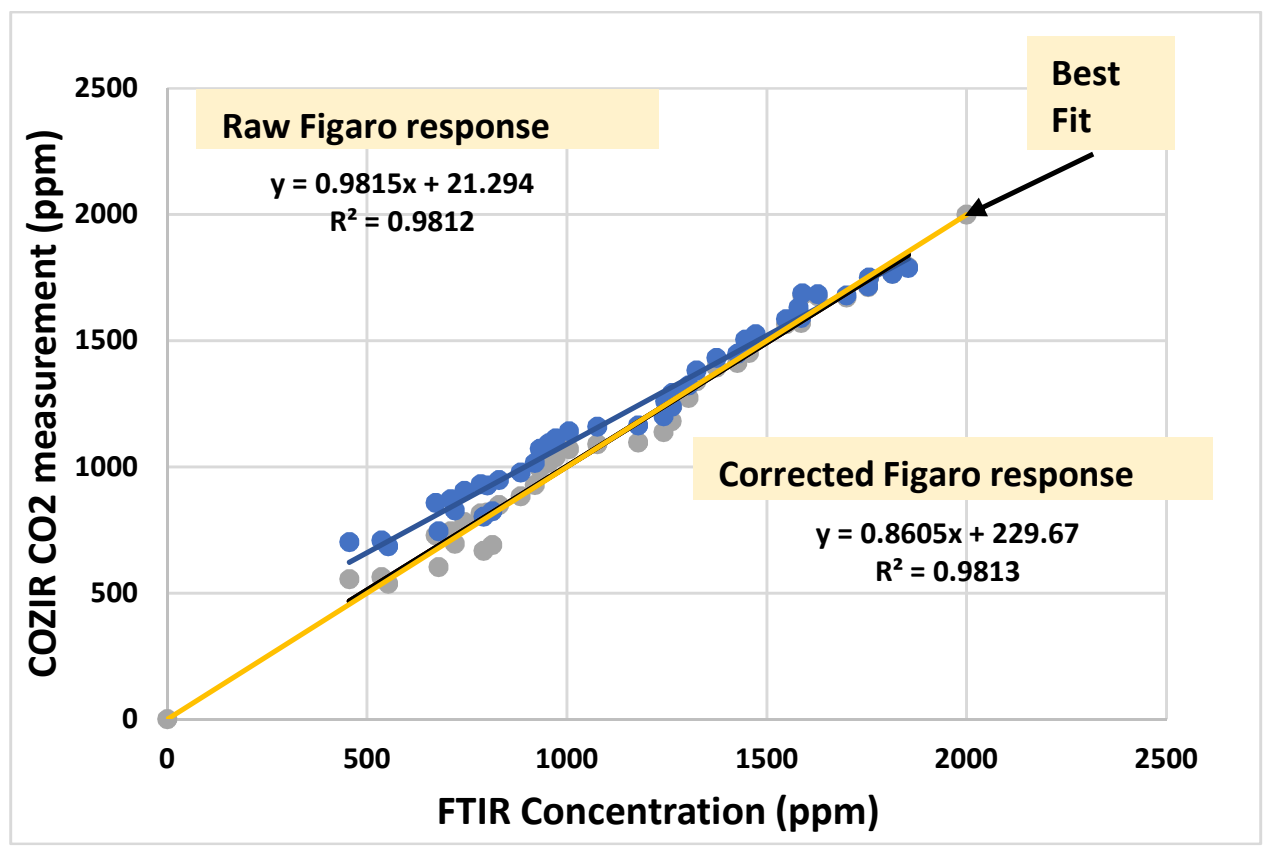

Figure 39 Test 8: COZIR sensor responses compared to FTIR responses due to increasing concentration changes.

Figure 39 shows corrected, and raw sensor responses compared to FTIR responses. The best fit line gives the ability to see the difference and compare raw and corrected responses. The plot shows that the calibration model corrected measurement has better agreement with FTIR response. Appendix C: Additional sensor calibration results 


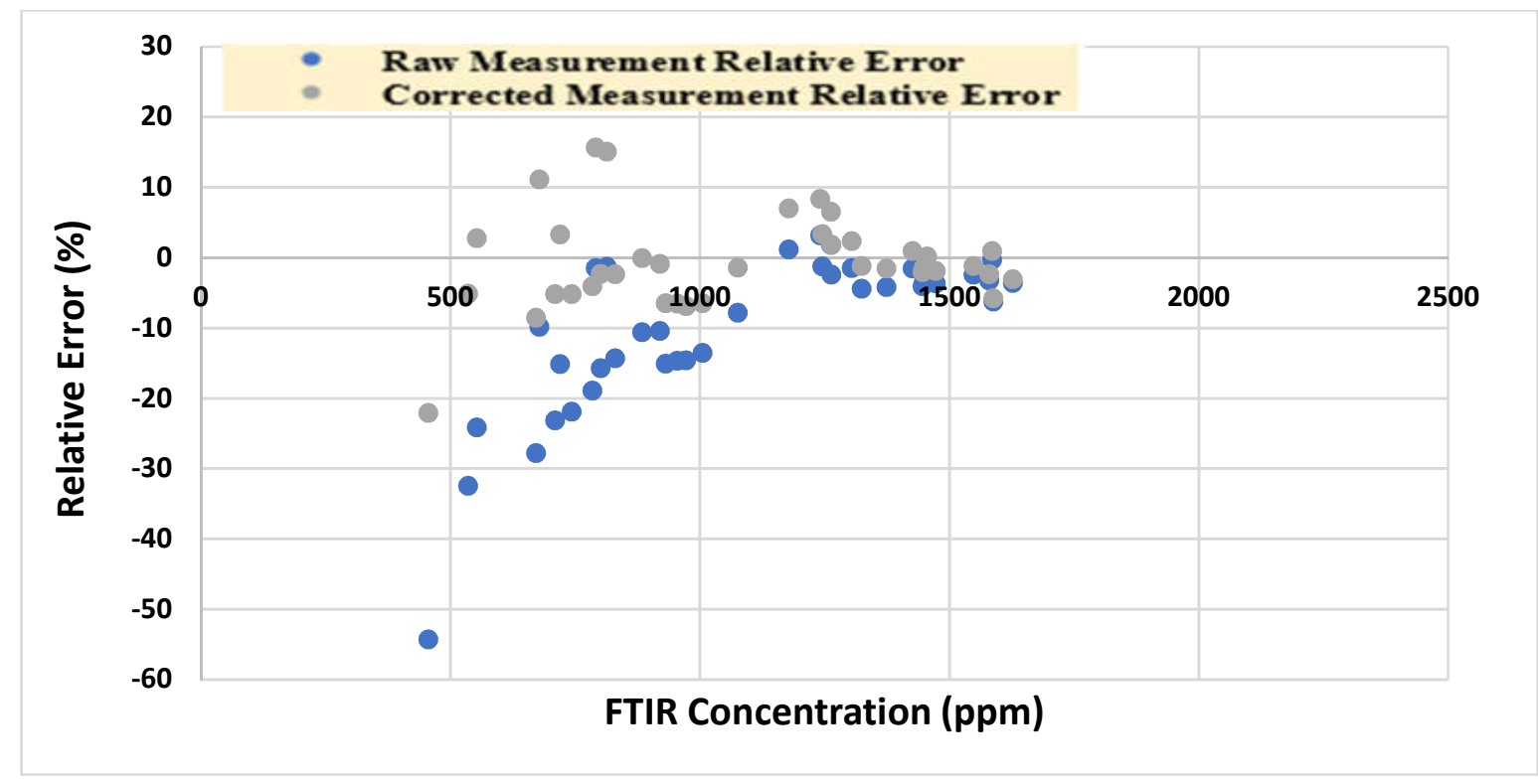

Figure 40 COZIR -raw measurement relative error compared to corrected measurement relative error -transient increase.

Figure 40 shows the relative errors for corrected and raw measurements. As it observed with previous sensors, the COZIR has high relative error at lower concentrations. Since FTIR responses are suspected at the lower concentration. The COZIR air calibration function should be repeated when the range adjustments are completed for FTIR.

Table 15 COZIR errors for transient concentration changes.

\begin{tabular}{|c|c|c|c|c|c|c|}
\hline Test ID & Test name & $\begin{array}{l}\text { Environment } \\
\text { Conditions }\end{array}$ & $\begin{array}{c}\text { Test } \mathrm{CO}_{2} \\
\text { concentration } \\
\text { range (ppm) }\end{array}$ & $\begin{array}{l}\text { Minimum } \\
\text { error (\%) }\end{array}$ & $\begin{array}{l}\text { Maximum } \\
\operatorname{error}(\%)\end{array}$ & $\begin{array}{c}\text { Overall } \\
\text { error }(\%)\end{array}$ \\
\hline 8 & $\begin{array}{l}\text { Raw-Transient } \mathrm{CO}_{2} \\
\text { concentration increase }\end{array}$ & \multirow{2}{*}{$\begin{array}{l}\text { Temperature: } 28^{\circ} \mathrm{C} \\
\text { RH: } 26 \pm 1.5 \\
\text { CO level: } 4 \pm 2 \mathrm{ppm} \\
\text { Pressure: } 14.15 \mathrm{psi}\end{array}$} & $\begin{array}{l}5000-10000 \\
\text { ppm }\end{array}$ & -54 & 3 & $25 \pm 22$ \\
\hline 8 & $\begin{array}{l}\text { Corrected Transient } \mathrm{CO}_{2} \\
\text { concentration increase }\end{array}$ & & $\begin{array}{l}5000-10000 \\
\text { ppm }\end{array}$ & -22 & 15 & $-3 \pm 18$ \\
\hline 9 & $\begin{array}{l}\text { Raw-Transient } \mathrm{CO}_{2} \\
\text { concentration decrease }\end{array}$ & \multirow{2}{*}{$\begin{array}{l}\text { Temperature: } 28 \pm 2{ }^{\circ} \mathrm{C} \\
\text { RH: } 30 \pm 2 \\
\text { CO level: } 4 \pm 2 \mathrm{ppm} \\
\text { Pressure: } 14.15 \mathrm{psi}\end{array}$} & $\begin{array}{l}10000-5000 \\
\text { ppm }\end{array}$ & -24 & 2 & $-11 \pm 13$ \\
\hline 9 & $\begin{array}{l}\text { Corrected Transient } \mathrm{CO}_{2} \\
\text { concentration decrease }\end{array}$ & & $\begin{array}{c}10000-5000 \\
\text { ppm }\end{array}$ & -11 & 12 & \pm 12 \\
\hline
\end{tabular}

COZIR responses are compared before and after corrections for the tests at the 0 to $2000 \mathrm{ppm}$ level. The comparison of the relative error is represented in Table 15 . The concentration level, raw measurement the relative error $-54 \%$ to $3 \%$ at Test 8 and $-24 \%$ to $2 \%$ at Test 9 . The corrected values are $-22 \%$ to $15 \%$ at Test 8 and $-11 \%$ to $11 \%$ at Test 9 . 
Over all the model has improved the sensor response if it is compared to raw measurement however since lower than $2000 \mathrm{ppm}$ level needs to further investigation for better understanding therefore the ${\mathrm{COZIR} \mathrm{CO}_{2}}$ sensor measurements should be repeated for high accuracy calculations. 


\section{Discussion}

The flow simulations are performed in order to determine the velocity profile at the chamber cross-section and also have an idea for fan selection. The simulated velocity profiles have similar trends with the experimental results; however, the magnitude of the velocity varies for each sampling point. The reason behind the difference because of the simulation defined revolution values(guessed) might be different from the real fan revolution. The fan is controlled by a VFC; during the experiments, the fan speed controlled manually.

Another simulation results are mass fraction though horizontal and vertical mass fraction, $\mathrm{CO}_{2}$ mass fraction (0.01) is defined as a small portion when it is compared to overall air the mass fraction (0.98), the results show close to constant mass fraction at cross-sectional area which helps us to conclude the chamber will have homogenous mixture after 100s of experiment time.

The sensors are evaluated in this study, which assumed they are affected by temperature, humidity, pressure, and $\mathrm{CO}$ interference. The calibration function is generated based on assumption. The calibration coefficients are applied to three tests, which concentration changes instantaneously. As they are shown in the Results section, the relative error considered separately for 5000ppm range. K30 FR and K30 1\% have similar technology and working principles, which is observed during the testing procedure. The level which is lower than $5000 \mathrm{ppm}$, where K30 sensors raw measurement errors are higher than the manufacturer's given accuracy.

Additionally, at the comparison results, the highest relative errors are observed lower than $2000 \mathrm{ppm}$ level, the reason might be because of the reference instrument limitations. The recipe for FTIR gas detection has a high concentration level. At the lower concentration, FTIR has higher noise. The sampling time of the FTIR is increased during the experiments in order to maintain the transient concentration changes at the low concentration level still the measurements might be affected by a high noise level. At the above 5000 ppm level, the raw measurement relative errors are higher than manufacturer accuracy despite the relative error relatively lower than below $5000 \mathrm{ppm}$ level. The calibration functions decreased the error below \% \pm 3 higher than $5000 \mathrm{ppm} \mathrm{CO}_{2}$ concentration. The manufacturer limits the accuracy specification up to 5000 ppm. However, the corrected sensors can reach to low error measurement. 


\section{Conclusions}

The study aimed to generate calibration functions for K30 FR and K30 1\% (range 10000ppm), FIGARO FG-030 (range 5000ppm), and COZIR (range 2000ppm) low-cost miniature gas sensors. In order to complete the study and perform the necessary experiments a test bench, specifically, the dynamic environmental simulation chamber (DESC) had to be designed, built, and characterized.

During the first stage, the design stage, a 3-D model of the chamber was built after general dimensions taken from literature. In order to understand the flow inside the closed-loop shaped test chamber, a CFD analysis was performed. After building the chamber from stainless steel, the actual flow characteristics were measured using a hotwire anemometer inserted into the chamber and moved across the horizontal and vertical cross-sectional plane at different airflow speeds, namely, high, medium, and low speeds. Comparison of experimental and simulated values indicated the velocity profiles to agree qualitatively. Differences were observed in the magnitude of the air velocity and were concluded to originate from the differences in actual fan speed in the chamber and the guessed fan speed used for the simulation.

Additional flow simulations were performed to understand the characteristic time scale for homogeneous mixing to occur in the chamber upon injection of different gaseous constituents or steam. The simulation showed the mixture to become homogeneous in less than 2 minutes. Therefore, for the experimental stage, it was decided to add a stabilization time of 5 minutes in order to allow for achieving homogeneous mixture before the start of data collection.

Moreover, a structural analysis was also performed to assure the supports are designed strong enough to carry the full weight of the DESC of $300 \mathrm{~kg}$. The structural analysis results showed that the selected support design was capable of carrying the DESC.

A stepwise multi-linear regression approach taking i) temperature, ii) pressure, iii) water content in the sample gas, as well as iv) $\mathrm{CO}$ as interfering gas in consideration, was used to develop calibration models for the different $\mathrm{CO}_{2}$ sensors investigated. Results showed that the calibrations models improved the sensor responses when the corrected responses were compared to raw measurements.

For the two K30 sensors, the overall relative error was observed to decrease from $\pm 10 \%$ to $\pm 3 \%$. The K30 sensors are affected by pressure, temperature, and humidity. Pressure has a negative impact on the sensor response; the temperature is influencing the sensor positively, and also humidity has a positive impact but significantly lower than the temperature effect. CO interference was found to be lower than impacts from all the other parameters considered (i.e. T, P, H).

For the Figaro sensor, the overall relative error was seen to decrease from $\pm 15 \%$ to $\pm 4 \%$ after calibration of the response model. The Figaro sensor is affected by pressure, which has the highest impact on the sensor and was observed to affect it negatively. The second most influencing parameter is the CO interference, 
which is affecting the sensor positively, humidity has a similar positive effect like CO. The effect of temperature is considerably lower compared to the other parameters.

Finally, for the COZIR sensor, the overall relative error was decreased from $\pm 22 \%$ to $\pm 14 \%$. CO has a significant positive interfering impact on the sensor. Pressure has a high negative impact on the sensor. Temperature and humidity show a lower impact when compared to other parameters. The COZIR sensor correction model did not decrease the error as desired, and thus, further investigation is needed for this specific sensor. 


\section{Recommendations for future work}

The simulated velocity profiles showed the guessed fan rotations are closer to real fan rotation, however, for better agreement between simulation and experiments, the fan rotation values should be investigated for the purpose of validation.

Overall, temperature and $\mathrm{CO}$ concentration have a negative impact on sensor readings, which cause underprediction, while humidity and pressure have a positive impact leading to over-prediction. The calibrated $\mathrm{K} 30 \mathrm{CO}_{2}$ sensors are capable of reading higher than $5000 \mathrm{ppm}$ with high accuracy, however, due to increased FTIR noise levels at lower concentrations, the study cannot conclude the same for lower than 5000 ppm concentration ranges. The low concentration levels need to be investigated with an FTIR that is setup for lower detection limits and decreased noise levels.

The laboratory and sensors have environmental limitations; therefore, experimental temperature ranges were limited in this study. The laboratory metrological ranges can be easily modified for different gas sensors and technologies which have a widened operational temperature, humidity, pressure ranges. 


\section{Bibliography}

[1] 40 C.F.R. § 50, "Subchapter C - Air Programs - Part 50 - National Primary and Secondary Ambient Air Quality Standards," 2015.

[2] P. E. Tolbert, M. Klein, J. L. Peel, S. E. Sarnat, and J. A. Sarnat, "Multipollutant modeling issues in a study of ambient air quality and emergency department visits in Atlanta," J. Expo. Sci. Environ. Epidemiol., vol. 17, no. SUPPL. 2, pp. 29-35, 2007.

[3] J. M. Samet, S. L. Zeger, F. Dominici, F. Curriero, I. Coursac, and D. W. Dockery, "The National Morbidity, Mortality, Part II : Morbidity and Mortality from Air Pollution in the United States Final Version Includes a Commentary by the Institute's Health Review Committee," Heal Th Eff. S Inst., no. 94, 2000.

[4] J. M. Samet, "Fine Particulate Air Pollution and Mortality," N. Engl. J. Med., vol. 343, no. 24, pp. 1742-1749, 2000.

[5] S. M. Gilboa et al., "Relation between ambient air quality and selected birth defects, seven county study, Texas, 1997-2000,” Am. J. Epidemiol., vol. 162, no. 3, pp. 238-252, 2005.

[6] R. Williams et al., “Air Sensor Guidebook,” 2014.

[7] Noah Scovronick, "Reducing Global Health Risks,” p. 148, 2015.

[8] R. Long, E. Smith, A. Brown, R. Long, and B. Sharpe-arcadis, “Air Quality Monitoring and Sensor Technologies Ron Williams and the Emerging Technologies Team Sam Garvey-Alion Science and Technology,” 2015.

[9] EPA, “Air Sensor Guidebook,” J. Chem. Inf. Model., vol. 53, no. 9, pp. 1689-1699, 2013.

[10] L. Spinelle, M. Gerboles, and M. Aleixandre, "NO9: CairClipNO 2 of CAIRPOL (F) Report of laboratory and in-situ validation of micro-sensor for monitoring ambient air pollution.”

[11] L. Spinelle, M. Gerboles, and M. Aleixandre, "Ozone micro-sensor, $\alpha$ Sense, model B4-O3 sensor Report of laboratory and in-situ validation of micro-sensor for monitoring ambient air."

[12] JRC, Report of laboratory and in-situ in itu validation of micro-sensor sensor for monitoring ambient air pollution. 2013. 
[13] X. Pang, M. D. Shaw, S. Gillot, and A. C. Lewis, "The impacts of water vapour and co-pollutants on the performance of electrochemical gas sensors used for air quality monitoring," Sensors Actuators B Chem., vol. 266, pp. 674-684, 2018.

[14] M. C. Carotta et al., "Array of thick film sensors for atmospheric pollutant monitoring," Sensors Actuators, B Chem., 2000.

[15] M. Gerboles, E. Diaz, and A. Noriega-Guerra, "Uncertainty calculation and implementation of the static volumetric method for the preparation of NO and SO2standard gas mixtures," Accredit. Qual. Assur., 1998.

[16] P. Pérez Ballesta, "Atmosphere generation system for the preparation of ambient air volatile organic compound standard mixtures," Anal. Chem., vol. 71, no. 11, pp. 2241-2245, 1999.

[17] H. Plaisance, A. Piechocki-Minguy, S. Garcia-Fouque, and J. C. Galloo, "Influence of meteorological factors on the NO 2 measurements by passive diffusion tube," Atmos. Environ., vol. 38, pp. 573-580, 2004.

[18] H. Plaisance, T. Leonardis, and M. Gerboles, "Assessment of uncertainty of benzene measurements by Radiello diffusive sampler," Atmos. Environ., 2008.

[19] M. Gerboles, D. Buzica, L. Amantini, and F. Lagler, "Laboratory and field comparison of measurements obtained using the available diffusive samplers for ozone and nitrogen dioxide in ambient air," J. Environ. Monit., vol. 8, no. 1, pp. 112-119, 2006.

[20] N. Helwig, M. Schüler, C. Bur, A. Schütze, and T. Sauerwald, "Gas mixing apparatus for automated gas sensor characterization," Meas. Sci. Technol., vol. 25, no. 5, 2014.

[21] N. A. Martin, D. J. Marlow, M. H. Henderson, B. A. Goody, and P. G. Quincey, "Studies using the sorbent Carbopack X for measuring environmental benzene with Perkin-Elmer-type pumped and diffusive samplers," Atmos. Environ., vol. 37, no. 7, pp. 871-879, 2003.

[22] A. Polidori, V. Papapostolou, and H. Zhang, "Laboratory Evaluation of Low-Cost Air Quality Sensors," no. August, 2016.

[23] A. Polidori, "Field Evaluation of Low-Cost Air Quality Sensors Field Setup and Testing Protocol," no. January, 2017. 
[24] L. Spinelle, M. Gerboles, G. Kok, and T. Sauerwald, "Sensitivity of VOC Sensors for Air Quality Monitoring within the EURAMET Key-VOC project," 2015.

[25] T. Sauerwald et al., "Highly sensitive benzene detection with metal oxide semiconductor gas sensors \&amp;ndash; An inter-laboratory comparison,” J. Sensors Sens. Syst., vol. 7, no. 1, pp. 235-243, 2018.

[26] M. Aleixandre and M. Gerboles, "Review of small commercial sensors for indicative monitoring of ambient gas," Chem. Eng. Trans., vol. 30, no. x, pp. 169-174, 2012.

[27] A. Wang, M. Brauer, and D. Sc, "Review of Next Generation Air Monitors for Air Pollution," Sch. Popul. Public Heal. Univ. Br. Columbia, pp. 1-79, 2014.

[28] J. Petersen, J. Kristensen, H. Elarga, R. Andersen, and A. Midtstraum, "Accuracy and Air Temperature Dependency of Commercial Low-cost NDIR $\mathrm{CO}_{2}$ Sensors: An Experimental Investigation," 4th Int. Conf. Build. Energy, Environ., vol. COBEE2018-, pp. 203-207, 2018.

[29] J. Hodgkinson, R. Smith, W. O. Ho, J. R. Saffell, and R. P. Tatam, "Non-dispersive infra-red (NDIR) measurement of carbon dioxide at $4.2 \mu \mathrm{m}$ in a compact and optically efficient sensor," Sensors Actuators, B Chem., vol. 186, pp. 580-588, 2013.

[30] J. S. Park, H. C. Cho, and S. H. Yi, "NDIR $\mathrm{CO}_{2}$ gas sensor with improved temperature compensation," Procedia Eng., vol. 5, pp. 303-306, 2010.

[31] N. Barsan and U. D. O. Weimar, “Conduction Model of Metal Oxide Gas Sensors,” pp. 143-167, 2002.

[32] K. Arshak, E. Moore, G. M. Lyons, J. Harris, and S. Clifford, "A review of gas sensors employed in electronic nose applications," Sens. Rev., vol. 24, no. 2, pp. 181-198, 2004.

[33] Z. Yunusa, "S e n s or s \& Tr a n s d u c e r s Gas Sensors : A Review,” no. April, 2014.

[34] RAE Systems, The PID Handbook. 2013.

[35] R. Systems by Honeywell, "Theory And Operation Of NDIR Sensors," RAE Syst., pp. 1-2, 2009.

[36] B. Bun, "Calibration using Supervised Learning for Low-Cost Air Quality Sensors,” p. 174, 2017.

[37] N. Zimmerman et al., "Closing the gap on lower cost air quality monitoring: machine learning 
calibration models to improve low-cost sensor performance," Atmos. Meas. Tech. Discuss., pp. 136, 2017.

[38] M. Gerboles, "Evaluation of low-cost sensors for air pollution monitoring," 2017.

[39] C. Borrego et al., "Assessment of air quality microsensors versus reference methods : The EuNetAir joint exercise," vol. 147, no. 2, pp. 246-263, 2016.

[40] L. Spinelle, M. Gerboles, M. G. Villani, M. Aleixandre, and F. Bonavitacola, "Field calibration of a cluster of low-cost available sensors for air quality monitoring. Part A: Ozone and nitrogen dioxide," in Sensors and Actuators, B: Chemical, 2015.

[41] A. Long, "Linear Regression and Non-Linear Regression,” no. November, 2016.

[42] E. F. K. Aguiar, H. L. Roig, L. H. Mancini, and E. N. C. B. de Carvalho, "Low-Cost Sensors Calibration for Monitoring Air Quality in the Federal District—Brazil," J. Environ. Prot. (Irvine,. Calif)., vol. 06, no. 02, pp. 173-189, 2015.

[43] C. R. Martin et al., "Evaluation and environmental correction of ambient $\mathrm{CO}_{2}$ measurements from a low-cost NDIR sensor," Atmos. Meas. Tech., vol. 10, no. 7, pp. 2383-2395, 2017.

[44] L. Spinelle, M. Gerboles, M. G. Villani, M. Aleixandre, and F. Bonavitacola, "Field calibration of a cluster of low-cost commercially available sensors for air quality monitoring. Part B: NO, CO and CO 2 ," Sensors Actuators, B Chem., 2017.

[45] K. L. Du and M. N. S. Swamy, Neural Networks and Statistical Analyses. 2013.

[46] L. Spinelle, Report of laboratory and in-situ validation of micro-sensor for monitoring ambient air pollution. 2013.

[47] B. Andersson, R. Andersson, L. Håkansson, M. Mortensen, R. Sudiyo, and B. Van Wachem, Computational fluid dynamics for engineers, vol. 9781107018.2011.

[48] US EPA, “Environmental protection agency,” no. 14, 2015.

[49] X. Fang and I. Bate, "Using Multi-parameters for Calibration of Low-cost Sensors in Urban Environment,” Proc. 2017 Int. Conf. Embed. Wirel. Syst. Networks, pp. 1-11, 2017.

[50] M. Karimi, G. Akdogan, and S. M. Bradshaw, "Effects of different Mesh schemes and turbulence 
models in CFD modelling of stirred tanks," Physicochem. Probl. Miner. Process., vol. 48, no. 2, pp. 513-531, 2012.

[51] EPA, "Office of Water Definition and Procedure for the Determination of the Method Detection Limit, Revision 2,” no. December, 2016.

[52] S. G. Brown and H. R. Hafner, “Air Toxics Data Analysis Workbook,” no. June, pp. 1-360, 2009. 


\section{Appendix}

\section{Appendix A: Sensor specifications}

The performance characteristics of sensor specifications are briefly explained below [6].

\subsubsection{Bias}

A common error of measurement can be higher or lower. There can be multiple bias calculation; one of the calculation methods is:

$$
B=\left(\frac{C}{C_{R}}\right)-1
$$

Where $\mathrm{B}$ is the bias, $\mathrm{C}$ is the average of the measurements, and $\mathrm{C}_{R}$ is the reference concentration of the pollutant.

\section{Precision}

The precision is an important indicator to measure the same concentration under similar conditions. Precision can be calculated and checked whether it is accurate or not for the related issue.

$$
P=C s / C m
$$

Where $\mathrm{P}$ is the precision, $\mathrm{Cs}$ is the standard deviation of the measurements, and $\mathrm{Cm}$ is the measurement means at a given concentration.

\section{Calibration}

The procedure checks and tunes sensor measurements by making a comparison with a reference instrument. Many calibration methods were used for the sensor over time by researchers and developers. The most common methods are explained in section 2.3.3.

\section{Detection limit}

The detection limit can be determined as the lowest concentration that the sensor can detect. Usually, the manufacturer provides the detection limit information. However, the detection limit may vary by the time. There are many ways to measure the detection limit; the most common method is the method detection limit (MDL). The MDL is defined as the minimum measured Concentration of a substance that can be reported with $99 \%$ confidence [51]. The calculation of the MDL is:

$$
M D L=t_{(n-1,1-\propto=0.99)} S
$$

Where MDL is a method detection limit, $t_{(n-1,1-\propto=0.99)}$ is t-value appropriate for a single-tailed 99th percentile $t$ statistic and a standard deviation estimate with $n-1$ degrees of freedom and $\mathrm{S}$ is sample standard deviation of the sample analyses. Figure 41 shows the graphical detection limit 


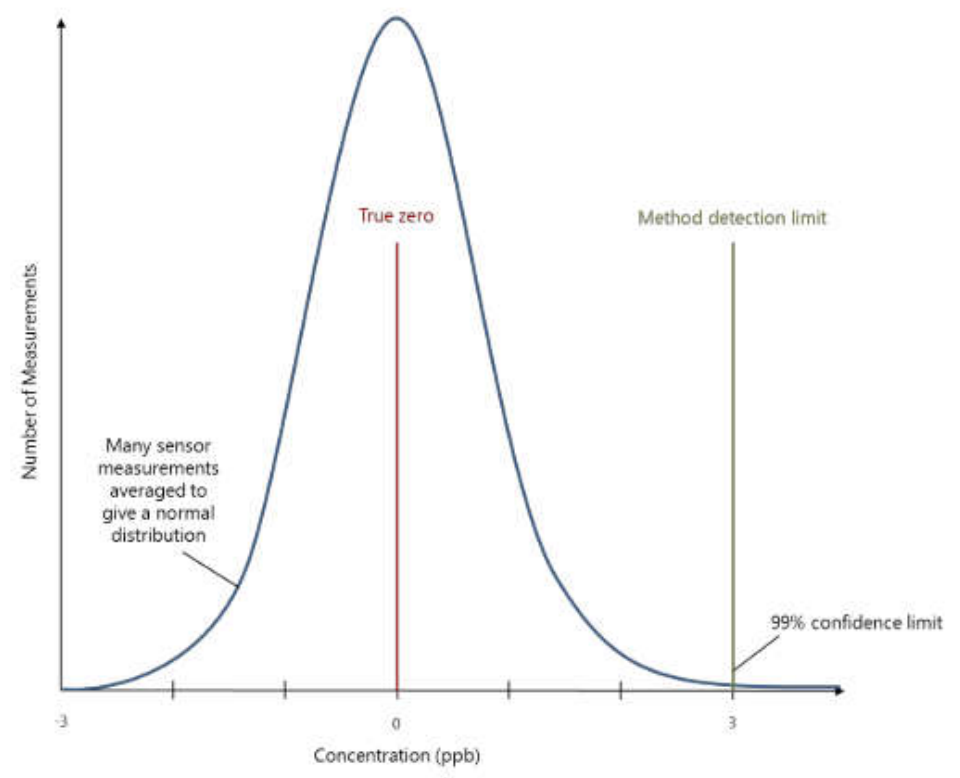

Figure 41 Representation of a detection limit [52].

\section{Response time}

The amount of the time that the sensor reacts to the change in concentration is vital because it shows how rapidly it responds for instant changes in concentration. They are typically used $t_{90}$ which means response time to measure $90 \%$ of the pollutant to concentration by the sensor [6].

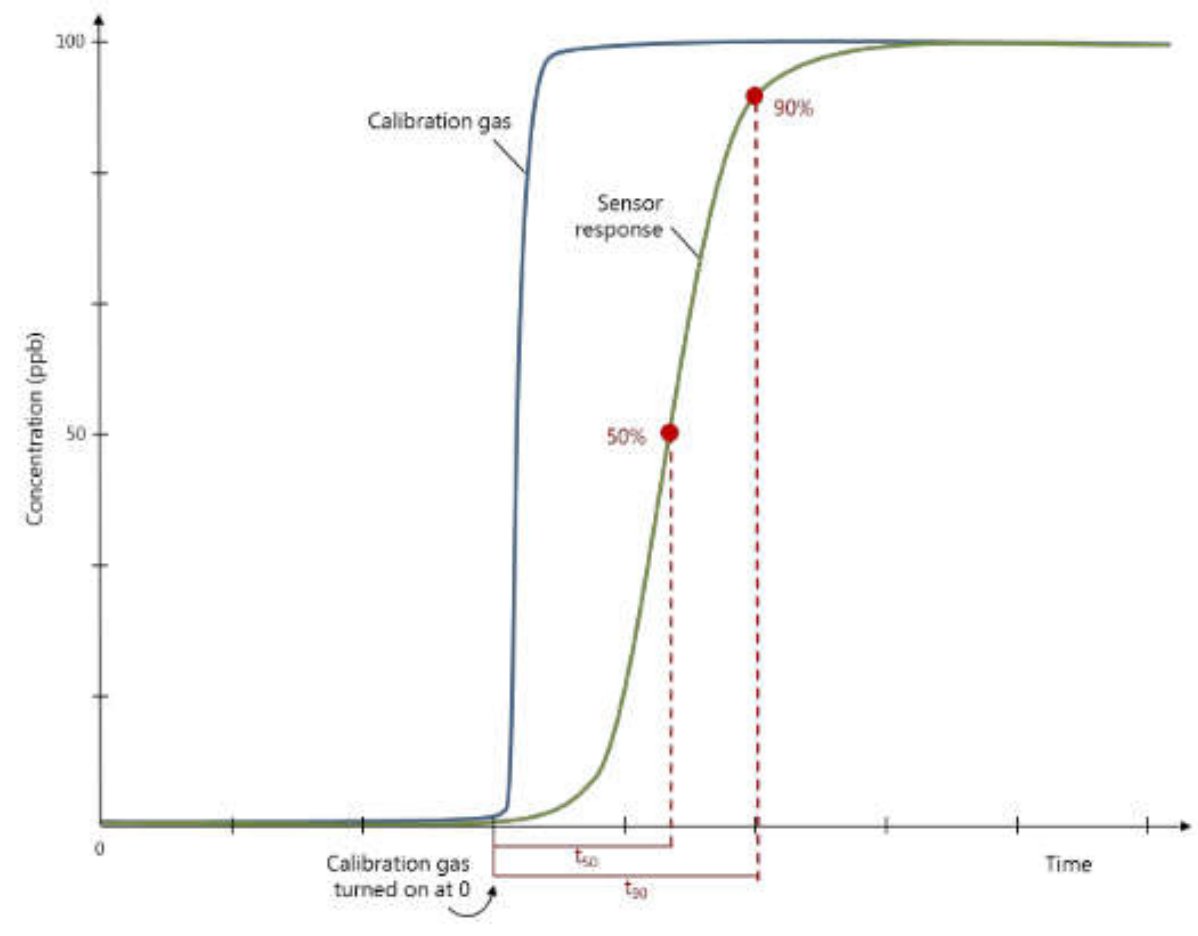

Figure 42 Response time to measure $50 \%$ and $90 \%$ of the gas [6]. 


\section{Sensor response}

Useful sensor response is collected for each concentration measured. Figure 43 shows the ideal sensor response.

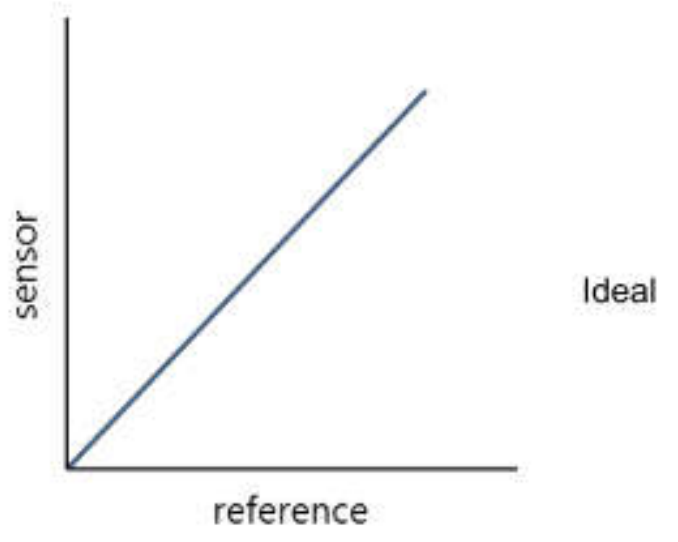

Figure 43 Ideal sensor response.

\section{Selectivity}

The ability of a sensor to respond to particular pollutant is called selectivity.

\section{Interferences}

The ideal sensor would only respond to the target pollutant described as selectivity. However, sensors may respond to other pollutants or meteorological conditions.

\section{Drift}

A gradual change in instrument response, quantitative characteristic (i.e., a standard concentration or zero air) is called drift.

\section{Climate susceptibility}

Climate susceptibility is a measure of an instrument's ability to variations in meteorological conditions, including changes in temperature and humidity. 
Appendix B: Additional simulation results

A. Velocity profile comparison

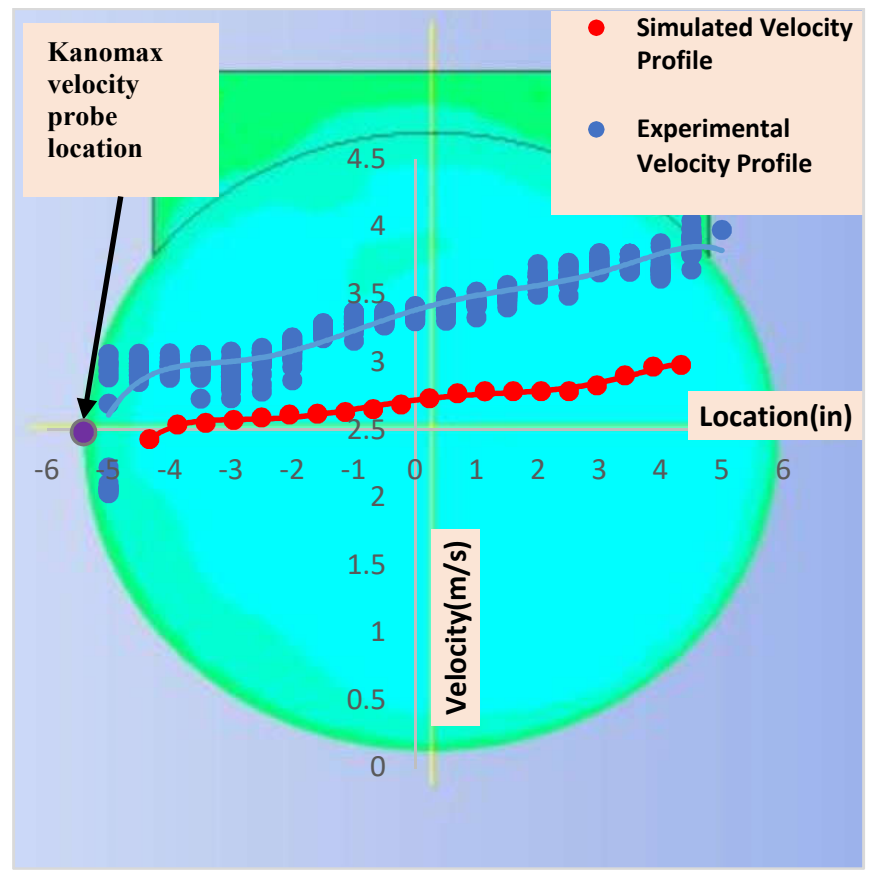

Figure 44 Vertical velocity profile comparison for medium speed level

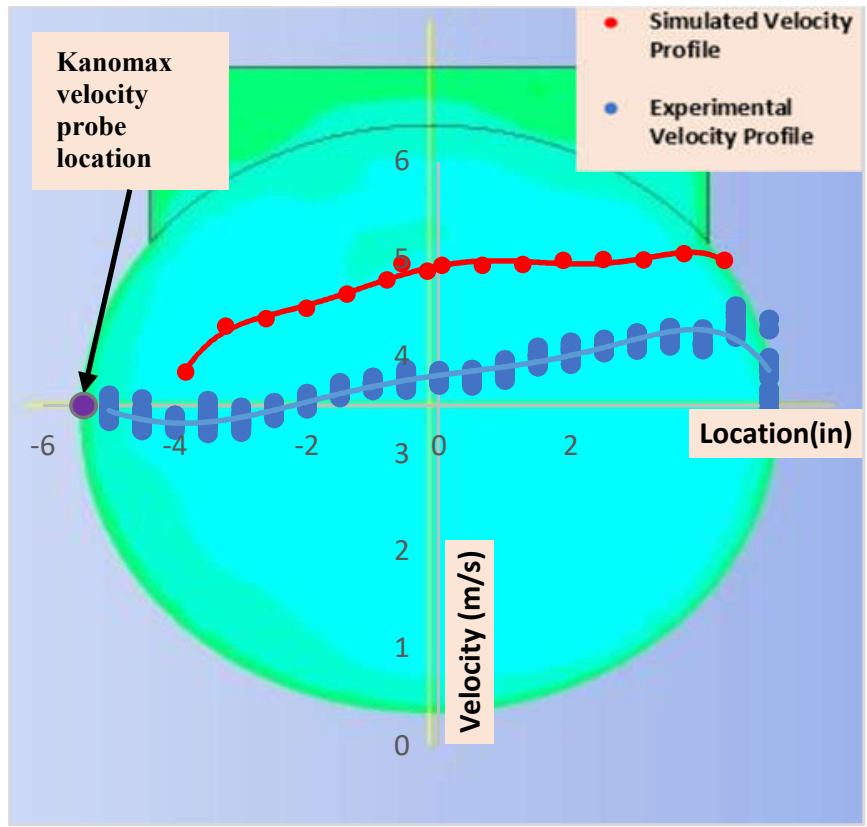

Figure 45 Vertical velocity profile comparison for high speed level 


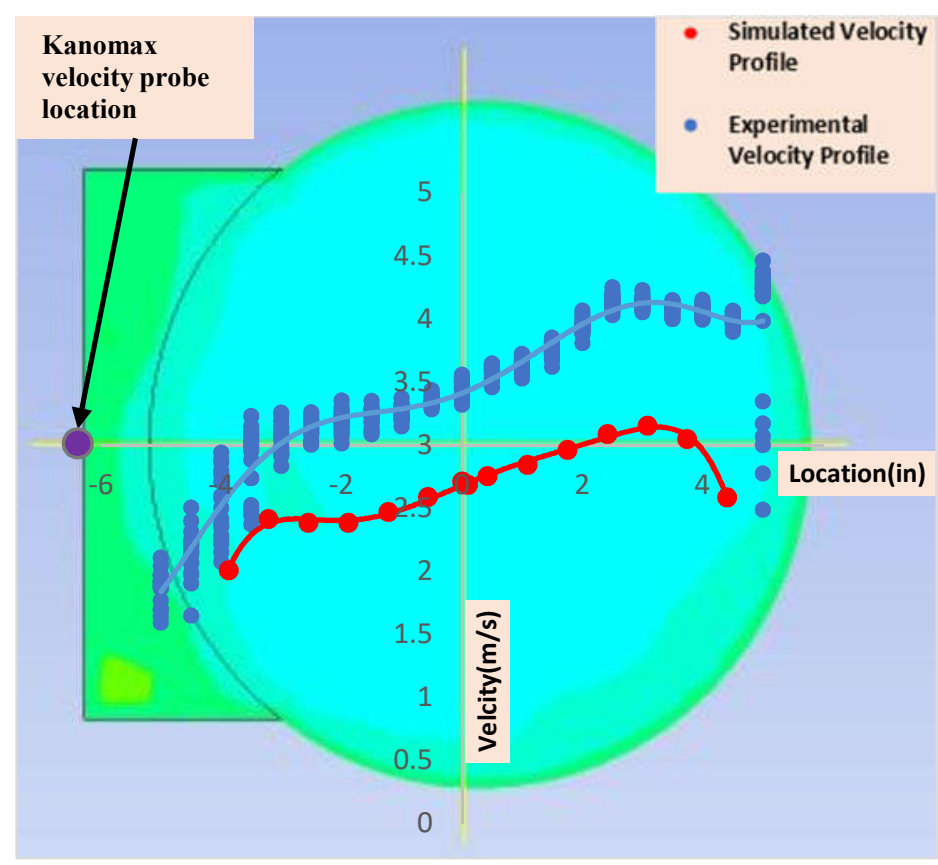

Figure 46 Horizontal velocity profile comparison for medium speed level

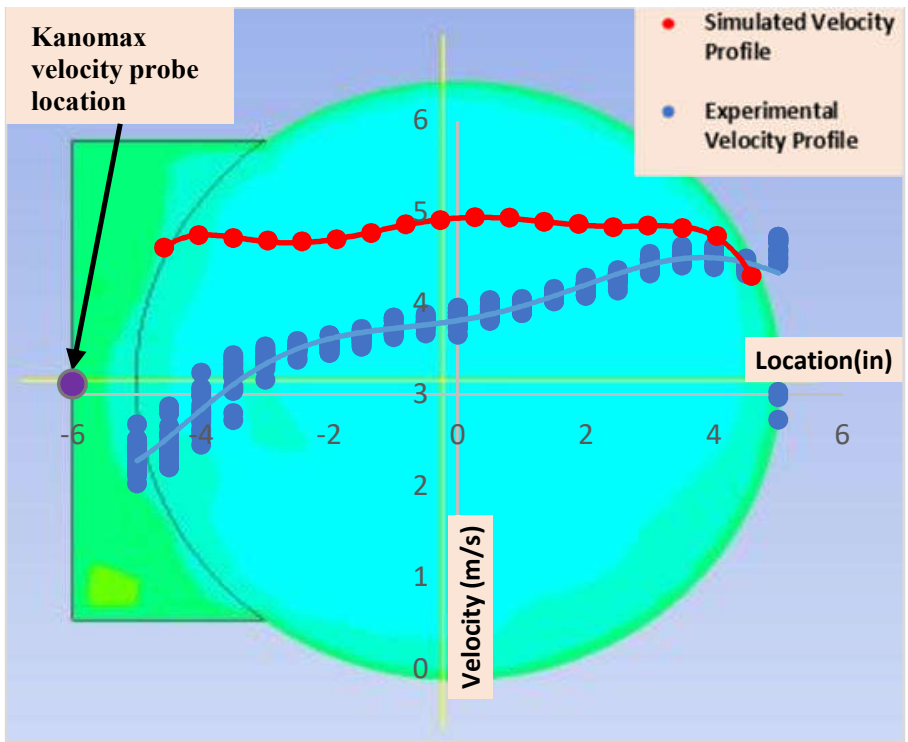

Figure 47 Horizontal velocity profile comparison for high speed level 
B. Mass fraction through the cross section

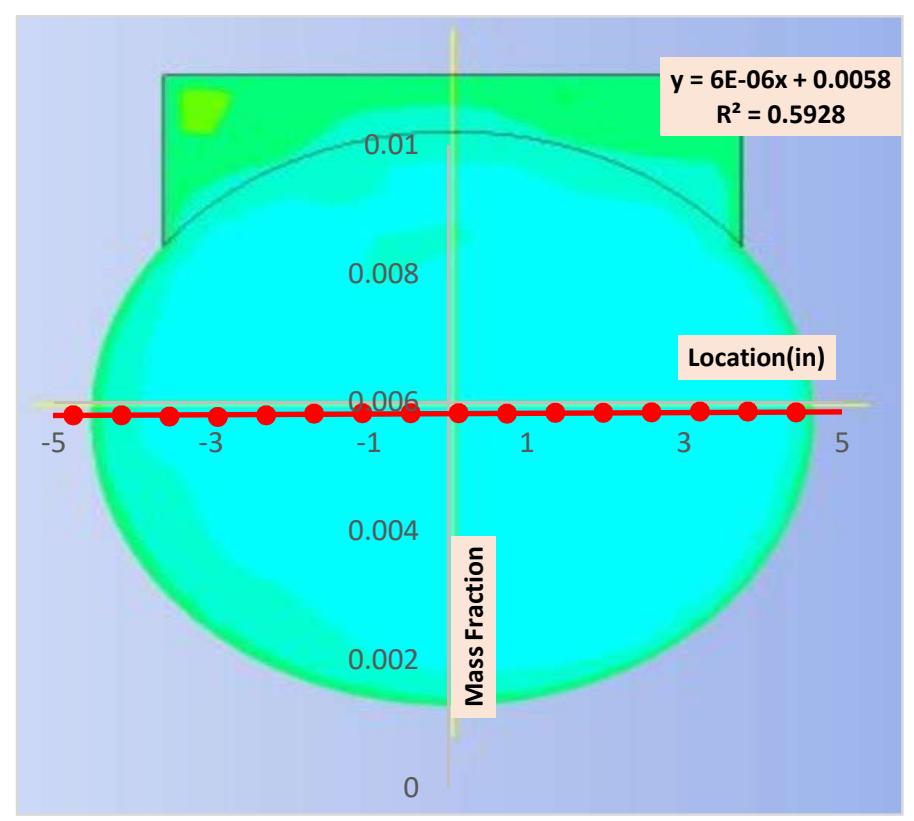

Figure $48 \mathrm{CO}_{2}$ Mass fraction through the vertical line-low Speed

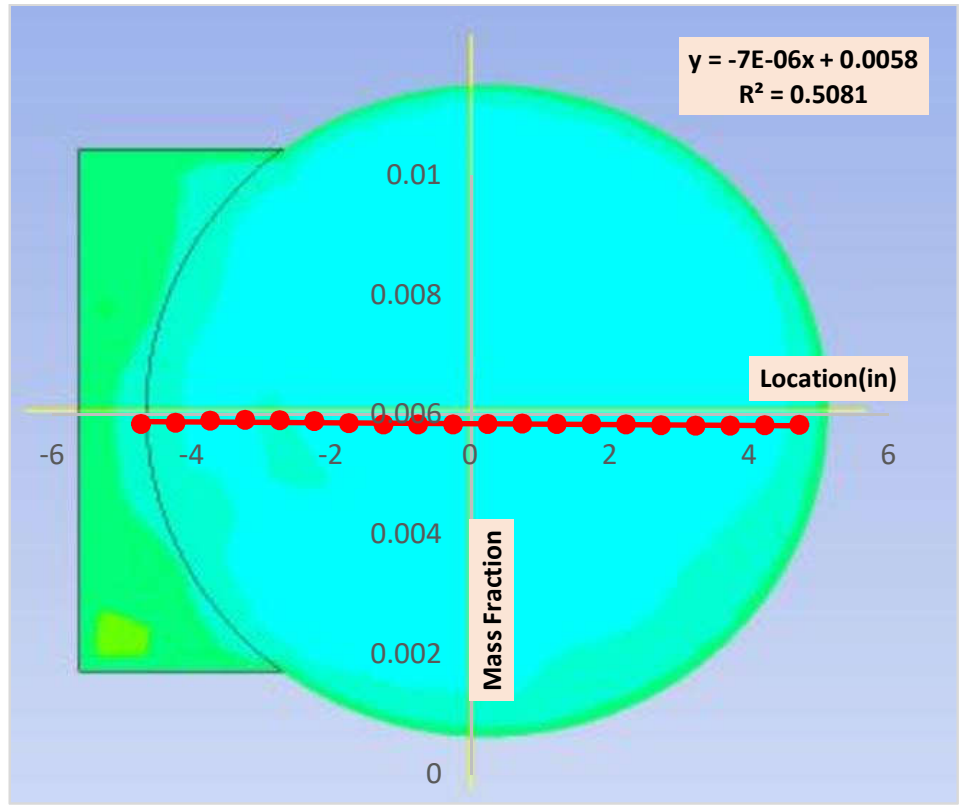

Figure $49 \mathrm{CO}_{2}$ mass fraction through the horizontal line-low speed 


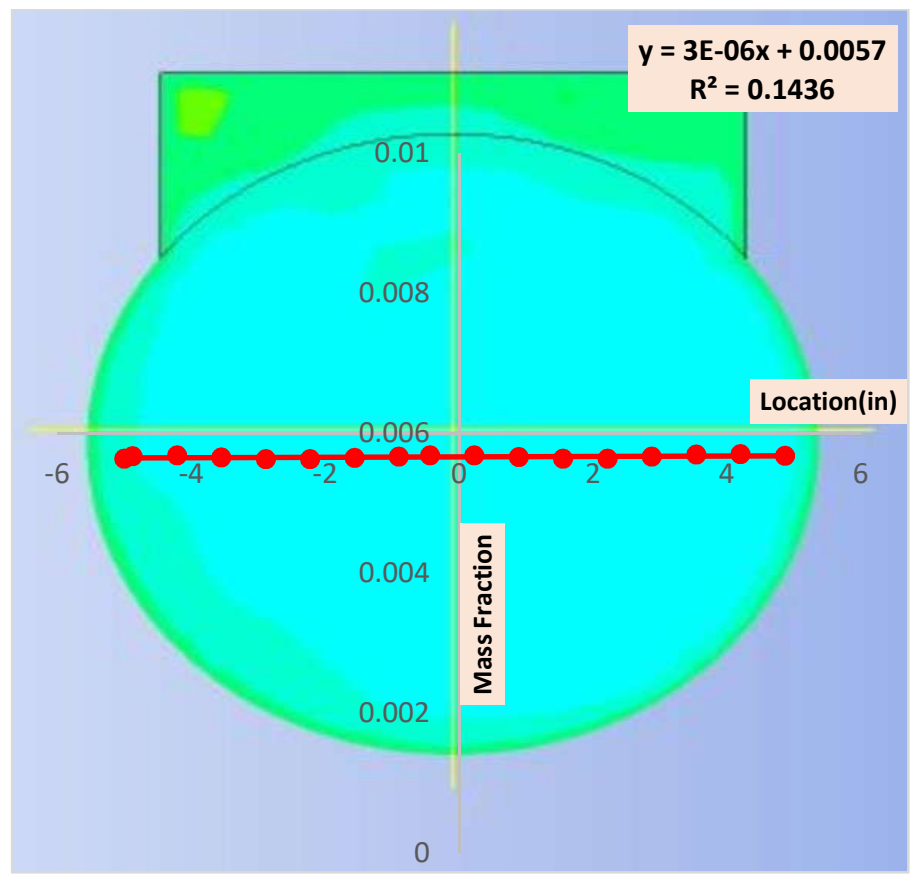

Figure $50 \mathrm{CO} 2$ mass fraction through the vertical line-medium speed

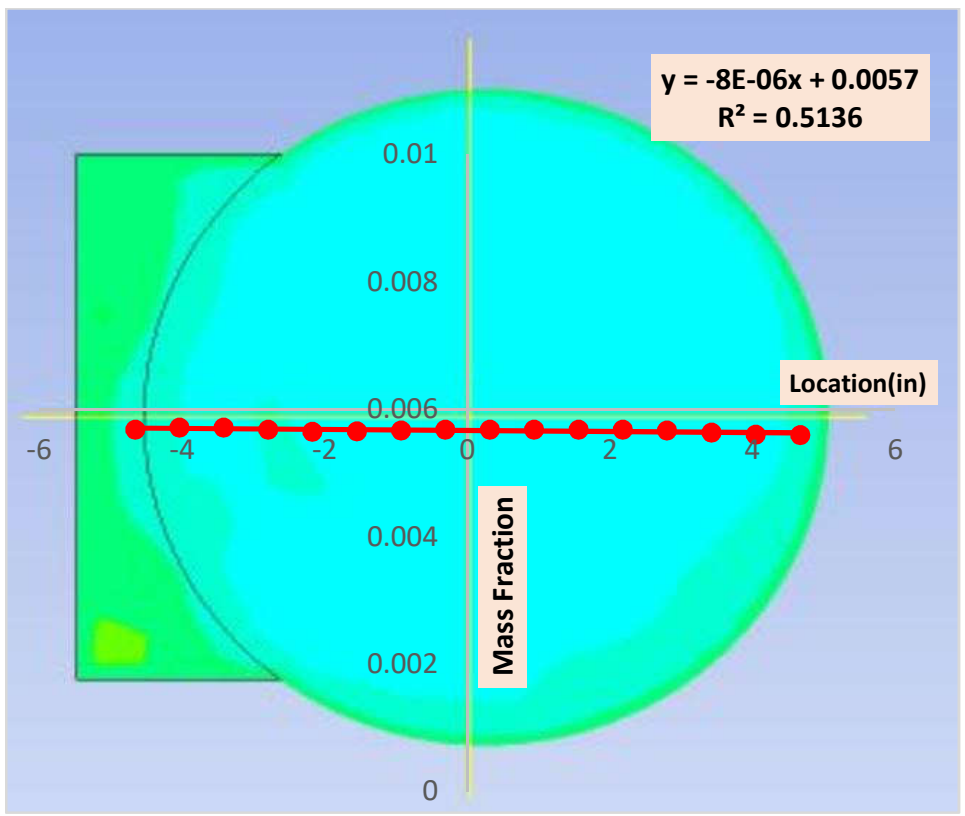

Figure 51 CO2 mass fraction through the horizontal line-medium speed 
Appendix C: Additional sensor calibration results

Comparison of all sensor responses

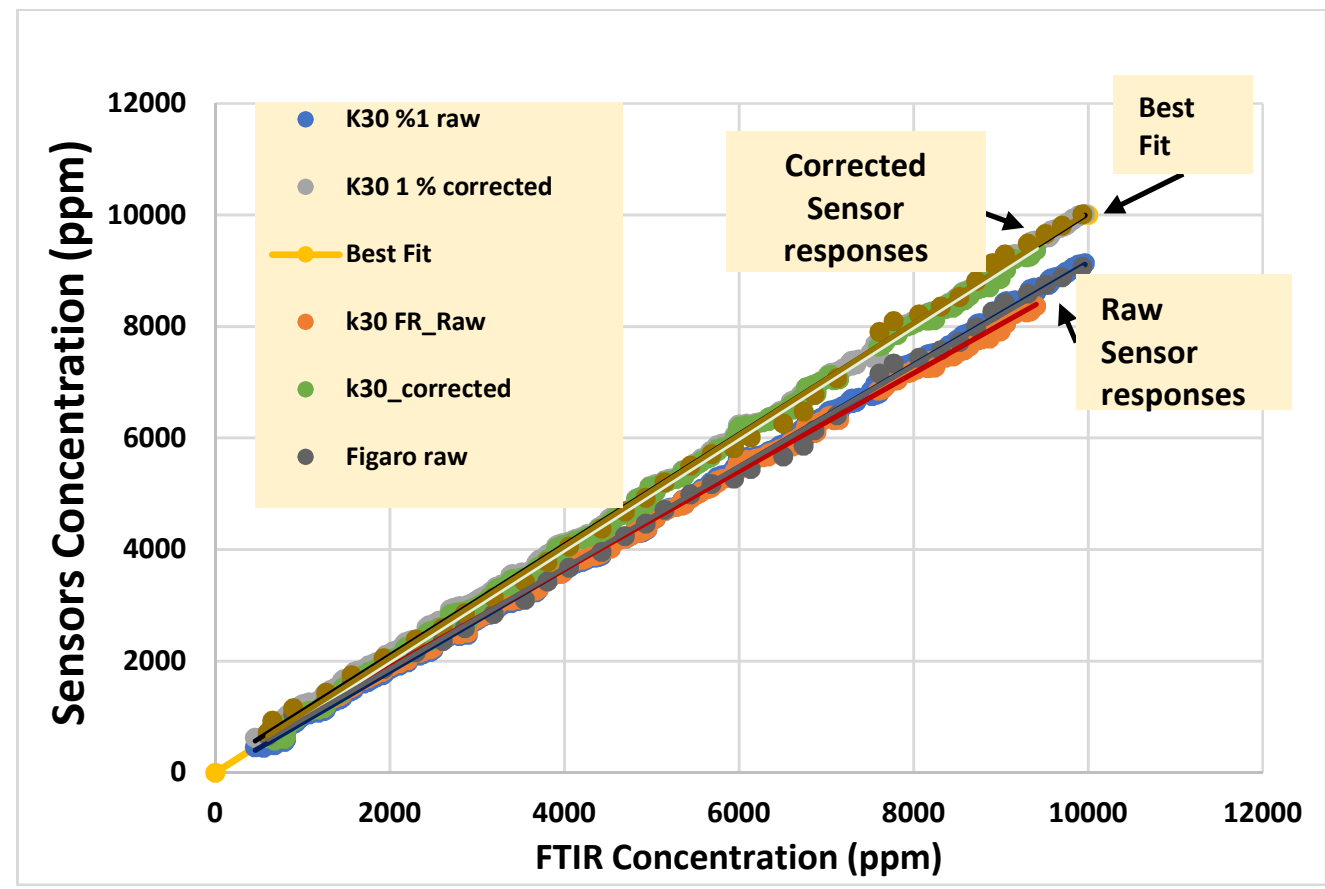

Figure 52 Comparison of the sensor responses with the reference instrument.

i. $\quad \mathrm{K} 30$ Fast response (FR) $\mathrm{CO}_{2}$ sensor evaluation results

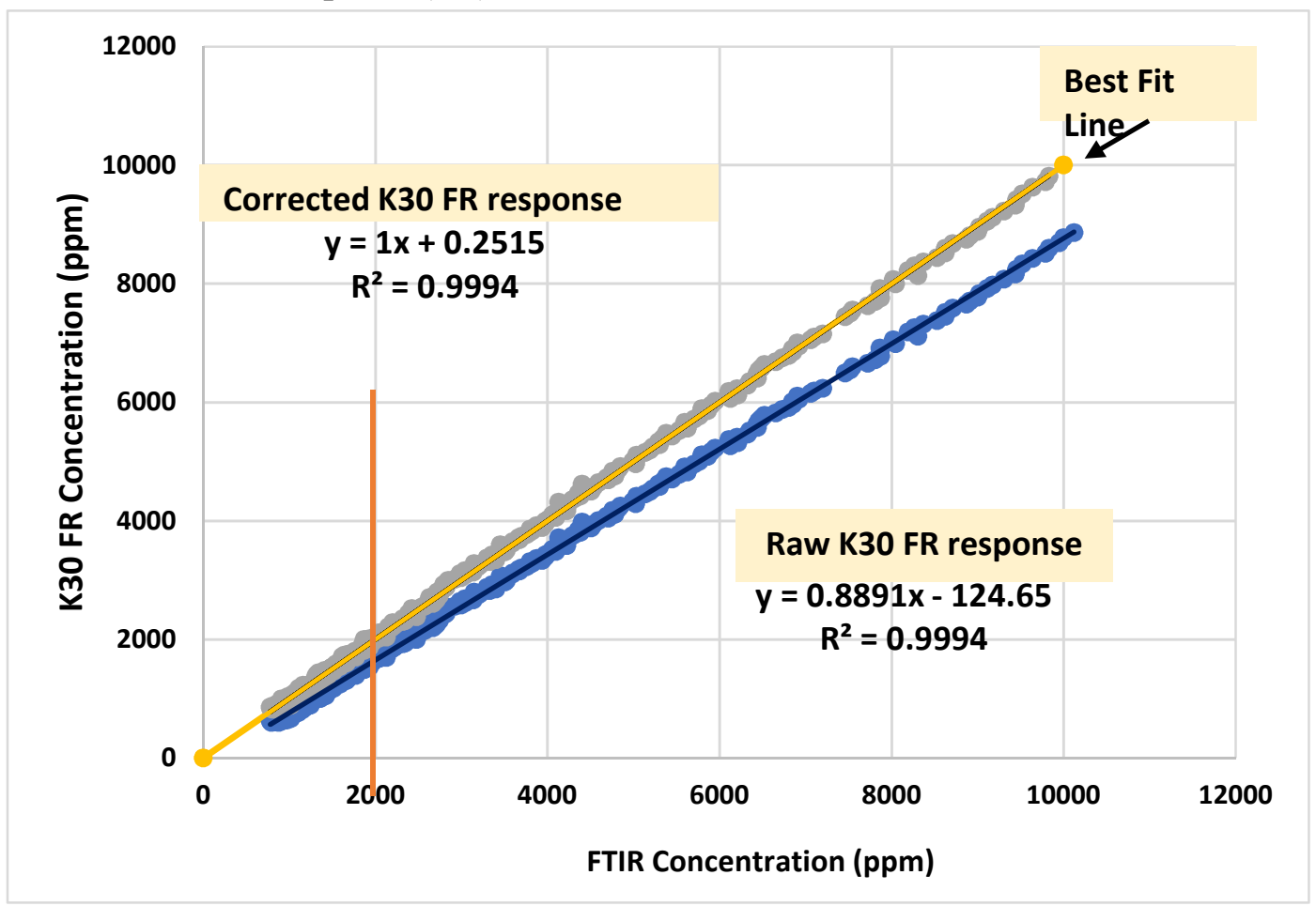

Figure 53 Test 9: K30 FR sensor responses compared to FTIR responses due to decreasing concentration changes. 


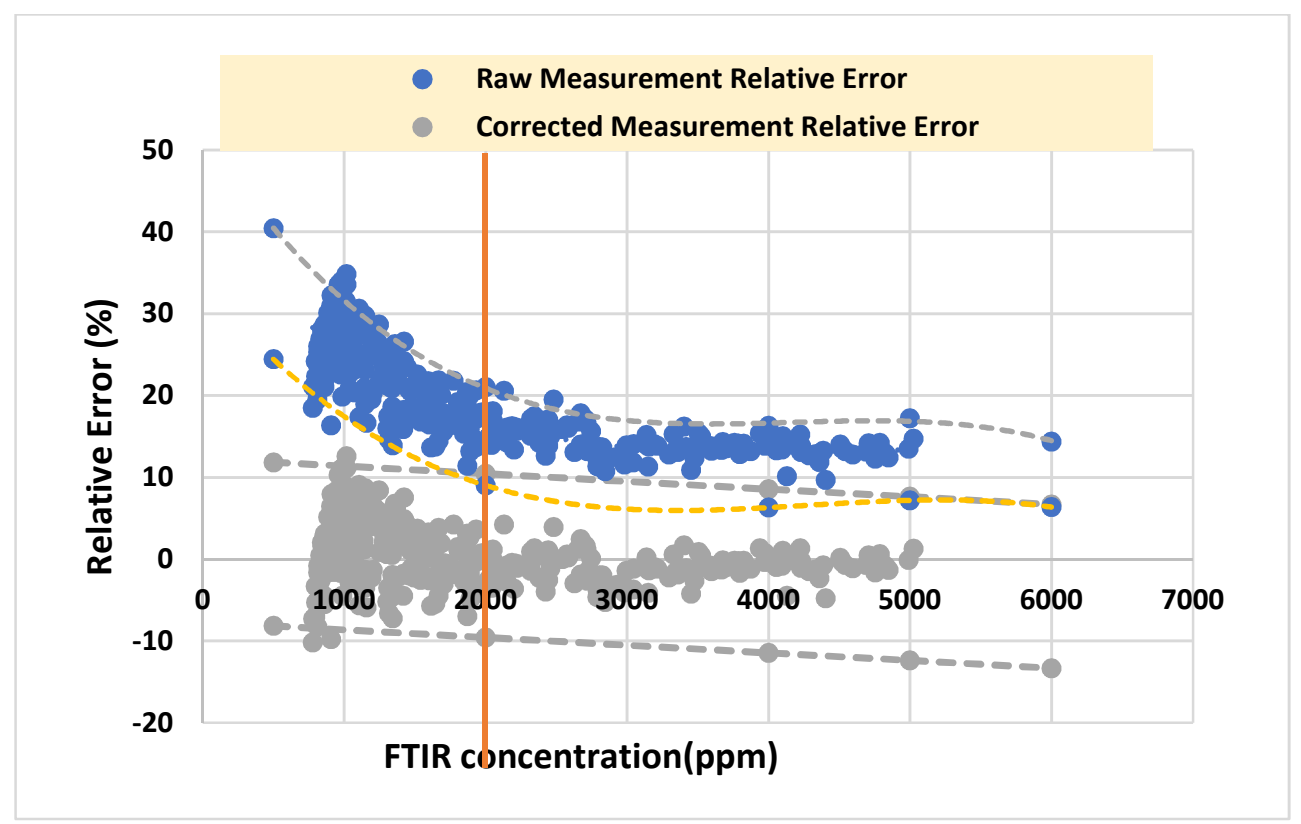

Figure 54 K30 FR- raw measurement relative error compared to corrected measurement relative error (0-5000ppm)-transient decrease.

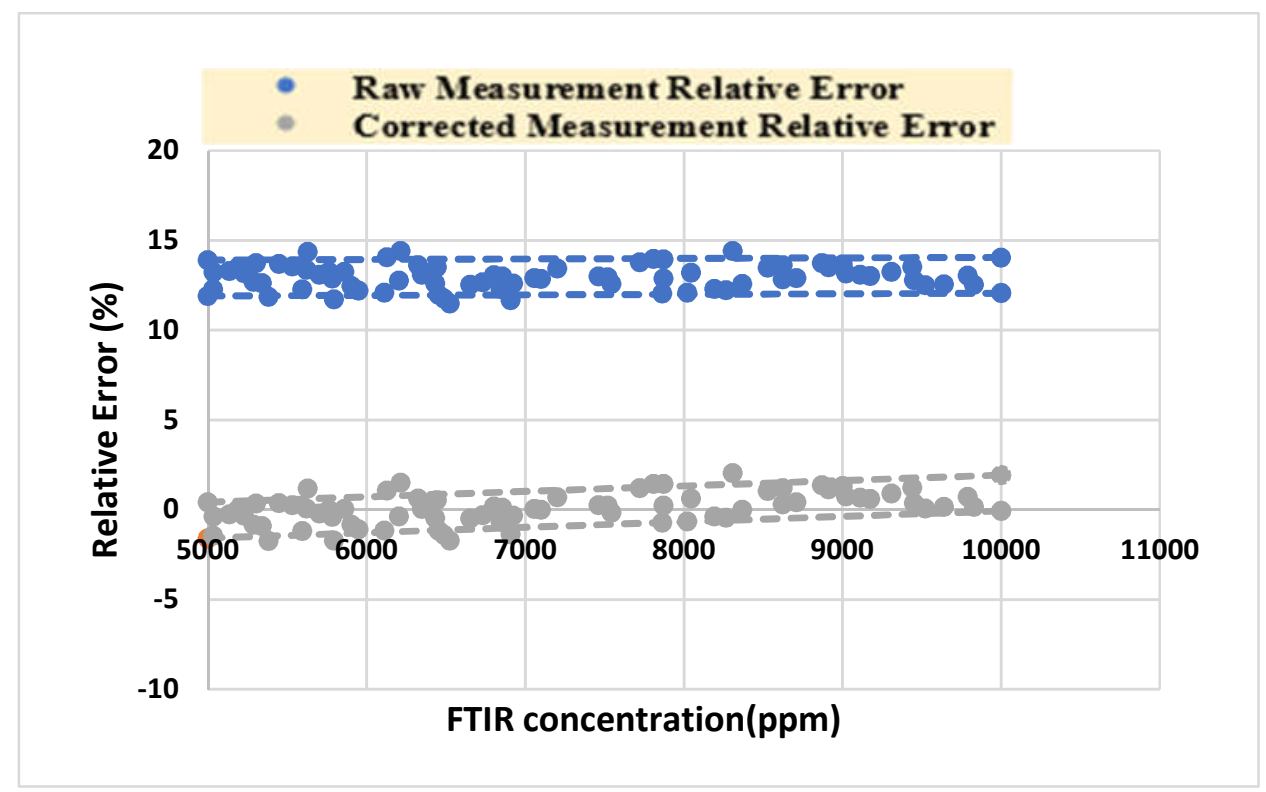

Figure 55 K30 FR- raw measurement relative error compared to corrected measurement relative error (5000-10000ppm)-transient increase. 


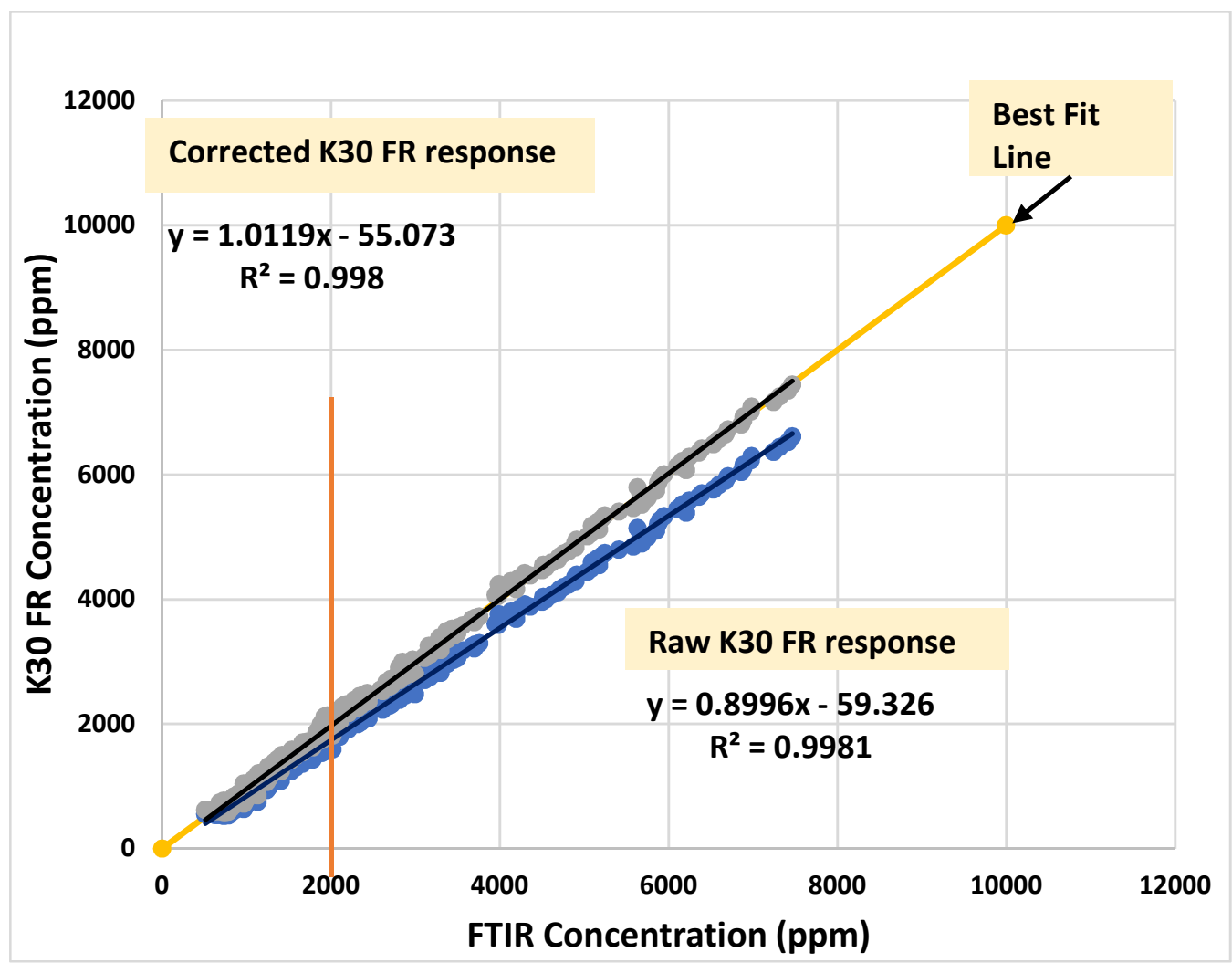

Figure 56 Test 7: K30 FR sensor responses compared to FTIR responses due to decreasing concentration changes-step-by-step. 


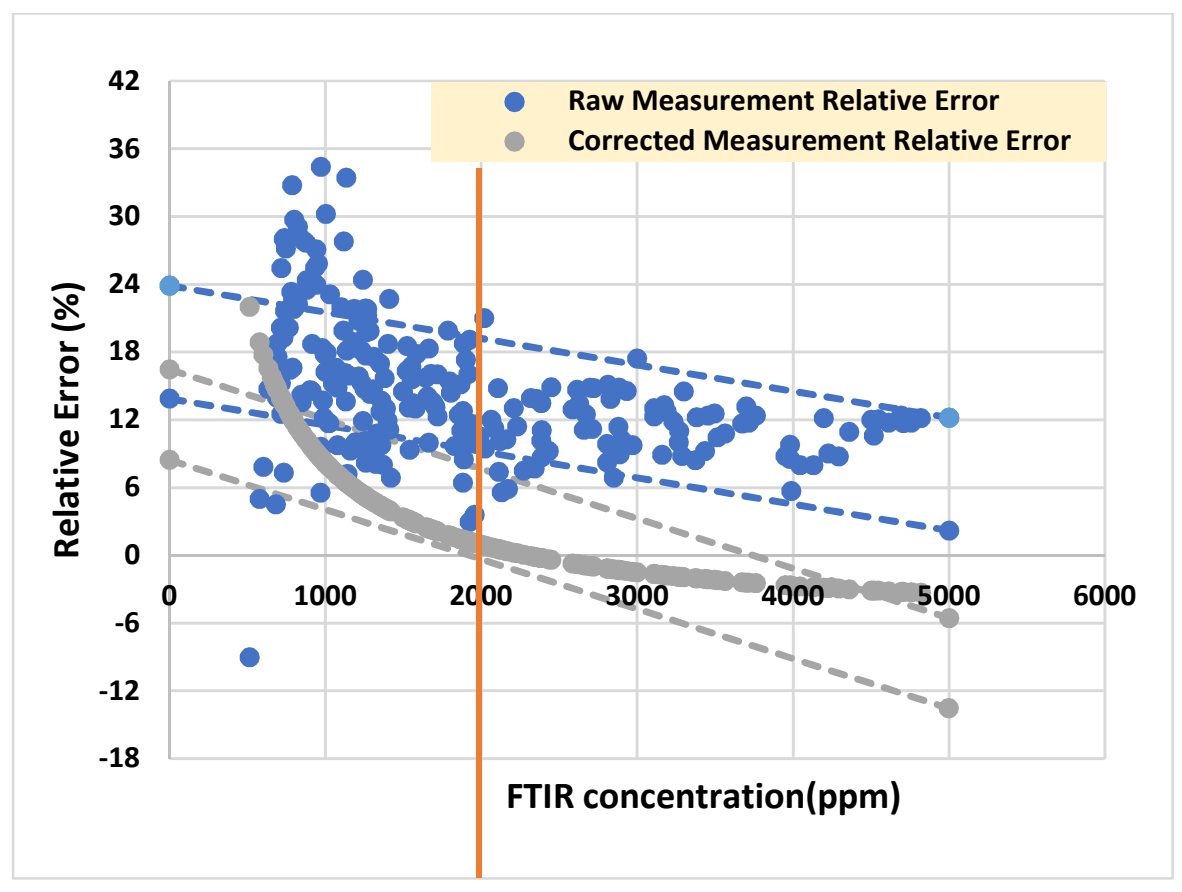

Figure 57 K30 FR -raw measurement relative error compared to corrected measurement relative error (0-5000ppm)-step by step decrease.

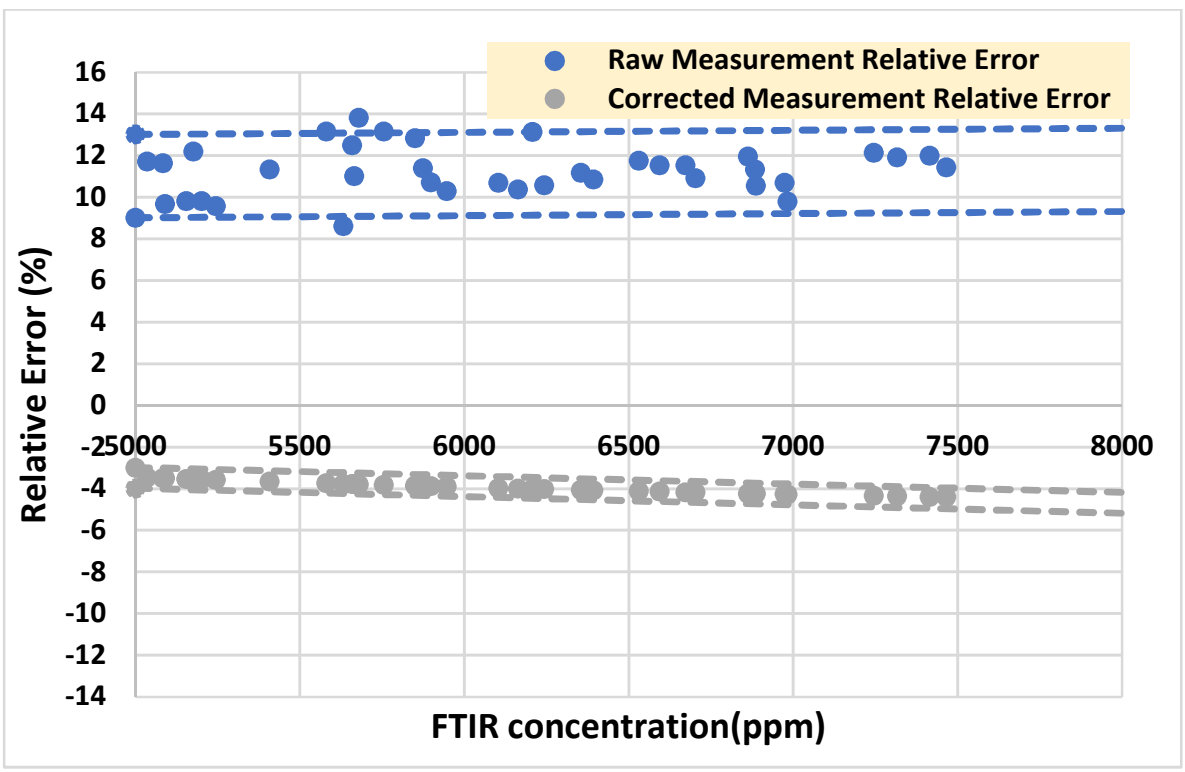

Figure 58 K30 FR- raw measurement relative error compared to corrected measurement relative error (5000-10000ppm)-step by step decrease. 
ii. $\quad \mathrm{K30} 1 \% \mathrm{CO}_{2}$ sensor evaluation results

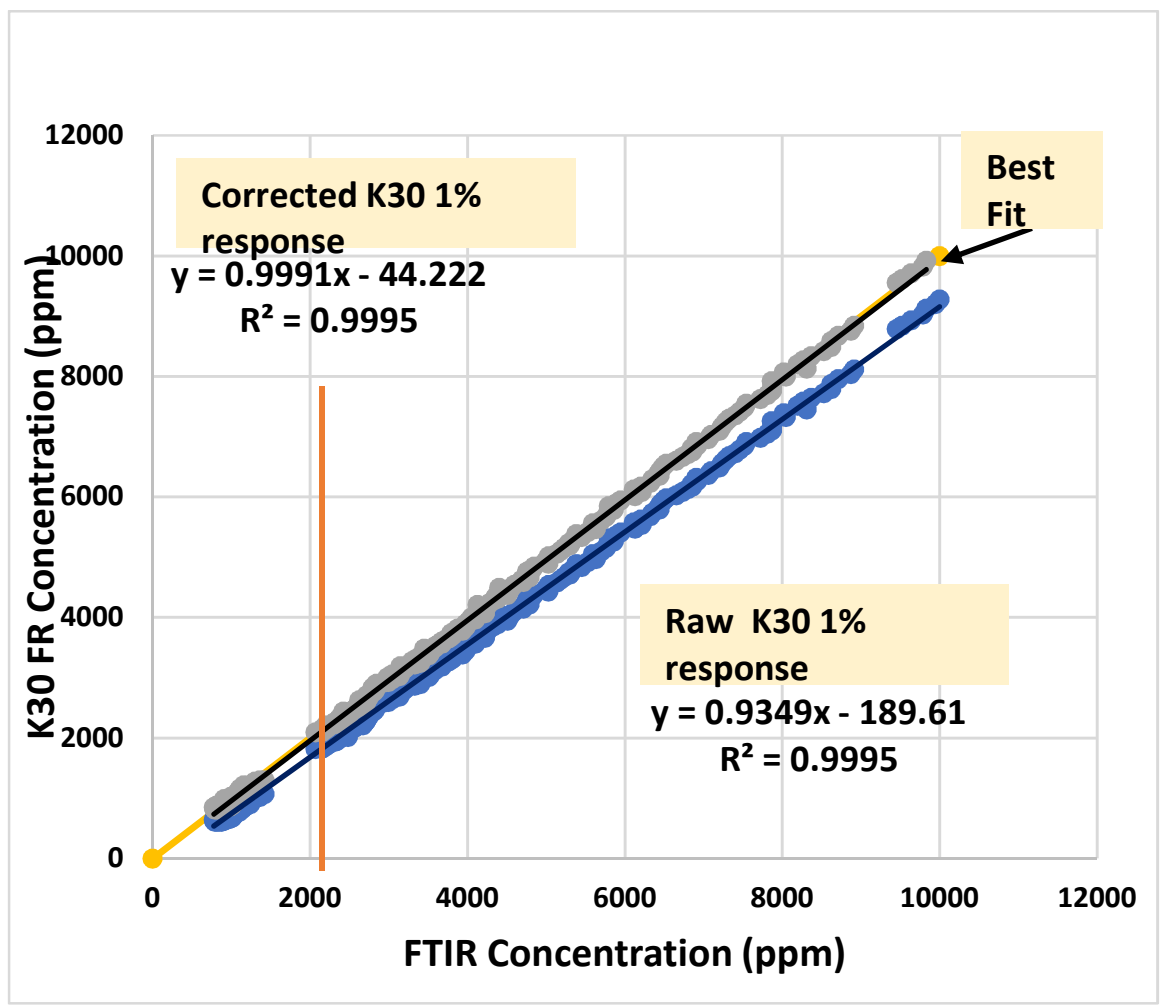

Figure 59 Test 9: K30 1\% sensor responses compared to FTIR responses due to decreasing concentration changes.

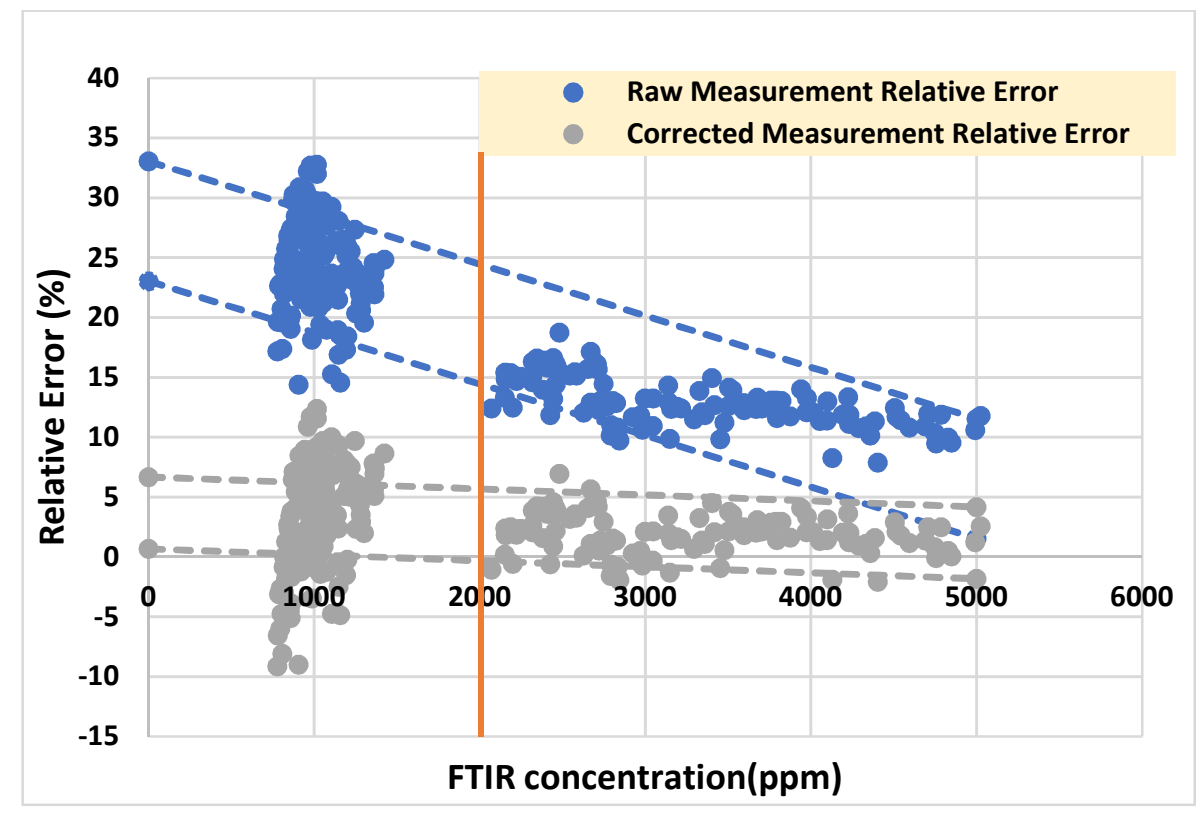

Figure 60 K30 1\%- raw measurement relative error compared to corrected measurement relative error (0-5000ppm)-transient decrease. 


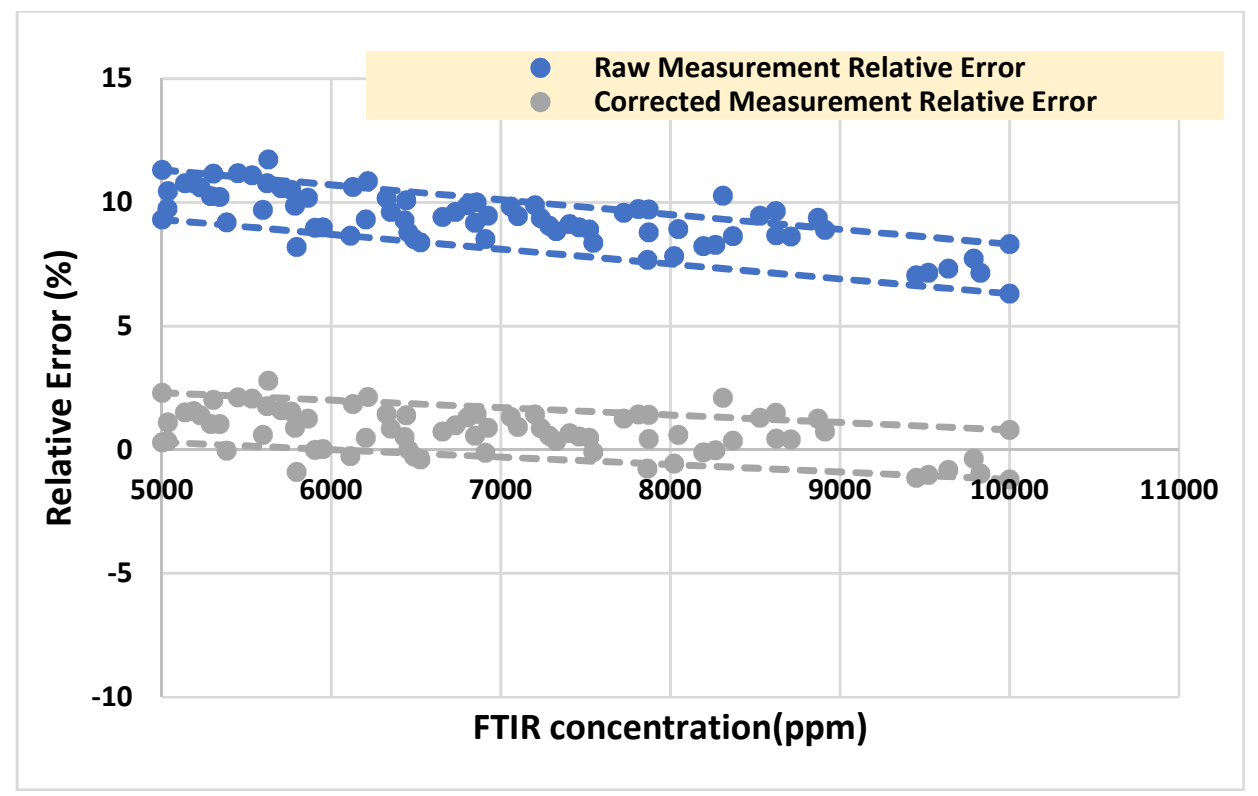

Figure 61 K30 FR- raw measurement relative error compared to corrected measurement relative error (5000-10000ppm)-transient increase

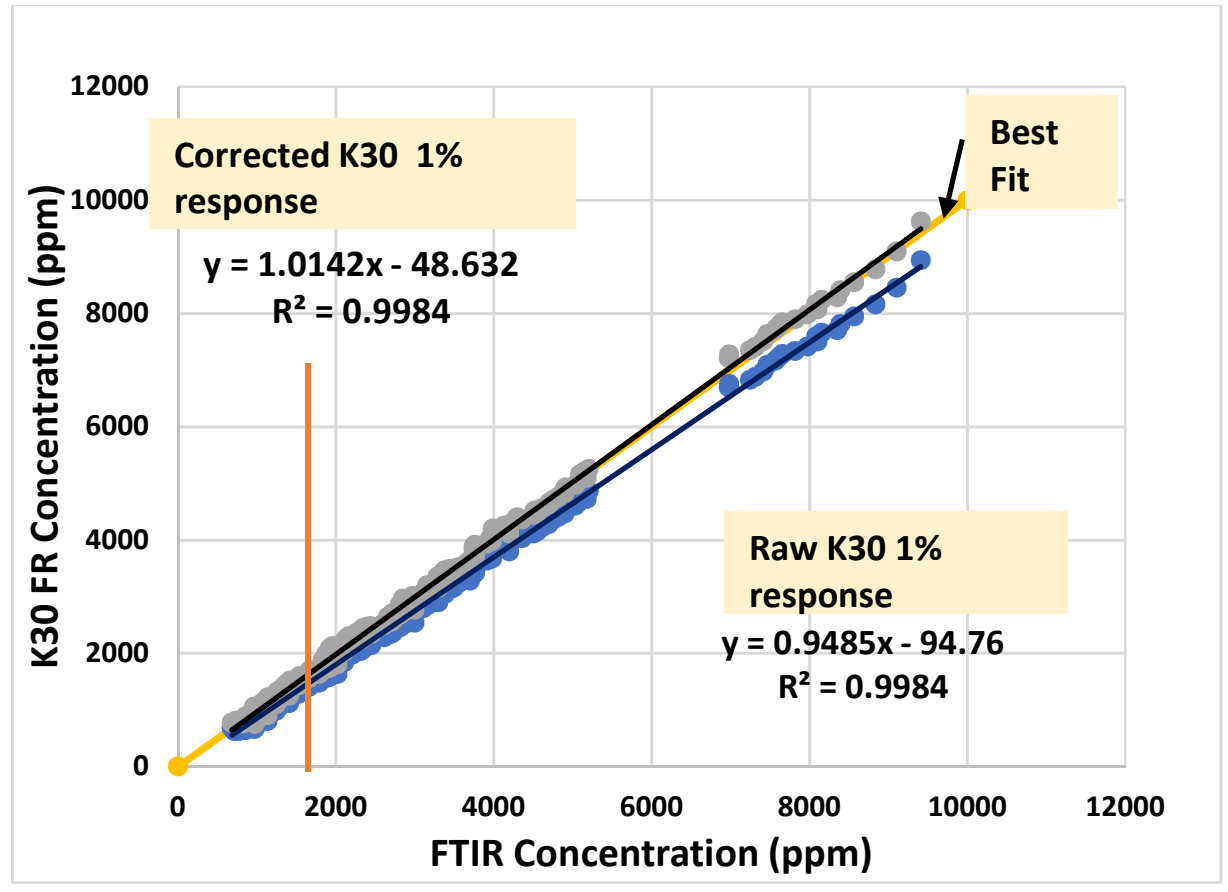

Figure 62 Test 7: K30 1\% sensor responses compared to FTIR responses due to decreasing concentration changes-step by step. 


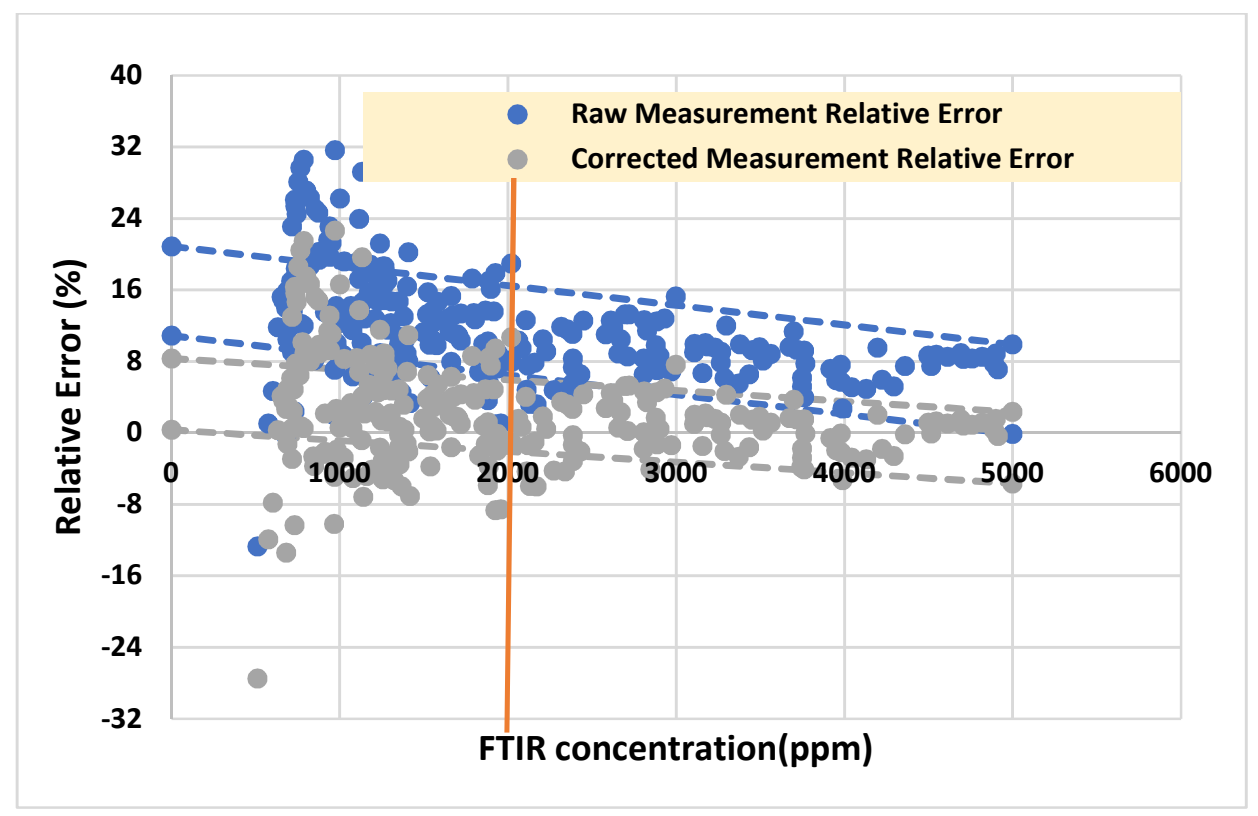

Figure $63 \mathrm{K30} 1 \%$ - raw measurement relative error compared to corrected measurement relative error (0-5000ppm)-step by step decrease.

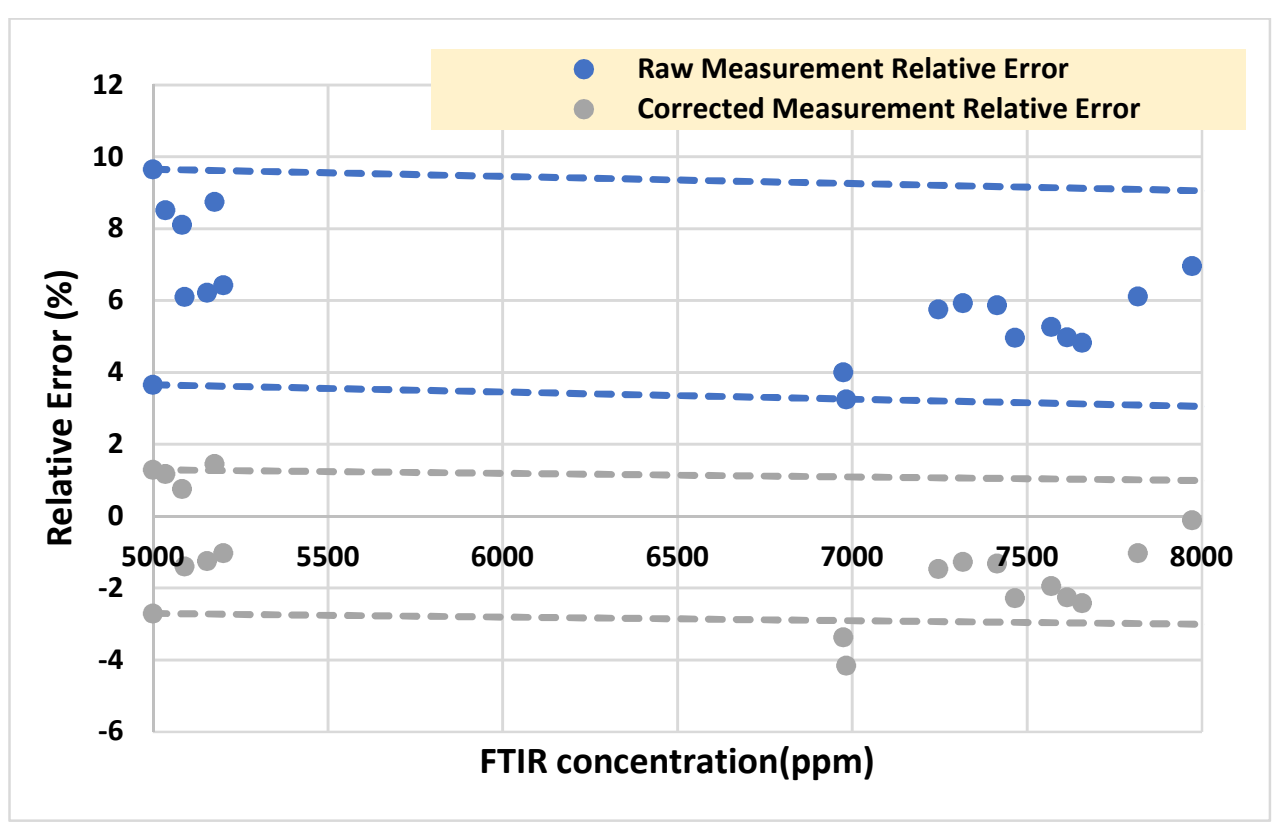

Figure 64 K30 1\% -raw measurement relative error compared to corrected measurement relative error (5000-10000ppm)-step by step decrease. 


\section{iii. Figaro}

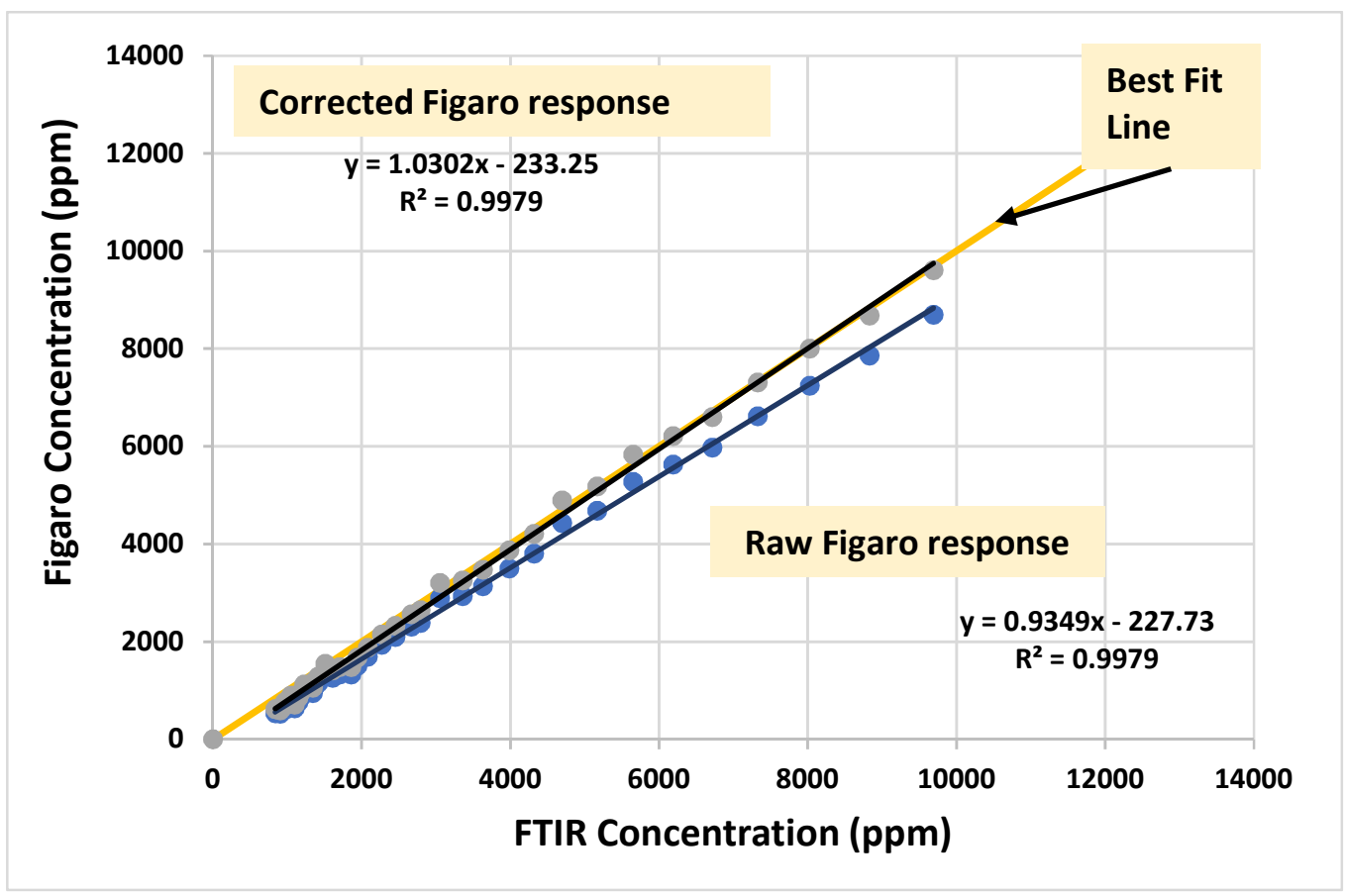

Figure 65 Test 9: Figaro sensor responses compared to FTIR responses due to decreasing concentration changes.

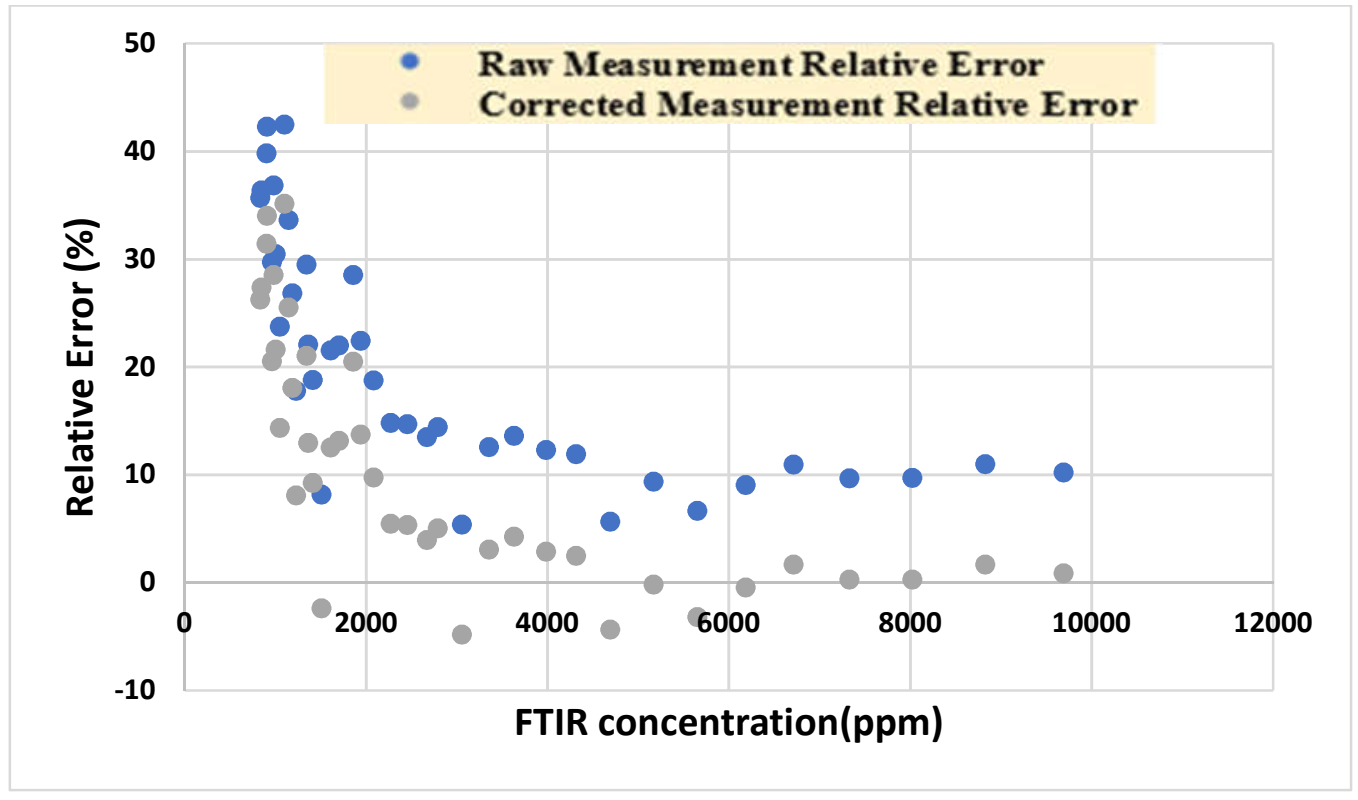

Figure 66 Figaro- raw measurement relative error compared to corrected measurement relative transient decrease 


\section{iv. COZIR}

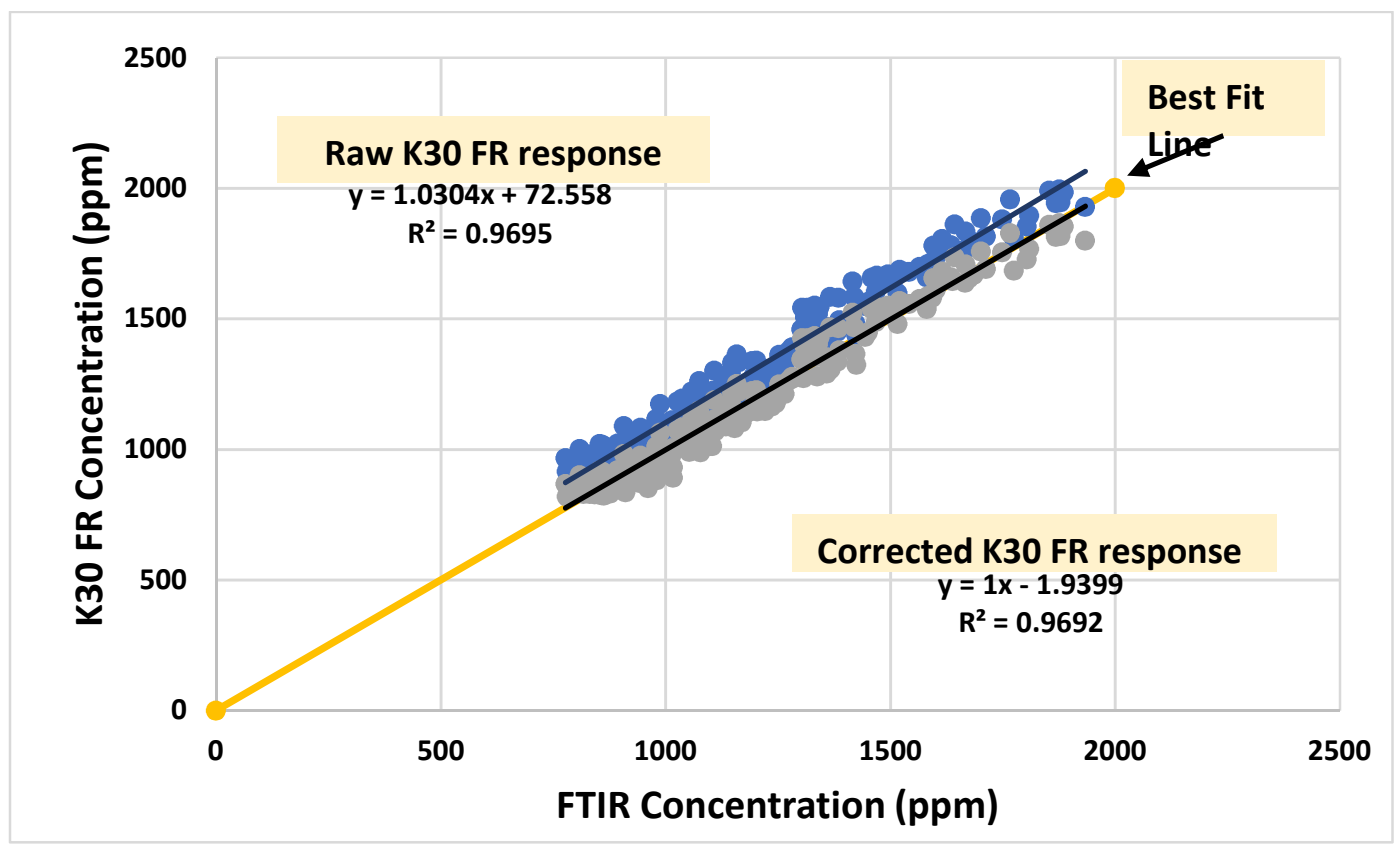

Figure 67 Test 9: COZIR sensor responses compared to FTIR responses due to decreasing concentration changes.

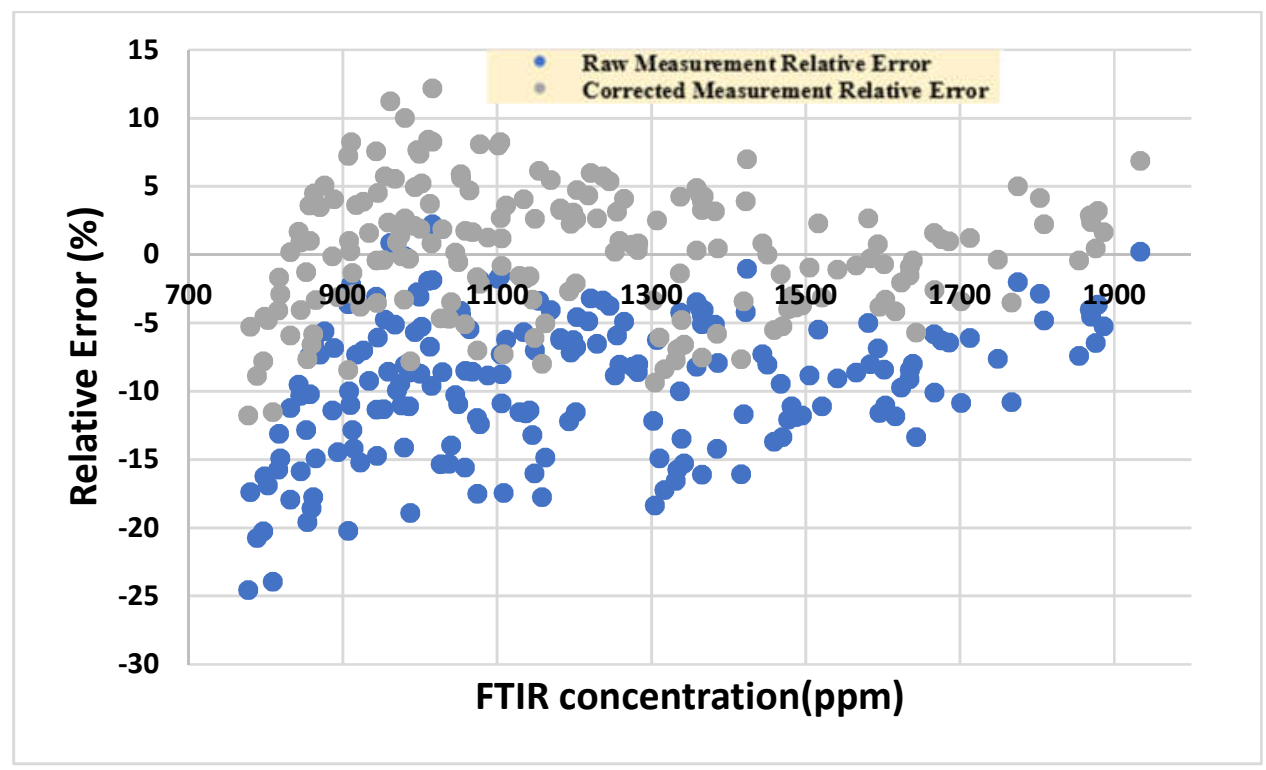

Figure 68 COZIR -raw measurement relative error compared to corrected measurement relative transient decrease 